\title{
ANDRÉ MÉFFE
}

\section{METODOLOGIA PARA CÁLCULO DE PERDAS TÉCNICAS POR SEGMENTO DO SISTEMA DE}

DISTRIBUIÇÃO

Dissertação apresentada à Escola Politécnica da Universidade de São Paulo para obtenção do título de Mestre em Engenharia. 


\section{ANDRÉ MÉFFE}

\section{METODOLOGIA PARA CÁLCULO DE PERDAS TÉCNICAS POR SEGMENTO DO SISTEMA DE}

DISTRIBUIÇÃO

Dissertação apresentada à Escola Politécnica da Universidade de São Paulo para obtenção do título de Mestre em Engenharia.

Área de Concentração:

Sistemas de Potência

Orientador:

Prof. Dr. Carlos César Barioni de Oliveira 
Aos meus pais,

Marilena, pelo amor e dedicação

Eloy (in memoriam), pelos ensinamentos e lições de vida. 


\section{AGRADECIMENTOS}

Ao Prof. Dr. Carlos César Barioni de Oliveira, meu orientador, pelo apoio e pelas contribuições que foram fundamentais para o desenvolvimento deste trabalho.

Aos professores Hector Arango e Nelson Kagan pelas valiosas contribuições na etapa de Qualificação desta Dissertação.

Aos meus amigos Ronaldo, Ferdinando e Sunny pela colaboração no desenvolvimento de diversas etapas deste trabalho.

Ao meu amigo Alden pelo apoio em muitos momentos difíceis da minha vida.

Ao meu irmão Junior e aos meus familiares que me apoiaram e me incentivaram durante essa etapa da minha vida.

À CAPES pelo apoio financeiro durante o programa de mestrado.

A todos que direta ou indiretamente contribuíram para o desenvolvimento deste trabalho.

À Deus por tudo, sem exceção. 


\section{SUMÁRIO}

\section{Lista de Figuras}

\section{Lista de Tabelas}

\section{Resumo}

Abstract

1. INTRODUÇÃ

1.1. As Perdas no Sistema Elétrico ................................................................... 1

1.2. Identificação e Classificação das Perdas ......................................................... 2

1.3. Escopo do Trabalho ............................................................................ 3

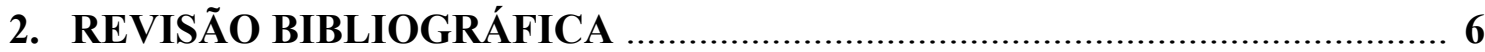

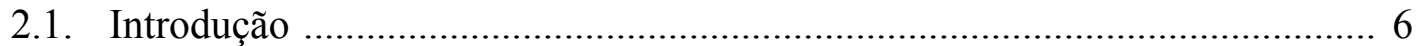

2.2. Medidor de Energia ................................................................................... 7

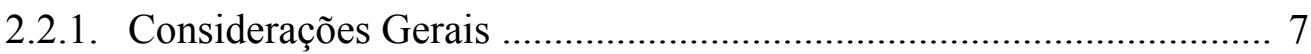

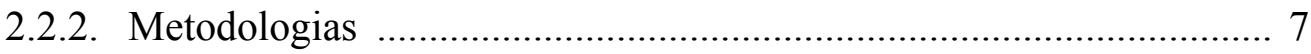

2.3. Ramal de Ligação ................................................................................. 9

2.3.1. Considerações Gerais ....................................................................... 9

2.3.2. Metodologias ............................................................................. 10

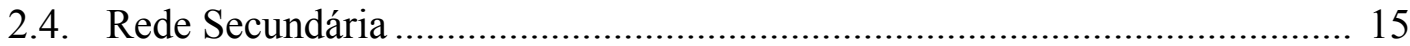

2.4.1. Considerações Gerais ...................................................................... 15

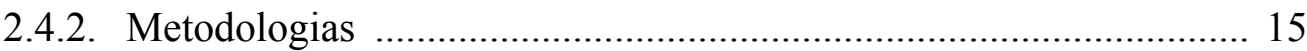

2.5. Transformador de Distribuição...................................................................... 21

2.5.1. Considerações Gerais ....................................................................... 21

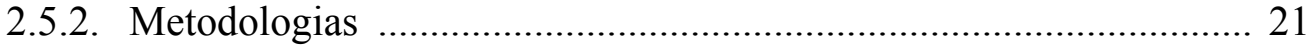

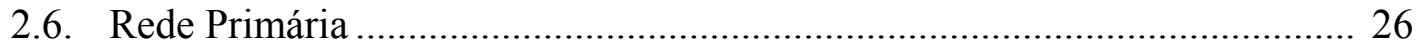

2.6.1. Considerações Gerais ......................................................................... 26

2.6.2. Metodologias ............................................................................... 26

2.7. Subestação de Distribuição........................................................................ 30

2.7.1. Considerações Gerais ...................................................................... 30

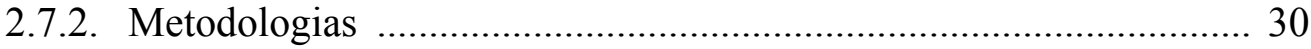


2.8. Sistema de Alta Tensão ....................................................................... 32

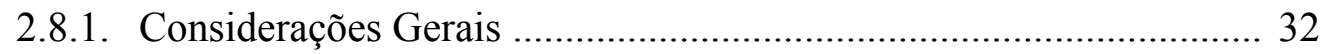

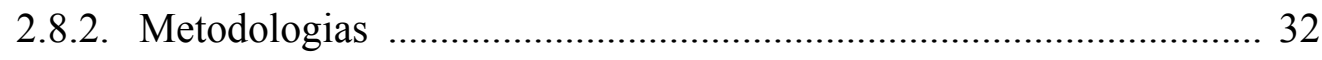

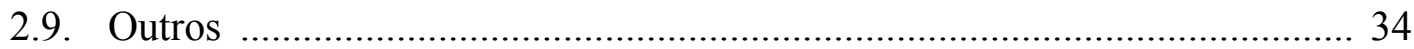

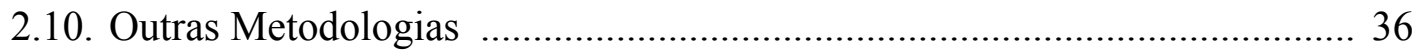

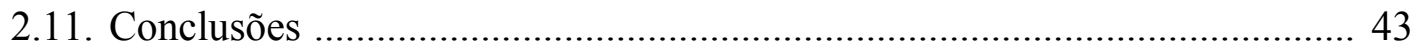

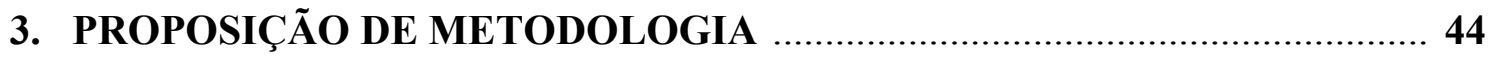

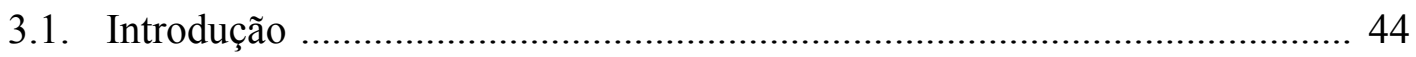

3.2. Fator de Carga e Fator de Perdas ......................................................... 45

3.3. Metodologia para Cálculo das Perdas Técnicas por Segmento ................... 45

3.3.1. Representação da Carga ................................................................. 48

3.3.2. Medidor de Energia ..................................................................... 57

3.3.3. Ramal de Ligação ..................................................................... 57

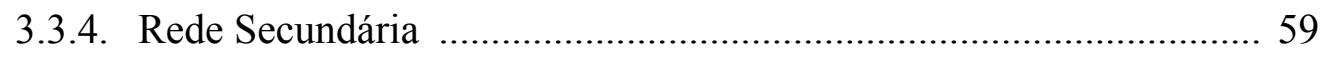

3.3.5. Transformador de Distribuição ...................................................... 61

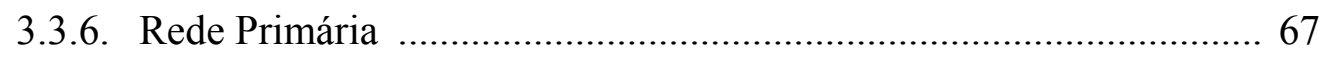

3.3.7. Subestação de Distribuição .............................................................. 71

3.3.8. Sistema de Alta Tensão ................................................................ 72

3.4. Metodologia para Balanço de Energia no Sistema de Distribuição ............. 76

3.4.1. Estimativa das Perdas Técnicas por Segmento .............................. 76

3.4.2. Estimativa das Perdas Não Técnicas ............................................ 80

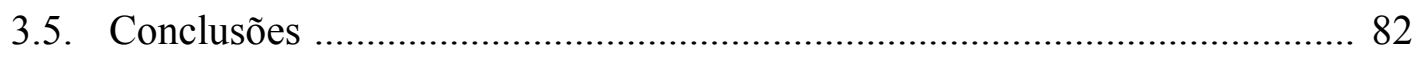

\section{SISTEMA COMPUTACIONAL DESENVOLVIDO PARA APLICAÇÃO}

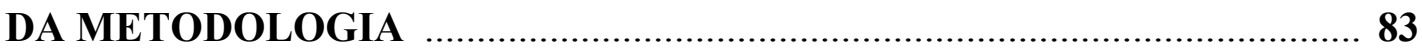

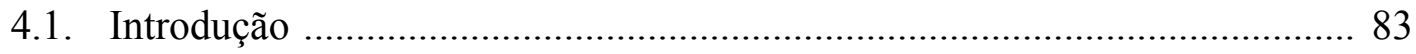

4.2. Estrutura Geral do Sistema Computacional ........................................... 85

4.3. Apresentação do Módulo PERTEC …..................................................... 87

4.3.1. Cálculo das Perdas Técnicas por Segmento .................................. 88

4.3.2. Apresentação dos Resultados do Cálculo ........................................ 90

4.4. Apresentação do Módulo de Balanço de Energia .......................................... 93

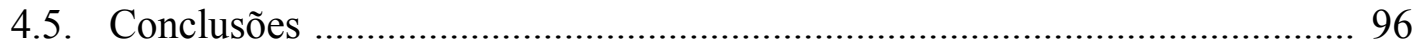


5. APLICAÇÃO DA METODOLOGIA E ANÁLISES COMPLEMENTARES 97

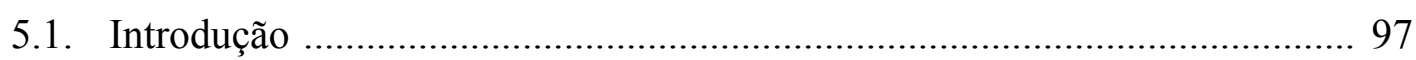

5.2. Aplicação do Módulo PERTEC para o Cálculo de Perdas .......................... 98

5.2.1. Resultados Obtidos ................................................................. 98

5.2.2. Comparação com Medições em Campo ....................................... 107

5.3. Aplicação do Módulo de Balanço de Energia ........................................... 110

5.4. Análise da Influência do Fator de Perdas ................................................ 113

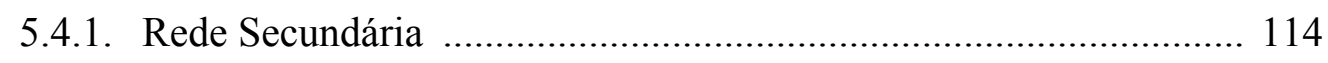

5.4.2. Transformador de Distribuição ................................................... 117

5.4.3. Rede Primária ......................................................................... 120

5.5. Comparação com Outras Metodologias ................................................. 123

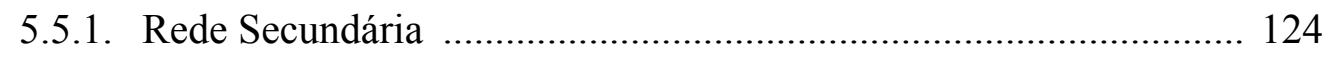

5.5.2. Transformador de Distribuição .................................................. 127

5.5.3. Rede Primária ........................................................................ 129

5.6. Análise da Influência da Temperatura dos Condutores no Cálculo das

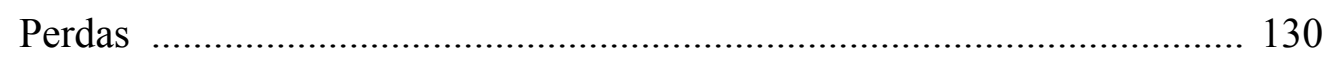

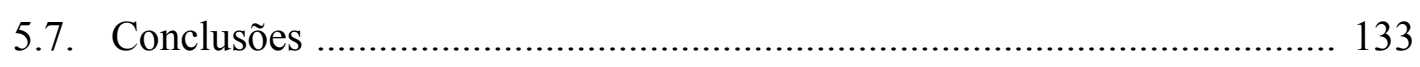

6. CONCLUSÕES E TÓPICOS PARA FUTURO DESENVOLVIMENTO .... 134

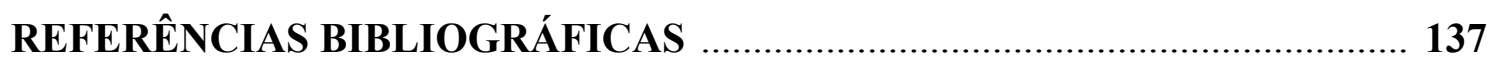




\section{LISTA DE FIGURAS}

Figura 2.1 - Representação do ramal monofásico ............................................... 11

Figura 2.2 - Representação do ramal bifásico ..................................................... 11

Figura 2.3 - Representação do ramal trifásico .................................................... 12

Figura 3.1 - Segmentos do sistema de distribuição ............................................... 46

Figura 3.2 - Exemplo de curva de carga típica de consumidor residencial ............ 50

Figura 3.3 - Exemplo de curva de carga típica de consumidor comercial .............. 50

Figura 3.4 - Exemplo de curva de carga típica de consumidor industrial ............... 51

Figura 3.5 - Representação do consumidor monofásico ....................................... 53

Figura 3.6 - Representação do consumidor bifásico .............................................. 54

Figura 3.7 - Representação do consumidor trifásico ........................................... 54

Figura 3.8 - Exemplo de curva de carga típica de consumidor primário ................ 55

Figura 3.9 - Exemplo de curva de carga típica de consumidor primário ................ 56

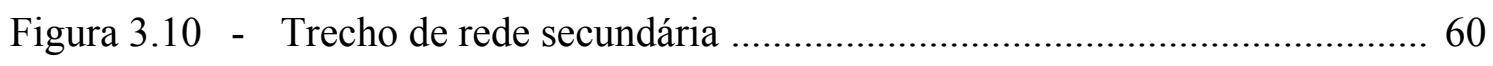

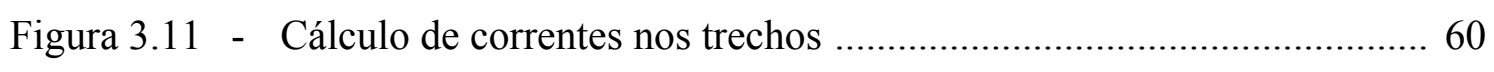

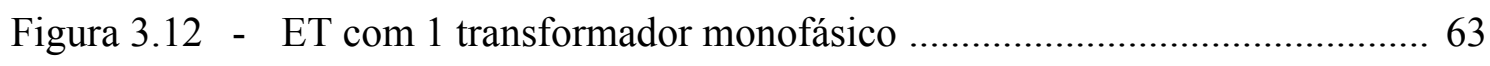

Figura 3.13 - ET com 2 transformadores monofásicos na ligação delta aberto ........ 64

Figura 3.14 - ET com 3 transformadores monofásicos na ligação delta fechado ..... 66

Figura 3.15 - ET com transformador trifásico na ligação delta-estrela .................... 67

Figura 3.16 - Correntes nos lados de baixa e média tensão .......................................6 69

Figura 3.17 - Estimador de estado em um sistema de potência ................................ 75

Figura 3.18 - Fluxo de energia no sistema de distribuição ....................................... 78

Figura 4.1 - Estrutura geral do sistema computacional .......................................... 85

Figura 4.2 - Tela principal do Módulo PERTEC …............................................. 88

Figura 4.3 - Guia ET / Rede Secundária da tela Rede de Distribuição .................... 89

Figura 4.4 - Relatório detalhado para perdas em Redes Secundárias ..................... 91

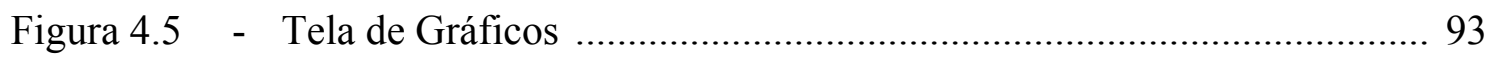

Figura 4.6 - Tela principal do módulo de Balanço de Energia ................................ 94

Figura 4.7 - Tela com o fluxo de energia no sistema ............................................ 95

Figura 5.1 - Relatório detalhado para transformador de distribuição ..................... 99

Figura 5.2 - Relatório detalhado para ramal de ligação ......................................... 99 
Figura 5.3 - Histograma da perda de energia no segmento rede secundária ........ 105

Figura 5.4 - Curva de carga da ET obtida por medição ........................................ 108

Figura 5.5 - Curva de carga da ET obtida por cálculo com o PERTEC .............. 109

Figura 5.6 - Comparação entre curvas de carga medida e calculada .................... 110

Figura 5.7 - Gráfico de dispersão (valores de $k$ para cada rede secundária) ......... 115

Figura 5.8 - Distribuição dos valores de $k$ ao longo de 20 faixas ......................... 115

Figura 5.9 - Distribuição dos erros para $k=0,15$ ao longo de 30 faixas .............. 116

Figura 5.10 - Distribuição dos erros para $k=0,30$ ao longo de 30 faixas ............... 116

Figura 5.11 - Gráfico de dispersão (valores de $k$ para cada transformador de distribuiç̧̃ão) …….................................................................... 118

Figura 5.12 - Distribuição dos valores de $k$ ao longo de 20 faixas .......................... 118

Figura 5.13 - Distribuição dos erros para $k=0,15$ ao longo de 30 faixas .............. 119

Figura 5.14 - Distribuição dos erros para $k=0,30$ ao longo de 30 faixas ….......... 119

Figura 5.15 - Gráfico de dispersão (valores de $k$ para cada rede primária) ............ 121

Figura 5.16 - Distribuição dos valores de $k$ ao longo de 20 faixas ......................... 121

Figura 5.17 - Distribuição dos erros para $k=0,15$ ao longo de 30 faixas .............. 122

Figura 5.18 - Distribuição dos erros para $k=0,30$ ao longo de 30 faixas .............. 122 


\section{LISTA DE TABELAS}

Tabela 1.1 - Nível esperado de perdas de energia ................................................ 3

Tabela 1.2 - Nível esperado de perda de energia dentro do segmento outros ........... 3

Tabela 3.1 - Ramais de ligação típicos por classe de consumo ............................... 58

Tabela 5.1 - Perda nos Medidores de Energia X Perda por Elemento Medidor ... 100

Tabela 5.2 - Perdas Técnicas por Segmento ...................................................... 100

Tabela 5.3 - Perdas em Medidor de Energia por Circuito ................................... 101

Tabela 5.4 - Perdas em Ramal de Ligação por Circuito ........................................ 101

Tabela 5.5 - Perdas em Rede Secundária por Circuito ........................................ 101

Tabela 5.6 - Perdas em Transformador de Distribuição por Circuito .................... 101

Tabela 5.7 - Perdas em Medidor de Energia por Subestação ................................ 102

Tabela 5.8 - Perdas em Ramal de Ligação por Subestação ................................... 103

Tabela 5.9 - Perdas em Rede Secundária por Subestação .................................... 103

Tabela 5.10 - Perdas em Transformador de Distribuição por Subestação .............. 103

Tabela 5.11 - Perdas em Rede Primária por Subestação ......................................... 103

Tabela 5.12 - Perdas em Medidor de Energia por Regional .................................. 104

Tabela 5.13 - Perdas em Ramal de Ligação por Regional ..................................... 104

Tabela 5.14 - Perdas em Rede Secundária por Regional ...................................... 104

Tabela 5.15 - Perdas em Transformador de Distribuição por Regional .................. 104

Tabela 5.16 - Perdas em Rede Primária por Regional .......................................... 104

Tabela 5.17 - Perdas em Subestação de Distribuição por Regional ........................ 105

Tabela 5.18 - Histograma da perda de energia nos medidores de energia .............. 106

Tabela 5.19 - Histograma da perda de energia nos ramais de ligação ..................... 106

Tabela 5.20 - Histograma da perda de energia nas redes secundárias .................... 106

Tabela 5.21 - Histograma da perda de energia nos transformadores de distribuição 106

Tabela 5.22 - Histograma da perda de energia nas redes primárias ........................ 106

Tabela 5.23 - Histograma da perda de energia nas subestações de distribuição ..... 107

Tabela 5.24 - Perdas de Energia por Segmento ....................................................... 111

Tabela 5.25 - Energia Faturada por nível de faturamento ..................................... 111

Tabela 5.26 - Resultados obtidos para energia de entrada de $110000 \mathrm{MWh}$.......... 112

Tabela 5.27 - Resultados obtidos para perdas não técnicas de 5,0\% ….................. 112 
Tabela 5.28 - Perdas de Energia para Rede Secundária …..................................... 114

Tabela 5.29 - Perdas de Energia para Transformador de Distribuição ................... 117

Tabela 5.30 - Perdas de Energia para Rede Primária ........................................... 120

Tabela 5.31 - Dados utilizados para a aplicação da expressão (2.13) ..................... 125

Tabela 5.32 - Comparação entre metodologias para o segmento Rede Secundária 126

Tabela 5.33 - Perdas de demanda $(\mathrm{kW})$ para cada faixa de potência ...................... 126

Tabela 5.34 - Dados utilizados para a aplicação das Metodologias CODI 1 e de

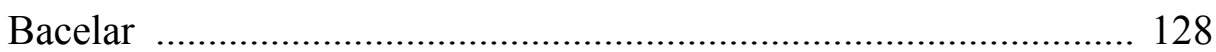

Tabela 5.35 - Comparação entre metodologias para o segmento Transformador de Distribuição .............................................................................. 128

Tabela 5.36 - Comparação entre metodologias para o segmento Rede Primária .... 130

Tabela 5.37 - Variação das perdas X Variação da temperatura .............................. 132 


\section{RESUMO}

Este trabalho tem por objetivo propor uma nova metodologia para o cálculo das perdas técnicas de energia e demanda por segmento do sistema de distribuição.

As perdas técnicas foram divididas em oito segmentos: medidor de energia, ramal de ligação, rede secundária, transformador de distribuição, rede primária, subestação de distribuição, sistema de alta tensão e outros. Neste último segmento, foram incorporadas as parcelas referentes a equipamentos (capacitores, reguladores de tensão, etc), perdas em conexões, corrente de fuga em isoladores, etc.

Desenvolveu-se um sistema computacional, para uso em microcomputador, que conta com dois módulos principais.

O primeiro módulo destina-se ao cálculo das perdas técnicas em redes específicas. $\mathrm{O}$ cálculo é feito de forma hierárquica, por exemplo, selecionada uma subestação específica, são calculadas as perdas na subestação e em todos os componentes a jusante (redes primárias, transformadores de distribuição, redes secundárias, ramais de ligação e medidores de energia). As perdas técnicas, em termos de energia e demanda, são obtidas por meio de cálculo elétrico específico para os segmentos envolvidos, com a utilização dos dados cadastrais da rede, dados de faturamento e curvas de carga típicas por classe de consumidor e tipo de atividade desenvolvida.

Com a aplicação deste módulo para todo o sistema da empresa, ou para uma parcela representativa, obtém-se um índice percentual de perda de energia para cada segmento. Estes índices são transferidos para o segundo módulo, que tem por objetivo efetuar o balanço de energia do sistema. A partir dos dados de energia nos pontos de suprimento, da energia total faturada mensalmente e dos índices de perdas por segmento, são obtidos os montantes de energia de perdas em cada segmento do sistema e uma avaliação das perdas não técnicas.

O trabalho ainda apresenta um exemplo de aplicação, em sistema de distribuição real, mostrando os resultados obtidos, e termina apresentando as principais vantagens da metodologia. Os resultados obtidos com a nova metodologia são comparados com os resultados obtidos com outras metodologias. 


\begin{abstract}
This work focuses on the development of a new methodology for calculating technical losses within the different segments of the electric distribution system.

In order to evaluate technical losses the electrical system was divided into eight segments: energy meter, customer connections, secondary feeder, distribution transformer, primary feeder, distribution substation, high voltage system and another segment that represents other technical losses. The latter comprises losses in equipment such as capacitors and voltage regulators as well as losses in electric connections, isolators, etc.

A computational system was developed and it comprises two modules.

The first one is intended to calculate technical losses in specific networks. The calculation is made in a hierarchical manner. If a distribution substation is selected for the calculation, the losses in that substation and the losses in all components downstream are calculated. The technical losses, in terms of energy and demand, are obtained by utilizing network topological data, consumed energy data and typical load curves per customer class and activity type.

An energy losses index, calculated as a percentage of the supplied energy, is obtained for each segment by applying this module to the entire utility's power system or in a representative part of it. These values are transferred to the second module, which has the objective of determining the overall energy balance. Technical and non-technical losses, in terms of energy, in each segment are obtained by utilizing the total amount of energy supplied to the system, energy consumed and energy losses indices per segment. This work shows the results obtained by applying the computational tool to a real distribution system. Such results are compared with the ones obtained by using other methodologies, and the main advantages of this new methodology are outlined.
\end{abstract}




\section{CAPÍTULO 1}

\section{INTRODUÇÃO}

\subsection{As Perdas no Sistema Elétrico}

A importância da energia elétrica na sociedade tem exigido das concessionárias níveis de qualidade cada vez maiores nos serviços por elas prestados. Por outro lado, é um desafio para as concessionárias de energia atender o mercado crescente com um nível mínimo de qualidade.

Os altos custos envolvidos na construção de novas unidades geradoras, novas linhas de transmissão e novas linhas de distribuição, associados ao esgotamento da capacidade geradora, exige a busca de novas alternativas para atender a demanda crescente de energia elétrica.

De um lado, exige-se cada vez mais que os diversos segmentos da sociedade utilizem a energia elétrica de forma racional.

Por outro lado, aliado aos conceitos de privatização e competitividade no setor elétrico, as concessionárias buscam a geração de lucros e a operação econômica do sistema. Para isso, diminuir as perdas é de fundamental importância não somente para gerar lucros e operar de forma econômica como também para conseguir um fornecimento de melhor qualidade.

Consequentemente, tais preocupações podem postergar, por algum tempo, grandes investimentos no setor elétrico e significar uma grande economia de dinheiro, já que a redução das perdas implicam numa menor capacidade do parque gerador necessário para atender a mesma carga.

A título de exemplo, em 1996, as perdas de energia no Brasil estiveram em torno de 55 TWh, o que representa $16 \%$ de toda a energia produzida no país. Desse total, $65 \%$ das perdas de energia dizem respeito aos sistemas de distribuição. Os outros 35\% dizem respeito à geração e aos sistemas de transmissão. Admitindo-se que as perdas poderiam ser reduzidas a $10 \%$ e que o custo unitário das perdas seja de $\mathrm{R} \$ 50,00 / \mathrm{MWh}$, a redução 
da perda de energia em 20,6 TWh representaria uma economia de mais de R\$ 1 bilhão por ano.

\subsection{Identificação e Classificação das Perdas}

$\mathrm{Na}$ tentativa de buscar uma redução das perdas, é necessário que as concessionárias saibam avaliar e identificar as perdas no sistema de distribuição.

A perda pode ser classificada quanto à natureza, origem, localização e segmento.

Quanto à natureza, a perda pode ser classificada em perda de demanda e perda de energia. A perda de demanda é a diferença entre a demanda de entrada e a demanda de saída num componente do sistema elétrico num dado instante. A perda de energia é a diferença entre a energia de entrada e a energia de saída num componente num dado intervalo de tempo.

Quanto à origem, a perda pode ser classificada em perda técnica e perda não técnica. A perda técnica é a energia ou demanda que se perde durante seu transporte, inerente ao processo e caracterizada por ocorrer antes do ponto de entrega. A perda não técnica é a energia ou demanda efetivamente entregue ao consumidor, ao consumo próprio ou a outra concessionária, mas que, por algum motivo, não foi computada nas vendas.

Quanto à localização, a perdas podem ser classificadas em perdas globais, perdas na transmissão e perdas na distribuição. As perdas globais são as perdas nos sistemas de geração, transmissão e distribuição. As perdas na transmissão são as perdas nos sistemas de geração e de transmissão. As perdas na distribuição são as perdas que ocorrem somente no sistema de distribuição.

Já as perdas técnicas podem ser classificadas de acordo com o segmento em que ocorrem. A rede primária, o transformador de distribuição, a rede secundária e o medidor de energia são alguns segmentos do sistema de distribuição.

O segmento pode ser definido como se segue: "um segmento é um conjunto de componentes que desempenham uma mesma função no sistema elétrico". Assim, por exemplo, todos os transformadores de distribuição presentes num determinado sistema de distribuição constituem o segmento transformador de distribuição, pois todos eles desempenham a mesma função: abaixar a tensão para níveis compatíveis ao consumo de clientes em baixa tensão. 


\subsection{Escopo do Trabalho}

A partir da bibliografia pesquisada $[1,2,3,6]$, pode-se estabelecer uma estimativa do nível de perdas técnicas de energia em cada segmento do sistema elétrico. A tabela 1.1 apresenta o nível de perdas técnicas de energia esperado em cada segmento em porcentagem do total da energia requerida pelo sistema e em porcentagem do total das perdas técnicas de energia.

Tabela 1.1 - Nível esperado de perdas de energia

\begin{tabular}{lcc}
\hline \multicolumn{1}{c}{ Segmento } & \multicolumn{2}{c}{ Faixa Esperada (\%) } \\
\cline { 2 - 3 } & Do total de perdas técnicas & Do total de energia \\
\hline Sistema de Alta Tensão & $16-25$ & $1,5-2,0$ \\
\hline Subestação de Distribuição & $9-17$ & $0,5-1,0$ \\
\hline Rede Primária & $15-30$ & $0,5-2,5$ \\
\hline Transformador de Distribuição & $15-55$ & $1,0-2,0$ \\
\hline Rede Secundária & $3-30$ & $0,1-2,0$ \\
\hline Ramal de Ligação & $0,5-6,0$ & $0,05-0,20$ \\
\hline Medidor de Energia & $3-7$ & $0,2-0,4$ \\
\hline Outros & $5-11$ & $0,2-0,8$ \\
\hline
\end{tabular}

A tabela 1.2 abre o segmento outros e mostra o nível esperado de perdas técnicas de energia expressa como porcentagem do total de perdas técnicas em cada um dos segmentos nele contidos.

Tabela 1.2 - Nível esperado de perda de energia dentro do segmento outros

\begin{tabular}{lc}
\hline \multicolumn{1}{c}{ Segmento } & Faixa Esperada (\%) \\
\hline Capacitores & até 1\% \\
\hline Reguladores de Tensão & \\
\hline Corrente de fuga nos isoladores & \\
\hline Corrente de fuga nos pára-raios & $5-10$ \\
\hline Efeito corona & \\
\hline Conexões & \\
\hline Outros & \\
\hline
\end{tabular}

Assim, pode-se ter uma idéia dos valores de perdas técnicas de energia que poderão ser encontrados em cada segmento. Nota-se que os 7 segmentos que mais contribuem para as perdas técnicas de energia são: sistema de alta tensão, subestação de distribuição, 
rede primária, transformador de distribuição, rede secundária, ramal de ligação e medidor de energia.

Portanto, decidiu-se dividir o sistema de distribuição, neste texto, em 8 segmentos, que são os segmentos citados acima mais um segmento que contemple os demais segmentos: o segmento outros.

Assim, os segmentos estudados neste texto serão referidos como se segue:

- Sistema de Alta Tensão;

- Subestação de Distribuição;

- Rede Primária;

- Transformador de Distribuição;

- Rede Secundária;

- Ramal de Ligação;

- Medidor de Energia;

- Outros.

Conhecendo-se as perdas técnicas e as perdas totais, pode-se determinar, por diferença, as perdas não técnicas. Assim, as concessionárias podem identificar os segmentos que têm maior contribuição para o nível de perdas totais e estabelecer um plano de ações para que se possa minimizá-las.

O objetivo deste trabalho é fazer uma revisão da literatura, analisando as metodologias existentes para cálculo das perdas técnicas de energia e de demanda por segmento do sistema de distribuição, propor uma nova metodologia para cálculo das perdas técnicas baseada no conceito das curvas de carga típicas dos consumidores e implementar essa metodologia por meio do desenvolvimento de um sistema computacional.

Para tal, este texto divide-se em seis capítulos.

No capítulo 1, apresenta-se a motivação do trabalho e seus principais objetivos.

O capítulo 2 apresenta uma revisão da literatura. Analisam-se diversas metodologias existentes para o cálculo das perdas técnicas de energia e de demanda. De um modo geral, poderá ser observado que a maior parte das metodologias calculam a perda técnica de energia em função de um fator de perdas (estimado a partir do fator de carga conhecido) e em função da perda técnica de demanda no horário de ponta do sistema. 
No capítulo 3 é proposta uma nova metodologia para cálculo das perdas técnicas, baseada no conceito das curvas de carga típicas e por meio do cálculo elétrico detalhado de cada componente pertencente a um segmento do sistema de distribuição. Por essa metodologia, à cada consumidor é associada uma curva de carga diária, de forma que se pode realizar o cálculo das perdas técnicas de demanda em cada instante do dia e em cada segmento agregando-se as curvas dos consumidores. Em seguida, a perda técnica de energia é calculada a partir da curva diária de perda, sem a necessidade de estimar um fator de perdas.

O capítulo 4 apresenta o sistema computacional desenvolvido para cálculo de perdas técnicas que utiliza a metodologia proposta no capítulo 3 . Este sistema é composto por 2 módulos. O primeiro módulo realiza o cálculo das perdas técnicas em cada componente de cada segmento. O segundo módulo destina-se a um cálculo estatístico e global. Com base nos níveis percentuais das perdas técnicas de energia em cada segmento calculados pelo primeiro módulo, pode-se determinar as perdas não técnicas e ter uma visão global das perdas técnicas ao longo do sistema de distribuição.

O capítulo 5 mostra algumas aplicações, com seus respectivos resultados, do sistema computacional desenvolvido utilizando-se dados reais de redes de distribuição. Também apresenta uma comparação entre os resultados obtidos com a metodologia proposta neste trabalho e com algumas metodologias apresentadas na revisão bibliográfica, além de apresentar um estudo da influência do fator de perdas no cálculo das perdas de energia.

Finalmente, o capítulo 6 apresenta as conclusões deste trabalho e alguns tópicos para desenvolvimento posterior. 


\section{CAPÍTULO 2}

\section{REVISÃO BIBLIOGRÁFICA}

\subsection{Introdução}

Este capítulo objetiva apresentar o estado da arte sobre o cálculo das perdas técnicas de energia e de demanda por segmento em sistemas de distribuição de energia elétrica. Será apresentada uma análise crítica de diversas metodologias existentes para o cálculo das perdas técnicas por segmento.

Como poderá ser visto no decorrer deste capítulo, a maior parte das metodologias pesquisadas $[3,4,6,12,14,15]$ não levam em conta todos os segmentos que são considerados neste trabalho. São poucas as metodologias que descrevem procedimentos para avaliar as perdas técnicas em todos os segmentos aqui considerados $[1,2]$.

Este capítulo dedica uma parte para cada segmento que se pretende estudar neste trabalho. Assim, pode-se avaliar quais os procedimentos existentes para o cálculo das perdas técnicas em cada segmento do sistema de distribuição.

Inicia-se a análise pelo segmento "mais próximo" do consumidor (medidor de energia), caminhando-se no sentido do segmento "mais distante" (sistema de alta tensão). Por último, analisa-se o segmento outros, que engloba as metodologias existentes para todos os outros segmentos que não se enquadram em nenhum dos anteriores.

Dentre as metodologias analisadas, estão as metodologias propostas pelo CODI [3] Comitê de Distribuição - e pelo CCON [12] - Comitê Coordenador de Operações Norte / Nordeste. Como poderá ser visto no decorrer deste capítulo, as metodologias propostas pelo CODI e pelo CCON são idênticas. 


\subsection{Medidor de Energia}

\subsubsection{Considerações Gerais}

Os medidores de energia ativa são compostos por um par de bobinas para cada fase. Assim, os medidores monofásicos, bifásicos e trifásicos possuem, respectivamente, 1 par, 2 pares e 3 pares de bobinas.

Cada par de bobinas, doravante denominado elemento medidor, é constituído por uma bobina de potencial e uma bobina de corrente. A perda que ocorre na bobina de corrente é assumida pelo consumidor, uma vez que ela é registrada pelo medidor. Já a perda na bobina de potencial é assumida pela concessionária. A perda de demanda na bobina de potencial não varia ao longo do dia, já que ela está submetida a uma tensão praticamente constante, que permite com que a perda de demanda no medidor seja assumida como independente da carga.

Sendo assim, para calcular a perda de energia no segmento medidor de energia, basta conhecer o valor da perda de demanda por elemento medidor e a quantidade total de medidores monofásicos, bifásicos e trifásicos.

\subsubsection{Metodologias}

As metodologias pesquisadas adotam um valor de perda de demanda por elemento medidor que varia de 1,2 a $1,5 \mathrm{~W}$ para realizar o cálculo da perda total de demanda neste segmento.

A metodologia do CODI [3] e do CCON [12] adota uma perda média de $1,2 \mathrm{~W}$ por elemento medidor. Assim, o cálculo da perda de demanda nos medidores de energia é realizado conforme a expressão que se segue:

$$
p_{m}=\frac{1,2 \cdot N_{m} \cdot\left(j_{1}+2 \cdot j_{2}+3 \cdot j_{3}\right)}{1000}[\mathrm{~kW}]
$$

onde: 
- $N_{m}$ - é o número total de medidores;

- $j_{1} \quad$ - é a incidência de medidores monofásicos $\left(0 \leq j_{1} \leq 1\right)$;

- $j_{2} \quad$ é a incidência de medidores bifásicos $\left(0 \leq j_{2} \leq 1\right)$;

- $j_{3}$ - é a incidência de medidores trifásicos $\left(0 \leq j_{3} \leq 1\right)$;

sendo $j_{1}+j_{2}+j_{3}=1$.

Supondo que a quantidade de medidores monofásicos, bifásicos e trifásicos seja, respectivamente, $N_{1}, N_{2}$ e $N_{3}$, calcula-se $j_{1}, j_{2}$ e $j_{3}$ pela expressão

$$
j_{i}=\frac{N_{i}}{N_{m}}
$$

$\operatorname{com} i=1,2,3$.

Em outras palavras, a incidência de medidores monofásicos, bifásicos e trifásicos é a porcentagem desses medidores em relação ao total de medidores.

Como a perda de demanda nos medidores de energia é constante (os medidores estão sempre ligados), o fator de perdas é igual a 1,0 e a perda de energia é calculada pela seguinte expressão:

$$
e_{m}=p_{m} \cdot \Delta t[\mathrm{kWh}]
$$

onde:

- $p_{m}$ - é a perda de demanda nos medidores de energia [kWh];

- $\Delta t \quad$ - é o período de análise [h].

Cipoli [2] calcula a perda de demanda nos medidores de energia utilizando o mesmo procedimento proposto pelo CODI [3] e pelo CCON [12]. A única diferença é que Cipoli considera que cada medidor consome, em média, 1,5 W por elemento medidor.

Assim como os autores citados acima, Bacelar [1] calcula as perdas nos medidores utilizando as expressões (2.1) e (2.3), ou seja, também considerando que cada medidor apresenta uma perda de $1,2 \mathrm{~W}$ por elemento. 
Nota-se que os autores convergem para uma mesma metodologia que é satisfatória para o cálculo das perdas de energia e de demanda nos medidores de energia. No entanto, é aconselhável que cada concessionária investigue o valor médio da perda de demanda por elemento medidor por meio de ensaios, pois tal valor pode variar dependendo do medidor utilizado e influir de forma significativa nos resultados.

As metodologias descritas acima aplicam-se aos medidores eletromecânicos. No entanto, sabe-se que já existem alguns modelos de medidores eletrônicos para fins de tarifação de consumidores de alta, média e baixa tensão.

Numa pesquisa realizada junto aos fabricantes, foi possível obter alguns valores típicos de consumo desses equipamentos. Os medidores de energia com tensão de alimentação de até $120 \mathrm{~V}$ apresentam um consumo de 2,5 W. Já os medidores com tensão de alimentação de até $240 \mathrm{~V}$ apresentam um consumo de 5,1 W. Além disso, deve-se somar $0,07 \mathrm{~W}$ por fase de corrente para saber o consumo total do medidor.

Os valores indicados acima são apenas para o medidor de energia. Deve-se notar que, devido às limitações de corrente e tensão do medidor, a medição deve ser feita de forma indireta, ou seja, com o auxílio de transformadores de corrente (TC) e transformadores de potencial (TP).

A vantagem desse tipo de medidor é a redução significativa de fraude na medição que ele proporciona, levando à uma redução das perdas não técnicas.

\subsection{Ramal de Ligação}

\subsubsection{Considerações Gerais}

As perdas num ramal de ligação dependem da carga. Sendo assim, para se calcular as perdas em um ramal de ligação, é necessário conhecer a resistência de cada condutor do ramal de ligação e o valor da corrente em cada um desses condutores em cada instante do dia. 


\subsubsection{Metodologias}

Geralmente, as metodologias existentes para cálculo das perdas de energia e de demanda nos ramais de ligação estabelecem um ramal típico com bitola e comprimento médios para realizar o cálculo neste segmento, pois seria muito trabalhoso, requerendo grande quantidade de dados adicionais, considerar cada ramal de ligação separadamente.

Outro fator que complica o cálculo das perdas nos ramais de ligação é a difícil determinação das correntes nos condutores de cada ramal. Por isso, as metodologias pesquisadas utilizam algumas regras simples para determinar essas correntes, como poderá ser visto mais adiante.

O CODI [3] / CCON [12] adota algumas hipóteses no cálculo da perda de demanda nos ramais de ligação:

- é estabelecido um ramal típico, representado por comprimento e bitola médios;

- a demanda de um consumidor trifásico é o triplo da demanda de um consumidor monofásico;

- a demanda de um consumidor bifásico é o dobro da demanda de um consumidor monofásico;

- o ramal monofásico tem 2 condutores percorridos por corrente (figura 2.1);

- o ramal bifásico e o ramal trifásico têm 3 condutores percorridos por corrente (figuras 2.2 e 2.3 ).

Deve-se utilizar a seguinte expressão:

$$
p_{r}=\frac{1000 \cdot R \cdot\left[\left(f_{s} \cdot \sum_{q=S \min }^{S \max } N_{q} \cdot S_{q} \cdot f_{u q}\right)-p_{s}\right]^{2}}{V_{f n}^{2} \cdot \cos ^{2} \varphi_{B T} \cdot N_{C}} \cdot \frac{2 \cdot i_{1}+3 \cdot\left(i_{2}+i_{3}\right)}{\left(i_{1}+2 \cdot i_{2}+3 \cdot i_{3}\right)^{2}}[\mathrm{~kW}]
$$

onde:

- $R \quad$ - é a resistência do condutor fase do ramal de ligação típico [ $\Omega$ ];

- $f_{s} \quad$ - é o fator de coincidência do sistema secundário; 
- $N_{q} \quad$ - é a quantidade de transformadores de potência $q$;

- $S_{q} \quad$ - é a capacidade nominal do transformador de potência $q$ [kVA];

- $f_{u q} \quad$ - é o fator de utilização típico dos transformadores de potência $q$;

- $p_{s} \quad$ - é a perda máxima de demanda na rede secundária $[\mathrm{kW}]$;

- $V_{f n} \quad$ - é a tensão fase-neutro da rede secundária [V];

- $\cos \varphi_{B T}$ - é o fator de potência típico da rede secundária;

- $N_{C} \quad$ - é o número total de consumidores ligados à rede secundária;

- $i_{1} \quad$ - é a incidência de consumidores monofásicos;

- $i_{2} \quad$ - é a incidência de consumidores bifásicos;

- $i_{3} \quad$ - é a incidência de consumidores trifásicos;

- $q$ - assume os valores $15,30,45,75 \mathrm{kVA}$, etc.

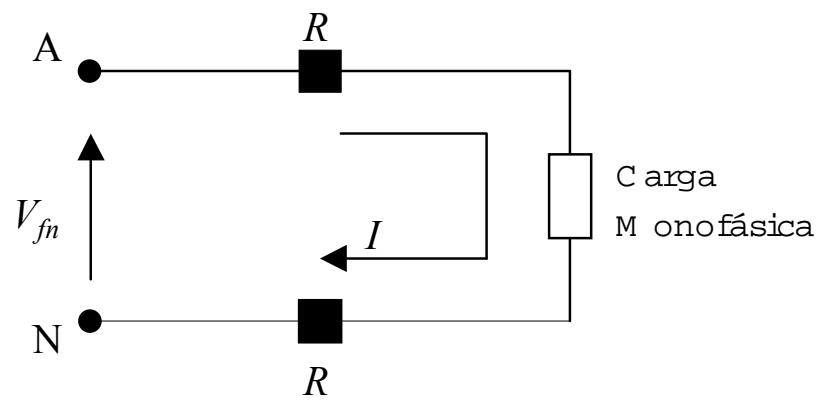

Figura 2.1 - Representação do ramal monofásico

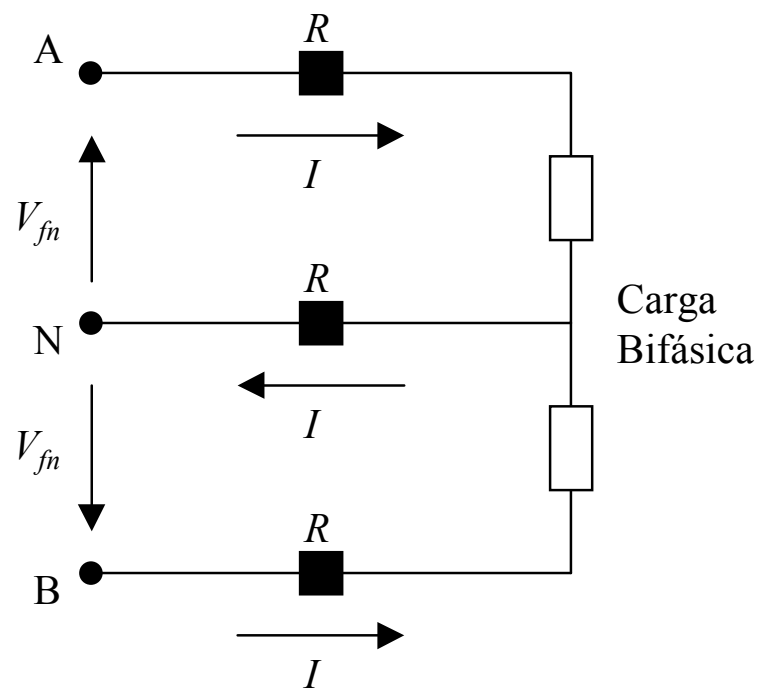

Figura 2.2 - Representação do ramal bifásico 


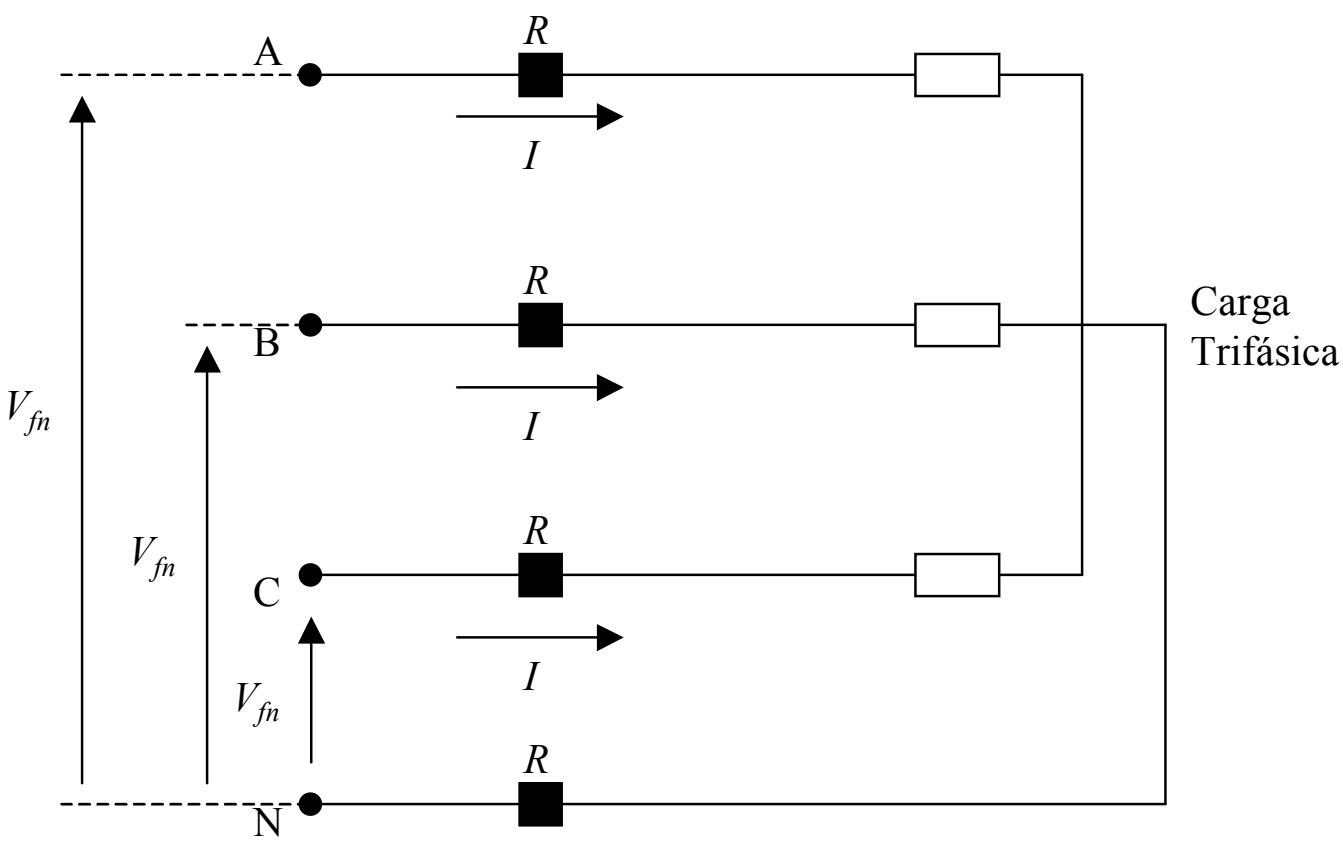

Figura 2.3 - Representação do ramal trifásico

Pelas hipóteses adotadas, o consumidor bifásico possui um ramal de ligação com três condutores (duas fases e um neutro) onde admite-se que a corrente no condutor neutro é igual à corrente nos condutores de fase. Já o consumidor trifásico possui um ramal de ligação com quatro condutores onde admite-se que a corrente no condutor neutro é nula. Essas hipóteses explicam o termo $2 i_{1}+3\left(i_{2}+i_{3}\right)$ que aparece na expressão (2.4).

Já o termo $\left(i_{1}+2 i_{2}+3 i_{3}\right)^{2}$ é explicado pelo fato de admitir-se que as demandas do consumidor trifásico e do consumidor bifásico são, respectivamente, o triplo e o dobro da demanda do consumidor monofásico.

O termo entre colchetes na expressão (2.4) representa uma estimativa da potência que efetivamente chega aos ramais de ligação. Essa potência é calculada somando-se os carregamentos de todos os transformadores de distribuição e descontando-se a perda de demanda na rede secundária. A expressão (2.4) está demonstrada em [12].

A perda de energia é obtida utilizando o fator de perdas $\left(F_{P}\right)$ correspondente, por meio da expressão abaixo:

$$
e_{r}=F_{P} \cdot p_{r} \cdot \Delta t[\mathrm{kWh}]
$$

onde:

- $F_{P}$ - é o fator de perdas; 
- $p_{r}$ - é a perda máxima de demanda nos ramais de ligação [kW];

- $\Delta t \quad$ - é o período de análise [h].

O fator de perdas, por sua vez, é calculado a partir do fator de carga pela expressão abaixo:

$$
F_{P}=k \cdot F_{C}+(1-k) \cdot F_{C}^{2}
$$

onde $0<k<1$. Os valores comuns mais utilizados para $k$ variam de 0,15 a 0,30 .

A metodologia apresentada para calcular as perdas de energia e de demanda é prática e possibilita a obtenção de uma boa estimativa do valor das perdas nos ramais de ligação.

Cipoli [2] sugere a utilização do número de consumidores por tipo de ligação (monofásica, bifásica ou trifásica), da demanda e do fator de carga típico dos consumidores por tipo de ligação e estima um comprimento médio de $15,5 \mathrm{~m}$ para calcular a perda nos ramais de ligação.

Segundo Bacelar [1], as perdas nos ramais de ligação são calculadas por:

$$
p_{r}=F_{c o n t}^{2} \cdot R \cdot I^{2}\left(2 N_{1}+3 N_{2}+3,5 N_{3}\right)[\mathrm{W}]
$$

onde:

- $F_{\text {cont }}$ - é o fator de contribuição na ponta;

- $R$ - é a resistência média dos condutores [ $\Omega]$;

- I - é a corrente média por fase [A];

- $N_{l}$ - é o número de consumidores monofásicos;

- $N_{2}$ - é o número de consumidores bifásicos;

- $N_{3}$ - é o número de consumidores trifásicos.

Bacelar adota as seguintes hipóteses: 
- a potência do consumidor bifásico é o dobro da potência do consumidor monofásico;

- a potência do consumidor trifásico é o triplo da potência do consumidor monofásico;

- o ramal monofásico tem 2 condutores percorridos por corrente (figura 2.1);

- o ramal bifásico tem 3 condutores percorridos por corrente (figura 2.2);

- admite-se que o ramal trifásico atende uma carga cujo fator de desequilíbrio é 1,15 , o que explica o fator 3,5 multiplicando o número de consumidores trifásicos na expressão (2.7). Assim, 4 condutores são percorridos por corrente.

- o fator de contribuição na ponta utilizado é 0,9 , que se mostrou adequado aos dados da concessionária local.

A resistência média do ramal de ligação é obtida pela média ponderada das resistências em relação aos consumos.

A corrente média por fase é obtida dos carregamentos médios dos transformadores de distribuição. Deve-se subtrair da demanda total coincidente a demanda de iluminação pública e a perda de demanda na rede secundária. $\mathrm{O}$ resultado deve ser dividido pelo número total de fases $\left(N_{1}+2 N_{2}+3 N_{3}\right)$. Obtém-se, então, a demanda média por condutor fase que, dividida pela tensão secundária utilizada resulta na corrente que se desejava calcular.

A perda de energia é calculada em base anual por

$$
e_{r}=8,76 \cdot p_{r} \cdot \frac{F_{P}}{F_{c o n t}^{2}}[\mathrm{kWh}]
$$

O fator de perdas $F_{P}$ é calculado por

$$
F_{P}=F_{C}^{1,65}
$$

onde $F_{C}$ é a média dos fatores de carga dos transformadores de distribuição urbana.

Como pode ser visto, é muito difícil quantificar as perdas nos ramais de ligação, dadas a diversidade existente e a imprecisão no cálculo da corrente que flui pelos seus condutores. No entanto, as perdas nos ramais de ligação correspondem a uma parcela 
pequena das perdas totais, não sendo necessário investir numa metodologia mais sofisticada.

Basicamente, as perdas nos ramais de ligação podem ser calculadas estipulando-se um ramal de ligação típico e estabelecendo-se algumas regras simples para a obtenção da corrente em cada condutor do ramal típico.

\subsection{Rede Secundária}

\subsubsection{Considerações Gerais}

As perdas na rede secundária dependem da carga. Sendo assim, para calcular as perdas em uma rede secundária, é necessário conhecer, para cada condutor (fases e neutro), a resistência de cada trecho da rede secundária e a corrente em cada trecho para cada instante do dia.

\subsubsection{Metodologias}

As metodologias pesquisadas para o cálculo das perdas de energia e de demanda neste segmento são mais variadas. Cada autor descreve um procedimento distinto dos demais e em algumas vezes aparecem fórmulas empíricas.

A metodologia proposta pelo CODI [3] / CCON [12] baseia-se na correlação entre a perda de demanda e a máxima queda de tensão no circuito secundário ou na correlação entre a perda de demanda e o carregamento do transformador que possui circuito secundário associado, doravante denominado transformador SEC. Qualquer transformador que não possua circuito secundário associado não se enquadra como transformador SEC. Como exemplo, um transformador exclusivo de um edifício não é um transformador SEC.

O CODI [3] / CCON [12] possui métodos de cálculo para banco de dados detalhado e para banco de dados simplificado, totalizando quatro métodos diferentes, que serão descritos a seguir. 
Quando se conhece a máxima queda de tensão e a distribuição por potência dos transformadores SEC, a perda máxima de demanda na rede secundária é calculada da seguinte forma:

$$
p_{s}=f_{s} \cdot \sum_{q=S_{\sin }}^{S_{\max }} N_{s q} \cdot S_{q} \cdot f_{u s q} \cdot \cos \varphi_{B T} \cdot 0,00473 \cdot \Delta V_{s q}^{1,011} \cdot 4 \cdot R_{1 s q}^{0,108} \cdot\left[\left(n_{s q}-5\right) \cdot R_{2 s q}\right]^{0,111} \cdot \delta_{s q}[\mathrm{~kW}]
$$

onde:

- $f_{s} \quad$ - é o fator de coincidência do sistema secundário;

- $N_{s q} \quad$ - é a quantidade de transformadores SEC de potência $q$;

- $S_{q} \quad$ - é a capacidade nominal do transformador SEC de potência $q[\mathrm{kVA}]$;

- $f_{u s q}$ - é o fator de utilização típico dos transformadores SEC de potência $q$;

- $\cos \varphi_{B T}$ - é o fator de potência típico da rede secundária;

- $\Delta V_{s q}$ - é a máxima queda de tensão típica da rede secundária associada ao transformador SEC de potência $q[\%]$;

- $R_{1 s q}$ - é a resistência dos condutores (dois primeiros vãos de cada lado) da rede secundária principal associada ao transformador SEC de potência $q$ $[\Omega / \mathrm{km}]$

- $R_{2 s q}$ - é a resistência dos condutores dos demais vãos da rede secundária associada ao transformador SEC de potência $q[\Omega / \mathrm{km}]$;

- $n_{s q} \quad$ - é o número médio de postes da rede secundária associada ao transformador SEC de potência $q$;

- $\delta_{s q}$ - é o fator de desequilíbrio típico da rede secundária associada ao transformador SEC de potência $q$;

- $q$ - assume os valores $15,30,45,75 \mathrm{kVA}$, etc.

Na expressão (2.10), o termo $f_{s} \cdot \sum_{q=S_{\min }}^{S_{\max }} N_{s q} \cdot S_{q} \cdot f_{u s q} \cdot \cos \varphi_{B T}$ corresponde ao carregamento total de todos os transformadores SEC. O restante da expressão faz o papel de correlacionar a perda de demanda com a máxima queda de tensão no circuito secundário e, apesar de complicada, pode-se notar que a perda de demanda aumenta com o aumento da queda de tensão e com o aumento do número de postes, pois quanto maior o número 
de postes, maior o comprimento da rede. Nota-se também, a presença de um fator de desequilíbrio para considerar o desbalanceamento da carga.

A expressão (2.10) estima a perda de demanda na rede secundária de acordo com a faixa de potência do transformador SEC em que cada rede está contida. Nota-se que, para todas as redes secundárias que são supridas por transformadores de potência $q$, são associados os mesmos valores de queda de tensão, resistência dos condutores, número de postes e fator de desequilíbrio.

Quando se conhece a máxima queda de tensão e o transformador SEC médio (banco de dados simplificado), calcula-se a perda máxima de demanda da seguinte forma:

$$
p_{s}=f_{s} \cdot N_{s} \cdot S_{M s} \cdot f_{u s} \cdot \cos \varphi_{B T} \cdot 0,00473 \cdot \Delta V_{s}^{1,011} \cdot 4 \cdot R_{1 s}^{0,108} \cdot\left[\left(n_{s}-5\right) \cdot R_{2 s}\right]^{0,111} \cdot \delta_{s}[\mathrm{~kW}](2.1
$$

onde:

- $N_{S} \quad$ - é a quantidade de transformadores SEC;

- $S_{M s} \quad$ - é a potência média dos transformadores SEC [kVA];

- $f_{u s} \quad$ é o fator de utilização típico dos transformadores SEC.

A potência média dos transformadores SEC é calculada por

$$
S_{M s}=\frac{S_{I N S T}}{N_{s}}[\mathrm{kVA}]
$$

onde $S_{I N S T}$ é o somatório das potências dos transformadores SEC.

A expressão (2.11) funciona de forma semelhante à expressão (2.10). A diferença é que a expressão (2.11) aplica-se à concessionárias que não conhecem a distribuição por potência de seus transformadores SEC. Devido a tal fato, os valores de queda de tensão, resistência dos condutores, número de postes e fator de desequilíbrio são valores típicos para o sistema secundário como um todo.

Quando se conhece o carregamento e a distribuição por potência dos transformadores SEC, a perda máxima de demanda é calculada da seguinte forma: 


$$
p_{s}=f_{s} \cdot \sum_{z=V_{\min }}^{V_{\operatorname{man}}}\left(\frac{61,76}{V_{z}^{2} \cdot \cos ^{2} \varphi_{B T}} \cdot \sum_{q=S_{\min }}^{S_{\min }}\left(N_{s z q} \cdot S_{q} \cdot f_{u s z q} \cdot \cos \varphi_{B T}\right)^{1,943} \cdot 4 \cdot R_{1 s z q}^{0,403} \cdot\left[\left(n_{s z q}-5\right) \cdot R_{2 s q q}\right]^{-0,0155} \cdot \delta_{s z q}\right)[\mathrm{kW}]
$$

onde:

- $f_{s} \quad$ - é o fator de coincidência do sistema secundário;

- $N_{s z q} \quad$ - é a quantidade de transformadores SEC de potência $q$ e tensão secundária $z$

- $S_{q} \quad$ - é a capacidade nominal do transformador de potência $q[\mathrm{kVA}]$;

- $f_{u s z q}$ - é o fator de utilização típico dos transformadores SEC de potência $q$ e tensão secundária $z$;

- $\cos \varphi_{B T}$ - é o fator de potência típico da rede secundária;

- $V_{z} \quad$ - é a tensão secundária $z[\mathrm{~V}]$;

- $R_{l s z q}$ - é a resistência dos condutores (dois primeiros vãos de cada lado) da rede secundária principal associada ao transformador SEC de potência $q \mathrm{e}$ tensão secundária $z[\Omega / \mathrm{km}]$;

- $R_{2 s z q}$ - é a resistência dos condutores dos demais vãos da rede secundária associada ao transformador SEC de potência $q$ e tensão secundária $z$ $[\Omega / \mathrm{km}]$

- $n_{s z q}$ - é o número médio de postes da rede secundária associada ao transformador SEC de potência $q$ e tensão secundária $z$;

- $\delta_{s z q}$ - é o fator de desequilíbrio típico da rede secundária associada ao transformador SEC de potência $q$ e tensão secundária $z$;

- $q$ - assume os valores $15,30,45,75 \mathrm{kVA}$, etc;

- $z \quad$ - assume os valores $220,380 \mathrm{~V}$, etc.

Assim como na expressão (2.10), pode-se identificar na expressão (2.13) um termo que corresponde à potência dos transformadores SEC. É o termo $N_{s z q} \cdot S_{q} \cdot f_{u s z q} \cdot \cos \varphi_{B T} \cdot \mathrm{O}$ restante da expressão faz o papel de correlacionar a perda de demanda com o carregamento típico dos transformadores SEC de potência $q$ e tensão secundária $z$.

Aqui, dentro da faixa de transformadores de potência $q$, seleciona-se os circuitos secundários cuja tensão vale $z$. Assim, os valores de carregamento, resistência dos condutores, número de postes e fator de desequilíbrio são valores típicos para as redes 
secundárias associadas a transformadores SEC cuja potência vale $q$ e cuja tensão secundária vale $z$.

Quando se conhece o carregamento e o transformador SEC médio (banco de dados simplificado), a perda máxima de demanda é calculada da seguinte forma:

$$
p_{s}=f_{s} \cdot \sum_{z=V_{\min }}^{V_{\max }} N_{s z} \cdot \frac{61,76}{V_{z}^{2} \cdot \cos ^{2} \varphi_{B T}} \cdot\left(S_{M s z} \cdot f_{u s z} \cdot \cos \varphi_{B T}\right)^{1,943} \cdot 4 \cdot R_{\mathrm{lsz}}^{0,403} \cdot\left[\left(n_{s z}-5\right) \cdot R_{2 s z}\right]^{-0,0155} \cdot \delta_{s z}[\mathrm{~kW}]
$$

onde:

- $N_{s z} \quad$ - é a quantidade de transformadores SEC de tensão secundária $z$;

- $S_{M s z}$ - é a potência média dos transformadores SEC de tensão secundária $z$ [kVA];

- $f_{u s z}$ - é o fator de utilização típico dos transformadores SEC de tensão secundária $z$.

A potência média dos transformadores SEC de tensão secundária $z\left(S_{M s z}\right)$ é calculada por uma expressão semelhante à (2.12), ou seja, para se obter $S_{M s z}$, basta dividir a potência total instalada de transformadores SEC de tensão secundária $z$ pela sua respectiva quantidade $N_{S z}$.

A expressão (2.14) funciona de forma semelhante à expressão (2.13), sendo que a primeira aplica-se à concessionárias que não conhecem a distribuição por potência de seus transformadores SEC. Devido a tal fato, os valores de carregamento, resistência dos condutores, número de postes e fator de desequilíbrio são valores típicos para as redes secundárias associadas a transformadores SEC cuja tensão secundária vale $z$.

Em qualquer um dos casos, após calcular a perda máxima de demanda, calcula-se a perda de energia na rede secundária pela expressão a seguir:

$$
e_{s}=F_{P} \cdot p_{s} \cdot \Delta t[\mathrm{kWh}]
$$

onde:

- $F_{P}$ - é o fator de perdas, obtido por (2.6); 
- $p_{s} \quad$ - é a perda máxima de demanda na rede secundária $[\mathrm{kW}]$;

- $\Delta t \quad$ - é o período de análise [h].

As expressões propostas pelo CODI / CCON utilizam inúmeras variáveis que precisam ser estimadas e é difícil avaliar sua adequação sem uma análise mais detalhada com valores e grandezas específicas de redes reais.

Essa metodologia poderia ser razoável para calcular a perda de energia na rede secundária de maneira simplificada. Mas para isso, deve-se dispor dos dados de queda de tensão na rede secundária ou de carregamento do transformador que a alimenta calculados ou medidos apropriadamente para encontrar uma correlação melhor entre a perda de demanda e a queda de tensão ou o carregamento. A idéia de se utilizar expressões que correlacionam as perdas com certos atributos é interessante, e poderia simplificar sobremodo os cálculos.

Bacelar [1] propõe o cálculo da perda de demanda por:

$$
p_{s}=F_{c o n t}^{2} \cdot k \cdot \delta \cdot n_{s} \cdot \lambda_{m} \cdot S \cdot \Delta V[\mathrm{~kW}]
$$

onde:

- $F_{\text {cont }}$ - é o fator de contribuição na ponta;

- $n_{s} \quad$ - é o número de circuitos secundários com cabos de mesma bitola no circuito principal, derivados de transformadores de mesma potência nominal $S$ e fator de utilização médio $\lambda_{m}$;

- $\lambda_{m}$ - é o fator de utilização médio dos transformadores que alimentam as redes secundárias;

- $S$ - é a potência nominal dos transformadores [kVA];

- $\Delta V$ - é a média das máximas quedas de tensão nos circuitos secundários derivados $\operatorname{dos} n_{s}$ transformadores, considerando os circuitos balanceados [pu];

- $\delta \quad$ - é o fator de desequilíbrio. 
A constante $k$ é determinada por processo estatístico e depende da bitola dos condutores utilizados no circuito principal da rede secundária. A tensão secundária praticamente não influencia seu valor.

A perda de energia é calculada pela expressão a seguir:

$$
e_{s}=8,76 \cdot p_{s} \cdot \frac{F_{P}}{F_{c o n t}^{2}}[\mathrm{kWh}]
$$

onde o fator de perdas $F_{P}$ é obtido por (2.9) e o fator de contribuição $F_{\text {cont }}$ utilizado é 0,9 .

\subsection{Transformador de Distribuição}

\subsubsection{Considerações Gerais}

As perdas no transformador de distribuição são compostas por duas parcelas: perdas no ferro e perdas no cobre. Enquanto as perdas no ferro independem da carga, as perdas no cobre dependem da carga.

Portanto, para calcular as perdas em um transformador de distribuição, é necessário conhecer as perdas nominais no ferro e no cobre e a curva de carga diária do transformador.

Os fabricantes de transformadores fornecem os valores nominais das perdas no ferro e no cobre, que são obtidos por ensaios em laboratório.

\subsubsection{Metodologias}

Neste segmento os autores pesquisados seguem linhas semelhantes para o cálculo da perdas de energia e de demanda. A formulação utilizada é quase sempre a mesma e a diferença básica reside na obtenção da curva de carga do transformador. 
O CODI [3] / CCON [12] apresenta dois tipos diferentes para o cálculo de perdas em transformadores de distribuição em função do banco de dados disponível na concessionária. A seguir, são apresentados estes métodos. Em ambos, primeiro calculase a perda de demanda para em seguida calcular a perda de energia utilizando o fator de perdas adequado. A perda de energia também é separada em duas parcelas: perda no ferro e perda no cobre, já que, para a perda de energia no ferro, o fator de perdas será sempre 1,0 , pois ela independe da carga. $O$ fator de perdas para calcular a perda de energia no cobre depende da carga e, portanto, assume valores entre 0 e 1 .

Quando se conhece a distribuição por potência dos transformadores instalados, as perdas no ferro e no cobre são calculadas da seguinte forma:

$$
\begin{aligned}
& p_{F e}=\sum_{q=S_{\min }}^{S_{\max }} N_{q} \cdot p_{F e q} \\
& p_{C u}=f_{s} \cdot \sum_{S_{\max }}^{S_{\max }} N_{q} \cdot p_{C u q} \cdot f_{u q}^{2}
\end{aligned}
$$

onde:

- $N_{q}$ - é a quantidade de transformadores de potência $q$;

- $p_{\mathrm{Feq}}$ - é a perda nominal no ferro do transformador de potência $q[\mathrm{~kW}]$;

- $\quad p_{C u q}$ - é a perda nominal no cobre do transformador de potência $q[\mathrm{~kW}]$;

- $f_{u q}$ - é o fator de utilização típico dos transformadores de potência $q$;

- $f_{s}$ - é o fator de coincidência do sistema secundário;

- $q$ - assume os valores $15,30,45,75 \mathrm{kVA}$, etc.

O fator de utilização típico dos transformadores de potência $q$ é calculado por

$$
f_{u q}=\sqrt{\frac{\sum_{i=1}^{m} f_{u i}^{2}}{m}}
$$

onde:

- $m$ - é a quantidade de transformadores de potência $q$; 
- $f_{u i}$ - o fator de utilização do $i$-ésimo transformador de potência $q$.

No caso da concessionária possuir um banco de dados detalhado, essa alternativa de cálculo seria viável. Entretanto, seria preciso definir com cuidado os valores para os fatores de utilização $\left(f_{u q}\right)$ e para os fatores de coincidência $\left(f_{s}\right)$.

Quando se conhece a potência instalada e o número total de transformadores (banco de dados simplificado), deve-se antes calcular a potência média dos transformadores pela expressão (2.12).

Em seguida, pode-se calcular as perdas de demanda no ferro e no cobre dos transformadores por:

$$
\begin{aligned}
& p_{F e}=N \cdot p_{\text {FeMed }} \\
& p_{C u}=f_{s} \cdot N \cdot p_{\text {CuMed }} \cdot f_{u}^{2}[\mathrm{~kW}]
\end{aligned}
$$

onde

- $\quad p_{\text {Femed }}$ - é a perda nominal no ferro do transformador de potência média $S_{M}[\mathrm{~kW}]$;

- $\quad p_{\text {CuMed }}$ - é a perda nominal no cobre do transformador de potência média $S_{M}[\mathrm{~kW}]$;

- $N$ - é o número total de transformadores de distribuição;

- $f_{u} \quad$ - é o fator de utilização típico dos transformadores de distribuição;

- $f_{s} \quad$ - é o fator de coincidência do sistema secundário.

Para determinar os valores de perdas nominais no transformador de potência média $S_{M}$, o CODI / CCON utilizou os limites máximos de perdas em transformadores estabelecidos pela ABNT para fazer uma regressão e obteve as seguintes expressões:

$$
\begin{aligned}
& p_{\text {FeMed }}=\frac{15,71}{1000} \cdot S_{M}^{0,74}[\mathrm{~kW}] \\
& p_{\text {CuMed }}=\frac{42,53}{1000} \cdot S_{M}^{0,76}
\end{aligned}
$$

As expressões acima aplicam-se a transformadores de distribuição cuja tensão nominal primária é $13,8 \mathrm{kV}$. 
O fator de utilização típico pode ser calculado de diversas maneiras.

Uma primeira maneira consiste em realizar campanhas de medições nos transformadores.

Uma segunda maneira consiste em calcular o fator de utilização em função dos critérios de projeto para carregamento inicial e final. Nesse caso, deve-se calcular o fator de utilização como sendo uma média aritmética dos fatores de utilização inicial e final.

Uma terceira maneira consiste em calcular o fator de utilização pela relação entre a demanda obtida da função kVAs e a potência total instalada de transformadores de distribuição.

Após calcular as perdas de demanda no ferro e no cobre pelas expressões (2.18) ou pelas expressões (2.20), calculam-se as perdas totais de demanda e de energia nos transformadores de distribuição pelas expressões a seguir:

$$
\begin{gathered}
p_{t}=p_{F e}+p_{C u}[\mathrm{~kW}] \\
e_{t}=p_{F e} \cdot \Delta t+F_{P} \cdot p_{C u} \cdot \Delta t[\mathrm{kWh}]
\end{gathered}
$$

Como pode ser observado, a perda de energia é calculada, mais uma vez, utilizando o fator de perdas, obtido por (2.6). Outro ponto a ser considerado é que o fator de coincidência é um dado difícil de ser obtido.

Para o cálculo das perdas no ferro, Cipoli [2] sugere valores médios que variam de acordo com a potência nominal do transformador. Para a perda no cobre, foi realizado um estudo e os valores das perdas anuais de energia em função da potência nominal do transformador foram tabelados.

Segundo Bacelar [1], a perda de demanda no ferro é calculada por

$$
p_{F e}=n \cdot p_{0 m}[\mathrm{~kW}]
$$

onde $p_{0 m}$ é a perda média dos ensaios em vazio dos $n$ transformadores de mesma potência, mesmo número de fases e mesma classe de tensão. A perda de energia no ferro é calculada por 


$$
e_{F e}=8,76 \cdot p_{F e}[\mathrm{MWh}]
$$

Para $n$ transformadores do mesmo tipo, a perda de demanda no cobre é calculada por

$$
p_{C u}=n \cdot p_{m} \cdot F_{c o n t}^{2} \cdot \lambda_{q}^{2}[\mathrm{~kW}]
$$

onde:

- $n$ - é a quantidade de transformadores do mesmo tipo;

- $p_{m}$ - é a perda média dos ensaios de curto-circuito dos $n$ transformadores [kW];

- $F_{\text {cont }}$ - é o fator de contribuição na ponta;

- $\lambda_{q}$ - é o fator de utilização médio quadrático, dado por:

$$
\lambda_{q}=\sqrt{\frac{\sum_{i=1}^{n} \lambda_{i}^{2}}{n}}
$$

onde $\lambda_{i}$ representa os fatores de utilização individuais e podem ser obtidos por um processo de amostragem. A perda de energia no cobre é obtida por

$$
e_{C u}=8,76 \cdot p_{C u} \cdot \frac{F_{P}}{F_{c o n t}^{2}}[\mathrm{kWh}]
$$

onde o fator de perdas $F_{P}$ é obtido por (2.9) e o fator de contribuição $F_{c o n t}$ utilizado é 0,9 .

Os valores médios utilizados de perda dos ensaios em vazio e em curto-circuito nos transformadores de distribuição são um pouco menores que os limites máximos admitidos pela ABNT.

Para os transformadores de distribuição rural, Bacelar [1] estimou um carregamento médio de $25 \%$ e adotou um fator de carga igual a 0,15 e um fator de contribuição de 0,9 . 


\subsection{Rede Primária}

\subsubsection{Considerações Gerais}

O cálculo das perdas na rede primária é semelhante ao da rede secundária, necessitandose os mesmos dados que são necessários para o cálculo na rede secundária, ou seja, para cada condutor, deve-se conhecer a resistência de cada trecho e a corrente em cada trecho para cada instante do dia.

\subsubsection{Metodologias}

Assim como para a rede secundária, cada autor apresenta uma alternativa diferente para o cálculo da perda de energia e de demanda na rede primária.

A metodologia proposta pelo CODI [3] / CCON [12] para calcular as perdas na rede primária usa um modelo estatístico baseado no algoritmo Árvore Cronológica de Comprimento Mínimo, o qual simula a criação de um circuito que atende uma determinada zona de ação convexa.

Esse algoritmo tem, em uma de suas aplicações mais importantes, a determinação de alguns parâmetros invariantes denominados Parâmetros Específicos de um Alimentador de Média Tensão. Esses parâmetros possuem a propriedade de apresentar valores estáveis quando analisados num conjunto de alimentadores pertencentes a zonas de ação de formas geométricas semelhantes.

Dentre esses parâmetros, vale destacar aqui o Momento Equivalente de Perdas $\left(M_{P}\right)$, definido pela expressão a seguir:

$$
M_{P}=\frac{D^{2} \cdot L}{p}\left[\mathrm{MW}^{2} \mathrm{~km} / \mathrm{kW}\right]
$$

onde:

- $D$ - é a demanda de ponta do circuito [MW];

- $L$ - é o comprimento total do circuito $[\mathrm{km}]$; 
- $p \quad$ - é a perda no instante de ponta $[\mathrm{kW}]$.

Após uma série de simulações utilizando este algoritmo, é possível obter uma lei para determinar o Momento Equivalente de Perdas $\left(M_{P}\right)$, conforme a expressão

$$
M_{P}=\frac{0,21495 \cdot N_{a}^{-0,36} \cdot N_{p}^{\left(0,483-0,00329 \cdot N_{a}\right)}}{r}\left[\mathrm{MW}^{2} \mathrm{~km} / \mathrm{kW}\right]
$$

onde:

- $N_{a} \quad$ - é o número de circuitos primários da subestação da qual se deriva o circuito primário em questão;

- $N_{p} \quad$ - é o número de pontos de carga (transformadores) do circuito primário;

- $r \quad$ - é a resistência unitária do condutor predominante no tronco do circuito primário $[\Omega / \mathrm{km}]$.

Na obtenção dessa lei, admitiu-se que o fator de potência e a tensão nominal do circuito primário eram, respectivamente, 0,894 e $13,8 \mathrm{kV}$. Por isso, foi introduzido um fator de correção para adequar a lei à realidade de cada concessionária. Assim, o Momento Equivalente de Perdas passa a ser calculado por

$$
M_{P}=\frac{0,21495 \cdot N_{a}^{-0,36} \cdot N_{p}^{\left(0,483-0,00329 \cdot N_{a}\right)}}{r} \cdot \frac{152,2}{V^{2} \cdot \cos ^{2} \varphi_{A T}}\left[\mathrm{MW}^{2} \mathrm{~km} / \mathrm{kW}\right]
$$

onde:

- $\quad V \quad$ - é a tensão nominal de linha do circuito primário [kV];

- $\cos \varphi_{A T}$ - é o fator de potência do circuito primário.

Combinando-se as expressões (2.29) e (2.31), obtém-se a expressão que se segue para o cálculo da perda de demanda em um circuito primário:

$$
p_{p}=\frac{r \cdot D^{2} \cdot L}{0,21495 \cdot N_{a}^{-0,36} \cdot N_{p}^{\left(0,483-0,00329 \cdot N_{a}\right)}} \cdot \frac{152,2}{V^{2} \cdot \cos ^{2} \varphi_{A T}}[\mathrm{~kW}]
$$


Essa expressão é aplicada aos demais circuitos primários da mesma subestação e também para os demais circuitos das outras subestações.

Sendo $p_{p i}$ a perda de demanda em $\mathrm{kW}$ no circuito $i$, calcula-se a perda total de demanda $p_{p}$ em $\mathrm{kW}$ nos $n$ circuitos primários por

$$
p_{p}=f_{p} \cdot \sum_{i=1}^{n} p_{p i}[\mathrm{~kW}]
$$

onde $f_{p}$ é o fator de coincidência do sistema primário.

Em seguida, a perda de energia é obtida por

$$
e_{p}=F_{P} \cdot p_{p} \cdot \Delta t[\mathrm{kWh}]
$$

onde:

- $F_{P}$ - é o fator de perdas;

- $p_{p}$ - é a perda máxima de demanda no circuito primário [kW];

- $\Delta t \quad$ - é o período de análise $[\mathrm{h}]$.

A avaliação acima descrita é uma avaliação expedita. Uma avaliação mais elaborada pode ser obtida utilizando um programa de fluxo de potência.

Esta metodologia trata o sistema como um todo, de maneira agregada. E isto só é conveniente quando se dispõe de poucos dados, pois os resultados obtidos são aproximados. Além disso, sendo o fator de perdas também estimado, pode-se cometer maiores erros ao calcular a perda de energia.

Quando se tem uma boa base de dados, um cálculo por fluxo de potência apresentaria melhores resultados.

Além disso, os parâmetros utilizados na expressão (2.31) mostrada acima podem não retratar a realidade de uma determinada concessionária. Esta expressão é válida de maneira indicativa e os coeficientes devem ser estimados para cada concessionária, pois os parâmetros variam com os padrões da rede, com a topologia da rede e com a distribuição da carga. 
O sistema computacional SISPAI - Sistema para Planejamento Agregado de Investimentos em Redes de Distribuição - foi desenvolvido para a implementação do modelo de planejamento agregado de investimentos e possibilita a obtenção de expressões estatísticas específicas para os alimentadores primários do sistema de distribuição de cada concessionária.

Segundo Cipoli [2], a perda de energia na rede primária é calculada periodicamente por um sistema computacional de gerenciamento da rede.

Para determinar as perdas de energia na rede primária, Bacelar [1] sugere a utilização de três procedimentos diferentes.

O primeiro procedimento consiste em usar um software de fluxo de potência, adotando o modelo de potência constante com a tensão para os grandes consumidores e o modelo de corrente constante com a tensão para a maioria das demais cargas. Este procedimento requer o cadastro completo da rede primária.

O segundo procedimento consiste em utilizar um sistema informatizado que gerencia os níveis de tensão, carregamento e perdas em redes rurais, além de outros recursos. Tal sistema considera apenas a rede rural que atende a localidades e despreza os demais ramais rurais. Assim, após o cálculo da perda de demanda, acrescenta-se 3,5\% ao valor calculado para compensar a perda nos ramais não cadastrados e considera-se um fator de contribuição de ponta de 0,9 . Para obter a perda de energia, utiliza-se o fator de carga médio das subestações de 0,5 e calcula-se o fator de perdas por (2.9). Assim, têm-se os dados necessários para calcular a perda anual de energia.

O terceiro procedimento é utilizado para calcular as perdas na maioria das redes urbanas e consiste em adotar modelos típicos de redes urbanas de acordo com o número de consumidores da localidade. Bacelar [1] define seis faixas de consumidores: localidades com menos de 200 consumidores, entre 200 e 500 consumidores, entre 500 e 1000, entre 1000 e 3000 , entre 3000 e 5000 e localidades com mais de 5000 consumidores.

Para calcular a perda de demanda em localidades com menos de 5000 consumidores, primeiro é obtida a demanda média de cada faixa de consumidor utilizando uma correlação estatística aos consumos mensais relativos a cada localidade e calculando-se a média aritmética das demandas encontradas. Para obter a demanda média em kVA, utiliza-se um fator de potência de 0,92 . 
Em seguida, cada faixa é dividida em 3 conjuntos, cada um deles representado por um modelo de rede urbana diferente. Utilizando o software de fluxo de potência citado no primeiro procedimento proposto por Bacelar, calcula-se a perda de demanda em cada conjunto.

Nos modelos de redes urbanas, considera-se que os transformadores estão distantes 300 m uns dos outros. Na faixa de 1000 a 3000 consumidores, a bitola utilizada no tronco é 2 AWG para metade dos casos e 4 AWG para a outra metade e a bitola utilizada nos ramais é 4 AWG. Repete-se o mesmo procedimento para as demais faixas até 5000 consumidores, variando-se a combinação de cabos utilizados.

Para localidades com mais de 5000 consumidores, os cálculos consideram as características específicas de cada rede como o número de alimentadores, demandas, bitolas de cabos, etc.

Conhecendo-se a perda de demanda, calcula-se a perda de energia considerando um fator de carga de 0,5 para localidades de até 5000 consumidores e, para localidades com mais de 5000 consumidores, considera-se o fator de carga das subestações que atendem essas localidades.

\subsection{Subestação de Distribuição}

\subsubsection{Considerações Gerais}

Basicamente, as perdas em uma subestação de distribuição são compostas pelas perdas em seus transformadores. As perdas nos transformadores da subestação de distribuição são calculadas de forma análoga aos transformadores de distribuição.

\subsubsection{Metodologias}

As metodologias pesquisadas para o cálculo das perdas em subestações de distribuição seguem a mesma tendência e são análogas às metodologias para o segmento transformador de distribuição. 
A metodologia proposta pelo CODI [3] / CCON [12] para cálculo das perdas nos transformadores de subestações é exatamente a mesma utilizada para cálculo das perdas nos transformadores de distribuição que foi exposta em 2.5.2. A única diferença está no fato de que, neste segmento, os transformadores possuem potências e tensões diferentes dos transformadores de distribuição.

Segundo Cordeiro e outros [21], as perdas de demanda nos transformadores das subestações são calculadas da seguinte forma:

$$
p_{t}=\sum_{i=1}^{n}\left(p_{F e}+p_{C u} \cdot F_{u}^{2}\right)[\mathrm{kW}]
$$

onde:

- $\quad p_{C u}$ - é a perda nominal no cobre do transformador $i[\mathrm{~kW}]$;

- $p_{F e}$ - é a perda nominal no ferro do transformador $i[\mathrm{~kW}]$;

- $n$ - é a quantidade total de transformadores;

- $F_{u}$ - é o fator de utilização do transformador $i$.

A perda de energia é obtida por

$$
e_{t}=p_{t} \cdot \Delta t[\mathrm{kWh}]
$$

Essa metodologia não separa as perdas de energia no cobre das perdas de energia no ferro, o que pode introduzir erros no cálculo. A perda no ferro apresenta um fator de perdas igual a 1,0, enquanto a perda no cobre apresenta um fator de perdas entre $0,0 \mathrm{e}$ 1,0 , pois ela depende da carga.

Neste segmento, Cipoli [2] calcula as perdas no ferro e no cobre dos transformadores de força e reguladores de tensão instalados nas subestações. São utilizados os dados médios nominais de perdas no ferro e no cobre nos transformadores e nos reguladores. Os dados médios nominais são agrupados de acordo com a faixa de potência do transformador. 
Bacelar [1] engloba uma parte das perdas nas subestações no cálculo das perdas no sistema de alta tensão. A outra parte, composta pelos transformadores $34,5 \mathrm{kV} / 13,8 \mathrm{kV}$ têm a sua perda avaliada separadamente. O procedimento utilizado consiste em calcular as perdas de demanda no ferro e no cobre com base nos valores máximos das perdas no ferro e no cobre garantidos pelos fabricantes. Admite-se que as perdas médias no ferro e no cobre dos transformadores de subestações são $90 \%$ dos valores máximos estabelecidos pelos fabricantes. A metodologia utilizada também engloba a perda nos capacitores de subestações neste segmento e o procedimento utilizado para o cálculo será descrito em 2.9.

\subsection{Sistema de Alta Tensão}

\subsubsection{Considerações Gerais}

Assim como para os segmentos rede primária e rede secundária, para calcular as perdas no sistema de alta tensão é necessário conhecer, para cada condutor, a resistência de cada trecho e a corrente em cada trecho para cada instante do dia.

\subsubsection{Metodologias}

Segundo Cordeiro e outros [21], a energia perdida no sistema de alta tensão é calculada por:

$$
P T=C+G L-S-M S[\mathrm{MWh}]
$$

onde:

- $C$ - é o valor das compras de energia de outras empresas [MWh];

- $G L$ - é a geração própria da empresa, descontando-se o consumo interno da unidade geradora [MWh];

- $S$ - é o valor das vendas de energia a outras empresas [MWh]; 
- $M S$ - é a quantidade de energia medida em todas as subestações de distribuição do sistema.

Neste caso, as variáveis da expressão (2.37) são obtidas diretamente por medição. É necessário que os equipamentos de medição tenham suas classes de precisão compatíveis com os valores medidos, de modo que os erros devidos à medição sejam minimizados. É muito importante ter precisão nas medições. Outro ponto a ser ressaltado é que a medição só é viável quando o número de pontos a serem medidos forem limitados.

Em não se dispondo das medições em todas as subestações, faz-se um cálculo de fluxo de potência considerando a quantidade de períodos mais adequada à curva de carga do sistema.

Já a metodologia proposta por Cipoli [2] consiste em simular o fluxo de potência considerando as curvas diárias de carga das várias barras que compõem o sistema elétrico e, com isto, obtém-se as perdas de demanda e de energia neste segmento do sistema.

Neste caso, deve-se verificar se as condições operativas da rede são as mesmas existentes em seu cadastro.

Bacelar [1] não separa o cálculo das perdas no sistema de alta tensão das perdas nas subestações de distribuição com tensão primária maior ou igual a $69 \mathrm{kV}$. Considera-se a existência de apenas um único segmento: sistema de alta tensão e subestações. A metodologia determina a perda de energia em suas redes de alta tensão calculando a diferença entre a energia total requerida pelo sistema e a energia medida nas subestações de distribuição com tensão primária igual ou superior a $69 \mathrm{kV}$, subtraindose a energia entregue aos consumidores atendidos em alta tensão maior ou igual a 69 $\mathrm{kV}$. 


\subsection{Outros}

As perdas nos outros segmentos (equipamentos, fuga em isoladores, efeito corona etc.), enquanto não se tem boas estimativas, são avaliadas como sendo uma porcentagem das perdas já calculadas, procurando-se verificar na literatura os valores típicos dessa porcentagem (por exemplo, 10\%). Nem sempre um valor adequado a uma empresa pode ser estendido para outras.

O CODI [3] / CCON [12] também propõe cálculo das perdas nos equipamentos instalados no sistema de distribuição da seguinte forma:

$$
p_{e q}=\sum N_{e q i} \cdot p_{e q i}[\mathrm{~kW}]
$$

onde:

- $N_{\text {eqi }}$ - é o número de equipamentos do tipo $i$ (regulador, capacitor, medidor de energia reativa, medidor de demanda etc.);

- $p_{\text {eqi }}$ - é a perda de demanda no equipamento do tipo $i[\mathrm{~kW}]$.

A perda de energia é calculada por

$$
e_{e q}=p_{e p} \cdot \Delta t[\mathrm{kWh}]
$$

No entanto, existe uma dificuldade muito grande para definir as perdas por equipamento e, como já foi exposto no capítulo 1, essas perdas correspondem a uma pequena porcentagem do total das perdas técnicas.

As outras parcelas das perdas tais como correntes de fuga em árvores ou isoladores, por efeito corona, em conexões, etc. são estimadas como sendo uma porcentagem (a ser definida pela concessionária) das perdas calculas anteriormente.

Cipoli [2] também determina as perdas em capacitores e reguladores de tensão. As perdas em reguladores de tensão são estimadas da mesma forma que em transformadores. 
As perdas em capacitores são estimadas da seguinte forma: capacitores com isolante de papel impregnado têm perda de 2 a $3 \mathrm{~W} / \mathrm{kVAr}$ e capacitores com filme isolante têm perda de $0,25 \mathrm{~W} / \mathrm{kVAr}$.

Além disso, considera-se que as perdas em conexões, por efeito corona, fugas em isoladores, medidores de demanda, medidores de reativos, relés fotoelétricos, transformadores de corrente e de potencial, fugas em pára-raios, etc. correspondem de $0,5 \%$ a $1,0 \%$ do total fornecido.

Bacelar [1] também calcula a perda nas conexões, nos reguladores de tensão e nos bancos de capacitores.

No caso das conexões, admite-se que uma conexão com temperatura próxima da temperatura do cabo já tem sua perda contemplada na perda dos condutores. Já uma conexão com temperatura maior que a temperatura do cabo, supõe-se que a sua perda é de 3,5 W. Para completar, admite-se que existem, em média, 10 conexões por alimentador primário e por circuito secundário com temperatura elevada. Para o cálculo da perda de demanda, considera-se um fator de contribuição de 0,9 . Para o cálculo da perda de energia, estima-se um fator de perdas de 0,2. Assim, as perdas de demanda nas conexões são calculadas por

$$
p_{c}=\frac{3,5 \cdot N_{c} \cdot 0,9^{2}}{1000}[\mathrm{~kW}]
$$

onde $N_{c}$ é o número de conexões que apresentam diferenças de temperatura elevadas e as perdas de energia são obtidas por

$$
e_{c}=8,76 \cdot p_{c} \cdot \frac{0,2}{0,9^{2}}[\mathrm{MWh}]
$$

Para o cálculo das perdas nos reguladores de tensão, utilizam-se os valores médios de perdas no cobre e no ferro obtidos de ensaios ou fornecidos pelo fabricante. $\mathrm{O}$ carregamento depende dos ajustes e das variações de tensão a que os reguladores são submetidos. Bacelar considera um carregamento médio de $35 \%$, um fator de perdas 
médio de $25 \%$ e um fator de contribuição de 0,9 para os seus reguladores de tensão monofásicos.

A perda nos capacitores é calculada em função de sua potência. Para capacitores com isolante do tipo papel impregnado, considera-se uma perda de $2 \mathrm{~W} / \mathrm{kVAr}$. Para capacitores com filme isolante, considera-se uma perda de $0,2 \mathrm{~W} / \mathrm{kVAr}$.

\subsection{Outras Metodologias}

$\mathrm{Na}$ literatura internacional, a maior parte dos autores se preocupam em desenvolver modelos para representar a carga e alguns segmentos do sistema de distribuição, como a rede primária, a rede secundária e o transformador de distribuição. Alguns autores propõem metodologias para o cálculo de perdas em ramal de ligação. São poucos os autores que propõem metodologias para os demais segmentos estudados neste trabalho e essas metodologias serão descritas mais detalhadamente a seguir.

Sun, Eichenberger e outros [14] utilizam um programa de fluxo de potência para calcular as perdas no sistema de distribuição. A grande preocupação dos autores reside na modelagem da carga, das linhas de distribuição, dos transformadores de distribuição e dos bancos de capacitores. Com exceção da modelagem da carga, a modelagem dos outros componentes citados não traz novidade alguma.

A carga é modelada por duas funções que determinam as potências ativa e reativa em função de variações na tensão e na freqüência da tensão a que está submetida. Assim, foram modeladas as cargas mais importantes, como ar condicionado, aquecedores, secadora de roupas, refrigeradores, lâmpadas incandescentes e fluorescentes entre outras. A cada tipo de carga está associado um par de funções.

Devido à complexidade e dificuldade em obter dados precisos para uma modelagem e análise detalhada do sistema de distribuição completo, os autores selecionaram uma parcela do sistema cujos circuitos possuíam características representativas do sistema inteiro. Os resultados obtidos nessa parcela são utilizados para prever os resultados no sistema com um todo.

No programa de fluxo de potência, são utilizadas curvas típicas de carga por circuito. No estudo realizado pelos autores, foram levantadas seis curvas típicas de carga para 
cada circuito. As curvas levantadas modelam o dia da semana, o dia do fim de semana e as variações da carga ao longo das estações do ano.

A metodologia citada destina-se ao cálculo das perdas nas redes primárias e nos transformadores de distribuição.

Flaten [15] utiliza um método que consiste em calcular as perdas por meio do carregamento em porcento de cada componente do sistema.

O primeiro passo desse método é determinar o carregamento em termos de energia e de demanda no componente em que se deseja calcular as perdas.

Entende-se por carregamento em termos de energia o carregamento médio anual de um determinado componente dividido por sua respectiva potência nominal. O carregamento em termos de energia também pode ser entendido pela energia anual que passa num determinado componente dividida pela energia anual que passaria se o componente tivesse carregamento constante e igual a sua potência nominal.

Em seguida, o carregamento [\%], seja em termos de energia ou em termos de demanda, deve ser elevado ao quadrado e multiplicado pela perda nominal à plena carga do componente.

O autor ainda utiliza alguns fatores de correção, como o fator de potência. Também é utilizado um fator para corrigir as variações de resistência (dos condutores da rede ou dos enrolamentos do transformador) devido à influência da temperatura ambiente e do carregamento do componente.

Flaten aplica o método para calcular as perdas nos transformadores de subestações de distribuição, nos transformadores que reduzem uma tensão primária alta para uma tensão primária média, nos transformadores de distribuição, na rede primária e na rede secundária.

Para o cálculo do carregamento da rede primária, é feita uma amostragem aleatória de alguns pontos da rede e soma-se as potências de todos os transformadores conectados a jusante de cada ponto sorteado. Esse procedimento permite mapear a rede, mostrando como ela está carregada em diferentes pontos. Conhecendo-se a potência $[\mathrm{kVA}]$ de todos os transformadores e o carregamento [\%] em termos de energia e demanda para cada ponto sorteado, determina-se os carregamentos médios [\%] em termos de energia e demanda para cada rede primária. O método não leva em conta as perdas nos condutores de neutro. 
Para o cálculo das perdas na rede secundária, uma das maneiras citadas por Flaten é utilizar os mesmos carregamentos [\%] em termos de energia e demanda que foram calculados para os transformadores de distribuição.

Poveda [4] utiliza um método cujo objetivo é calcular as perdas em sistemas de distribuição que apresentam grande quantidade de cargas não registradas, ou seja, sistemas que apresentam perdas não técnicas elevadas.

Dado um circuito primário, conhecendo-se a energia suprida (medida no início do circuito) e a energia total faturada (energia registrada), determina-se a perda total de energia subtraindo-se da energia suprida a energia registrada. Além da energia suprida, o equipamento de medição também registra a curva diária de carga (demanda ativa e reativa) em intervalos de 15 minutos.

As perdas técnicas no sistema de distribuição incluem as perdas resistivas na rede primária, nos enrolamentos dos transformadores de distribuição e na rede secundária, as perdas nos núcleos dos transformadores de distribuição e as perdas nos medidores de energia.

As perdas resistivas são calculadas para o horário de ponta por métodos usuais. Em seguida, levanta-se a curva das perdas resistivas a partir da relação quadrática entre a demanda no intervalo e a demanda máxima, como se segue:

$$
p_{r, i}=\left(\frac{D_{i} \cdot \cos \varphi_{\text {máx }}}{D_{\text {máx }} \cdot \cos \varphi_{i}}\right)^{2} \cdot p_{r}[\mathrm{~kW}]
$$

onde:

- $p_{r, i} \quad$ - é a perda resistiva no instante $i[\mathrm{~kW}]$;

- $D_{i} \quad$ - é a demanda ativa no instante $i[\mathrm{~kW}]$;

- $D_{\text {máx }} \quad$ - é a demanda máxima registrada $[\mathrm{kW}]$;

- $\cos \varphi_{i} \quad$ é o fator de potência no instante $i$;

- $\cos \varphi_{\text {máx }}$ - é o fator de potência no horário de ponta;

- $p_{r} \quad$ - é a perda de demanda no horário de ponta [kW]. 
As incógnitas entre parênteses são obtidas por medição da curva de carga em intervalos de 15 minutos.

Para os circuitos primários utiliza-se a curva medida no início do circuito.

Para os transformadores de distribuição, considera-se que a curva no início do alimentador é uma boa estimativa da curva de carga no transformador.

Para as redes secundárias, escolhe-se uma amostra de redes pertencentes ao mesmo circuito e levanta-se a curva de carga nos terminais de baixa tensão de seus respectivos transformadores de distribuição. Em seguida, obtém-se uma curva típica de carga para cada estação do ano e utiliza-se o mesmo procedimento descrito acima.

Os ramais de ligação são agrupados nas bitolas mais comuns e os comprimentos mais freqüentemente usados são considerados para definir a perda de demanda no horário de ponta dos respectivo cliente. Para determinar a curva de perda nos ramais de ligação, utiliza-se a curva do transformador de distribuição mais próximo da carga. Entretanto, considera-se a demanda máxima individual ao invés da demanda máxima diversificada. Para calcular as perdas não técnicas, considera-se que as cargas não registradas e as cargas registradas possuem o mesmo perfil de curva de carga. Isso implica que os dois tipos de carga possuem o mesmo fator de carga.

A curva de carga total (das cargas registradas e não registradas) é obtida subtraindo-se a curva total de perdas da curva medida no início do alimentador.

Subtraindo-se a energia registrada (faturada) e a energia de perdas técnicas da energia suprida (medida no início do alimentador), obtém-se a energia de perdas não técnicas.

Como a carga registrada e a carga não registrada possuem o mesmo fator de carga e conhece-se a energia de perdas não técnicas, pode-se obter a perda (não técnica) máxima de demanda. Em seguida, é só seguir o mesmo procedimento descrito acima para determinar o perfil da carga não registrada.

Grainger e Kendrew [6] consideram 5 segmentos para o cálculo das perdas em sistemas de distribuição: subestações de distribuição, rede primária, transformadores de distribuição, rede secundária e ramais de ligação.

Aqui também os autores utilizam o fator de perdas estimado pela expressão (2.6), além de definirem um fator de ajuste para contabilizar as perdas que ocorrem num determinado segmento devido às perdas nos segmentos a jusante. 
Para o cálculo das perdas nas subestações de distribuição, os autores possuíam dados de medições em 130 subestações de uma concessionária. Devido ao enorme volume de dados medidos, foi necessário formar grupos de subestações com características de carga semelhantes e identificar dias importantes que possuíam curvas de carga diária semelhantes. O objetivo foi usar as Subestações Significativas e os Dias Significativos para uma análise detalhada e cálculo das perdas.

Os autores dividiram as 130 subestações mencionadas acima em 7 grupos (clusters). Dentro de cada um desses grupos de subestações foram definidos 4 grupos de dias, cada um com uma curva de carga diferente. Assim, utilizando os dados de medições (intervalos de 60 minutos ao longo de um ano inteiro), foram levantadas 28 curvas de carga normalizadas para representar a carga das subestações reais. Utilizando-se a curva de carga normalizada, a demanda de ponta em cada transformador da SE para cada dia do ano e os dados de perdas nominais fornecidos pelos fabricantes dos transformadores, calculam-se as perdas em cada subestação real em base anual.

Para a rede primária, como suas linhas alimentam uma combinação de carga concentrada com carga uniformemente distribuída em cada trecho, obtém-se as perdas encontrando antes uma carga equivalente para cada trecho. Outra alternativa é assumir que o alimentador possui uma área de influência retangular com densidade de carga uniforme.

Nos dois casos, é necessário conhecer os carregamentos do alimentador e de seus ramais no horário de ponta e também ao longo do ciclo de carga. Com essas informações, as perdas são calculadas por um programa, onde os 477 alimentadores trifásicos foram representados por modelos de linha detalhados, levando-se em consideração a bitola do condutor utilizado, o comprimento e a geometria da linha. As cargas e suas posições geográficas na rede foram reconstruídas por meio de um programa de gerenciamento da carga do transformador de distribuição e as demandas de cada alimentador foram determinadas.

Em seguida, foram escolhidos 26 alimentadores para um estudo mais detalhado, sendo que esses alimentadores escolhidos representavam os 477 existentes no sistema. Os dados desses 26 alimentadores foram utilizados para formar grupos de alimentadores semelhantes e foi feita uma análise das perdas de demanda obtidas.

Como era esperado pelos autores, foi encontrada uma correlação forte entre os comprimentos dos ramais monofásicos e bifásicos e suas respectivas perdas. Dessa 
forma, determinou-se que as perdas nos ramais monofásicos e bifásicos de cada alimentador podem ser calculadas por, respectivamente, 210 e $440 \mathrm{~W}$ por quilômetro. Entretanto, o comprimento das linhas trifásicas não tiveram uma correlação boa com suas respectivas perdas, exceto pelos alimentadores que suprem consumidores comerciais. Por outro lado, deve-se notar que uma boa aproximação para as perdas em um alimentador trifásico poderiam ser obtidas por uma correlação com a queda de tensão em pu.

Para os transformadores de distribuição, seus carregamentos foram monitorados diretamente no caso de consumidores comerciais ou calculados indiretamente no caso de consumidores residenciais.

A maior parte dos consumidores comerciais tem medidores para fornecer a demanda de ponta. Para os transformadores que atendem consumidores residenciais, foi estabelecida uma correlação entre a energia e a demanda de ponta no transformador.

A partir de um estudo, foram determinados os fatores de perdas para as classes de consumo residencial, comercial de pequeno porte e comercial de grande porte. Assim, pode-se calcular as perdas anuais de energia por:

$$
e_{t}=\left(F_{P} \cdot d_{\text {máx }}^{2} \cdot p_{C u}+p_{F e}\right) \cdot 8760[\mathrm{kWh}]
$$

onde:

- $F_{P}$ - é o fator de perdas;

- $d_{\text {máx }}^{2}$ - é a demanda máxima no transformador [pu];

- $p_{C u}$ - é a perda nominal no cobre $[\mathrm{kW}]$;

- $p_{F e}$ - é a perda nominal no ferro [kW].

Como os consumidores comerciais são servidos diretamente pelos transformadores, as perdas no sistema secundário são devidas apenas aos consumidores residenciais. Para cada potência nominal de transformador, foi encontrado o carregamento médio quadrático utilizando-se os carregamentos de cada transformador daquela potência. Em seguida, foram escolhidas 20 localidades para cada potência nominal de transformador cujos carregamentos se aproximavam de seus respectivos carregamentos médios quadráticos. Para cada uma dessas localidades, o carregamento do transformador é corrigido por um fator que leva em conta os fatores de coincidência dos consumidores 
ligados diretamente ao transformador e dos consumidores ligados à rede secundária. Com o novo carregamento obtido, a resistência e o comprimento da rede, a tensão nominal e o fator de perdas, a perda de energia anual é facilmente calculada e os resultados são estendidos para abranger o sistema inteiro.

As perdas associadas aos ramais de ligação aéreos e subterrâneos foram calculadas utilizando-se valores típicos de bitola, comprimento e fator de perdas para cada classe de consumidor e para cada tipo de ramal (aéreo e subterrâneo). Os valores típicos de fatores de perdas foram obtidos a partir de um estudo. 


\subsection{Conclusões}

Neste capítulo procurou-se analisar algumas das metodologias existentes para o cálculo das perdas técnicas disponíveis.

Observa-se que nem todas as metodologias avaliam as perdas nos segmentos definidos neste trabalho, pois conforme pode ser visto, em alguns segmentos as perdas não são avaliadas. Em linhas gerais as metodologias existentes em cada segmento parecem seguir a mesma tendência, principalmente quanto ao cálculo de perdas nos transformadores. Outro ponto em comum é o cálculo das perdas de energia de forma indireta, ou seja, primeiro calcula-se a perda de demanda no horário de ponta do sistema para em seguida calcular a perda de energia utilizando o fator de perdas, que deve ser estimado.

Com a metodologia que será proposta no capítulo seguinte, o cálculo das perdas de energia será feito utilizando as curvas típicas de carga determinadas para o sistema da concessionária, dispensando o cálculo das perdas técnicas de energia a partir de estimativa do fator de perdas.

Lembrando que, uma vez calculadas as perdas globais do sistema de distribuição e suas perdas técnicas, é possível estimar, por diferença, o montante das perdas não técnicas. Este conhecimento ajuda a estabelecer uma estratégia de otimização, priorizando-se o combate às perdas técnicas ou às perdas não técnicas. $\mathrm{Na}$ maioria dos casos, essa finalidade coincide com a garantia de que os diversos componentes individuais que constituem a rede estejam dimensionados de forma a apresentarem, a cada momento, carregamento dentro das respectivas faixas econômicas. 


\section{CAPÍTULO 3}

\section{PROPOSIÇÃO DE METODOLOGIA}

\subsection{Introdução}

No capítulo anterior apresentou-se uma revisão bibliográfica referente a metodologias existentes para avaliação das perdas técnicas nos sistemas de distribuição de energia elétrica.

O sistema de distribuição foi dividido em oito segmentos: sistema de alta tensão, subestação de distribuição, rede primária, transformador de distribuição, rede secundária, ramal de ligação, medidor de energia e outros. Neste último segmento, foram incorporadas as parcelas de perdas referentes a equipamentos (capacitores, reguladores de tensão, etc.), corrente de fuga em isoladores, corrente de fuga em páraraios, efeito corona, perdas em conexões e outros.

Nas diversas metodologias analisadas, as perdas de energia nos principais segmentos do sistema, que incluem as perdas nas linhas e nos transformadores, são calculadas de forma indireta, ou seja, a partir do cálculo das perdas máximas de demanda e de estimativas do fator de perdas.

Este capítulo tem por objetivo apresentar proposição da metodologia a ser utilizada para a avaliação das perdas técnicas dos segmentos supra citados que compõem um sistema de distribuição.

Para a avaliação das perdas de energia nos principais segmentos do sistema de distribuição, propõe-se a utilização de metodologia baseada no uso de curvas de carga típicas por classe de consumidor e por tipo de atividade desenvolvida. 


\subsection{Fator de Carga e Fator de Perdas}

A maior parte das metodologias apresentadas no capítulo anterior dependem de uma estimativa do fator de perdas para calcular a perda de energia a partir da perda máxima de demanda.

Com exceção das perdas independentes da carga (perdas constantes), cujo fator de perdas é sempre igual a 1,0, o fator de perdas para as perdas dependentes da carga (perdas variáveis) é um dado difícil de ser obtido, uma vez que ele depende da curva diária de perda.

Por isso, geralmente os autores propõem estimar o fator de perdas a partir do fator de carga, pois este último é um dado que pode ser obtido a partir da demanda máxima e da energia num determinado período num determinado componente do sistema de distribuição. Normalmente, utiliza-se a expressão

$$
f_{p}=k \cdot f_{c}+(1-k) \cdot f_{c}^{2}
$$

que resulta, em função de $k$, a relação $f_{c}^{2} \leq f_{p} \leq f_{c}$. Entretanto, além da dificuldade de se determinar o valor de $k$ mais adequado $(k=1,0$ para curva de carga aproximadamente constante, que resultaria em $f_{p}=f_{c} ; k=0$ para curva de carga com valor máximo com duração muito reduzida e carga praticamente constante no restante do tempo, que resultaria $f_{p}=f_{c}^{2}$ ), deve-se destacar que a relação somente seria válida se fosse aplicada trecho a trecho de uma rede.

No capítulo 5 deste trabalho será mostrado como a estimativa do fator de perdas a partir do fator de carga pode influir nos resultados das perdas de energia ao realizar o cálculo indireto, comparando-se os resultados obtidos a partir do cálculo direto com os resultados obtidos a partir do cálculo indireto.

\subsection{Metodologia para Cálculo das Perdas Técnicas por Segmento}

A metodologia proposta neste trabalho destina-se ao cálculo detalhado das perdas nos principais segmentos do sistema de distribuição. Para aplicar essa metodologia, é necessário que a concessionária tenha uma base de dados onde estão cadastrados os 
dados de todas suas redes primárias, redes secundárias, transformadores de distribuição, subestações de distribuição, redes de alta tensão e também os dados de todos os seus consumidores.

A figura 3.1 ilustra, de forma simplificada, os vários segmentos do sistema de distribuição.

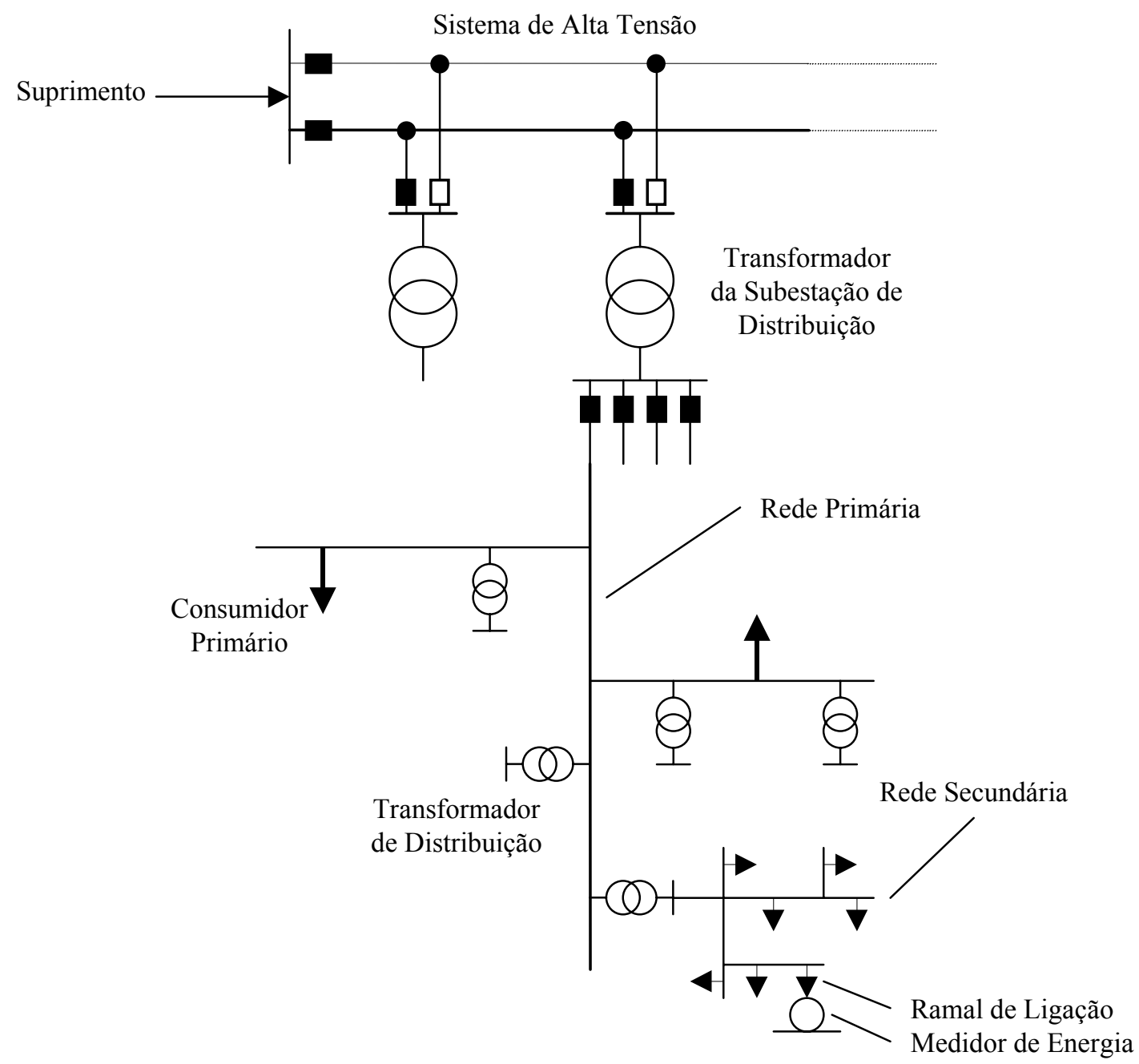

Figura 3.1 - Segmentos do sistema de distribuição

A metodologia proposta para o cálculo das perdas técnicas nos diversos segmentos, que será detalhada nos próximos itens, pode ser resumida pelos passos a seguir:

a) Atribui-se a cada medidor de energia um valor fixo de perdas.

b) Calculam-se as perdas nos ramais de ligação assumindo-se valores típicos de 
comprimento e de resistência ôhmica de condutores padronizados e utilizando as curvas de carga típicas dos consumidores.

c) Para cada rede secundária ligada a um transformador de distribuição, doravante denominado ET (estação transformadora), de um alimentador primário, calcula-se a perda de energia a partir de cálculo elétrico da rede por fase, utilizando a metodologia de curvas de carga.

d) Calculam-se as parcelas das perdas no ferro e no cobre nos transformadores de distribuição (ET’s), a partir de seus dados nominais e da sua curva de carga diária por fase, obtida pela agregação das curvas de carga dos consumidores secundários ligados à ET.

e) Ao término do cálculo de todas as ET's de um alimentador primário, calcula-se a perda de energia na rede primária a partir de cálculo elétrico da rede por fase, utilizando a metodologia de curvas de carga, incluindo-se os consumidores primários. Ao final deste cálculo, obtém-se a curva de carga diária do alimentador.

f) Repetem-se os passos anteriores para todos os alimentadores de uma determinada subestação. Em seguida, calculam-se as parcelas de perdas no ferro e no cobre nos transformadores da subestação de distribuição (SE), a partir de seus dados nominais e da sua curva de carga diária por fase, obtida pela agregação das curvas de carga dos alimentadores que dela se derivam. Ao final deste cálculo, obtém-se a curva de carga diária da subestação.

g) Ao término do cálculo de todas as SE's, calcula-se a perda de energia no sistema de alta tensão a partir de cálculo elétrico da rede por fase, utilizando a metodologia de curvas de carga, incluindo-se os consumidores ligados em alta tensão.

h) A diferença entre a energia medida nos pontos de suprimento e a soma da energia faturada com as parcelas de perdas calculadas nos passos anteriores é igual a soma das perdas não técnicas com as perdas técnicas classificadas no segmento "outros" (perdas em equipamentos, fuga em isoladores, etc). 
Como poderá ser visto mais adiante, um dos principais dados necessários para a aplicação da metodologia é a energia mensal faturada de cada consumidor. Portanto, o menor período em que as perdas de energia são calculadas é 1 mês. Assim, a metodologia pode ser aplicada em cada mês do ano de forma a obter as perdas de energia mensais em \% e em MWh e, consequentemente, as perdas de energia anuais em $\%$ e em MWh.

\subsubsection{Representação da Carga}

Antes de detalhar a metodologia proposta para o cálculo das perdas técnicas de energia em cada segmento, é necessário entender como a carga será representada.

Basicamente, são três os tipos de carga presentes nos sistema de distribuição:

- consumidores secundários, que são alimentados em baixa tensão;

- consumidores primários, que são alimentados em média tensão;

- carga de iluminação pública, que é alimentada em baixa tensão.

Para representar os dois primeiros tipos de carga, deve-se estabelecer, por meio de medições em campo, uma base de dados contendo as curvas típicas de carga dos consumidores em termos de potência ativa e reativa. $\mathrm{Na}$ indisponibilidade da curva típica em termos de potência reativa, pode-se fazer uma estimativa do fator de potência por uso final e em função do horário do dia. Assim, para um consumidor residencial, por exemplo, sabe-se que durante o dia a carga predominante é o refrigerador. Portanto, o fator de potência nesse horário é menor que o fator de potência no início da noite, quando o chuveiro está ligado.

A seguir é detalhada a representação de cada um dos três tipos de carga mencionados acima. 


\subsubsection{Consumidores Secundários}

Os consumidores secundários são representados por curvas de carga típicas, obtidas a partir de medições realizadas em campo. Neste trabalho, para ilustrar a aplicação da metodologia desenvolvida, são utilizadas as curvas obtidas para uma determinada concessionária no projeto de Curvas de Carga do CED - Centro de Excelência de Distribuição $[10,11]$-, nas quais foram levantadas as curvas de carga típicas em termos de potência ativa. Os consumidores foram divididos em três tipos:

- residencial;

- comercial;

- industrial.

Para consumidores residenciais, a partir do consumo típico mensal, pode-se determinar a curva de carga típica, que é dividida em estratos de consumo. Tais consumidores foram divididos em quatro estratos de consumo mensal:
a) de 0 a $200 \mathrm{kWh}$;
b) de 200 a $400 \mathrm{kWh}$;
c) de 400 a $500 \mathrm{kWh}$;
d) acima de $500 \mathrm{kWh}$.

$\mathrm{Na}$ figura 3.2 apresenta-se um exemplo de curva de carga típica de consumidor residencial, no segundo estrato de consumo.

Para consumidores comerciais e industriais, deve-se conhecer o tipo de atividade desenvolvida. Os consumidores comerciais foram divididos em 47 atividades principais e os industriais em 26 atividades principais.

Nas figuras 3.3 e 3.4 são apresentados exemplos desses dois tipos de consumidores: um consumidor comercial com código de atividade 5465 (estabelecimentos particulares de cursos livres) e um consumidor industrial com código de atividade 1520 (fabricação de estruturas de madeira e carpintaria). 


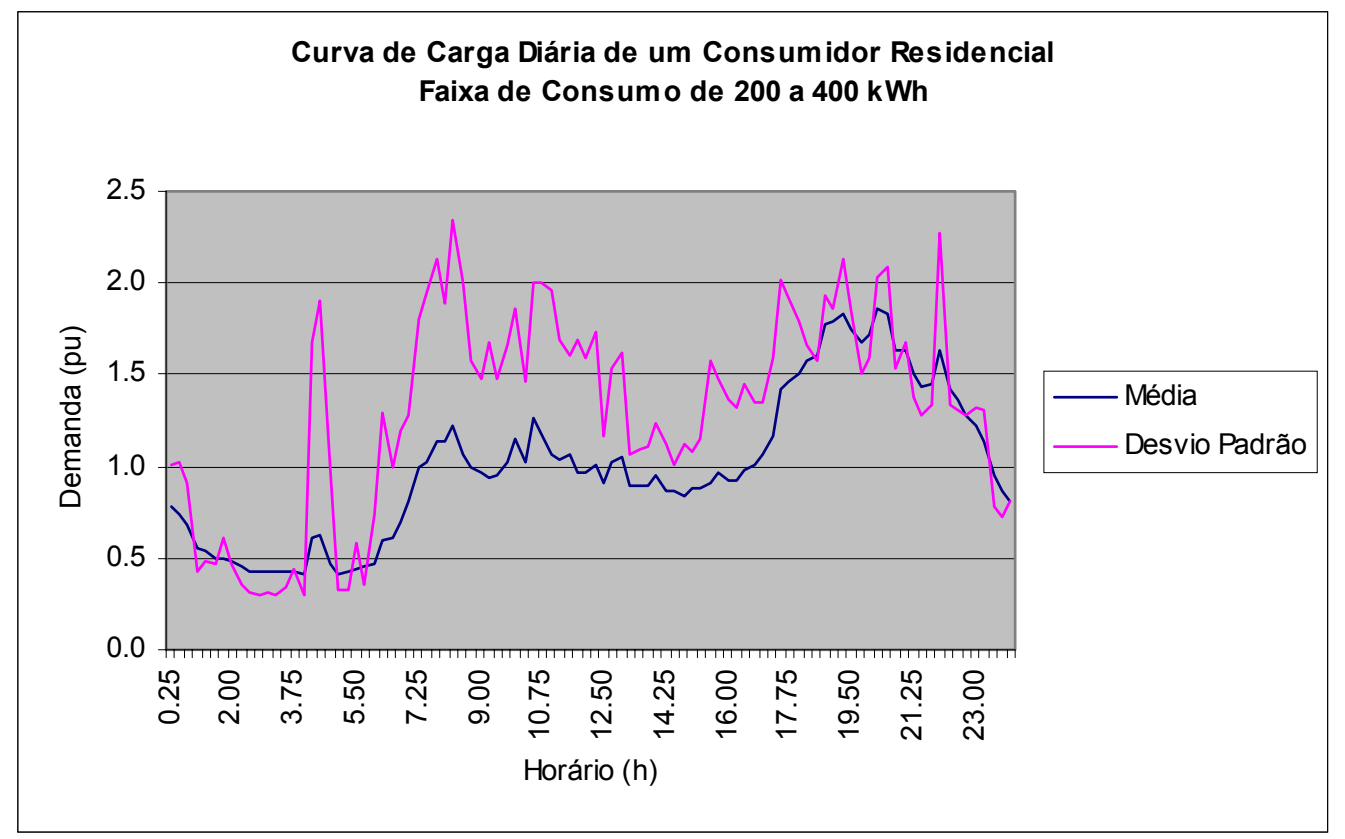

Figura 3.2 - Exemplo de curva de carga típica de consumidor residencial

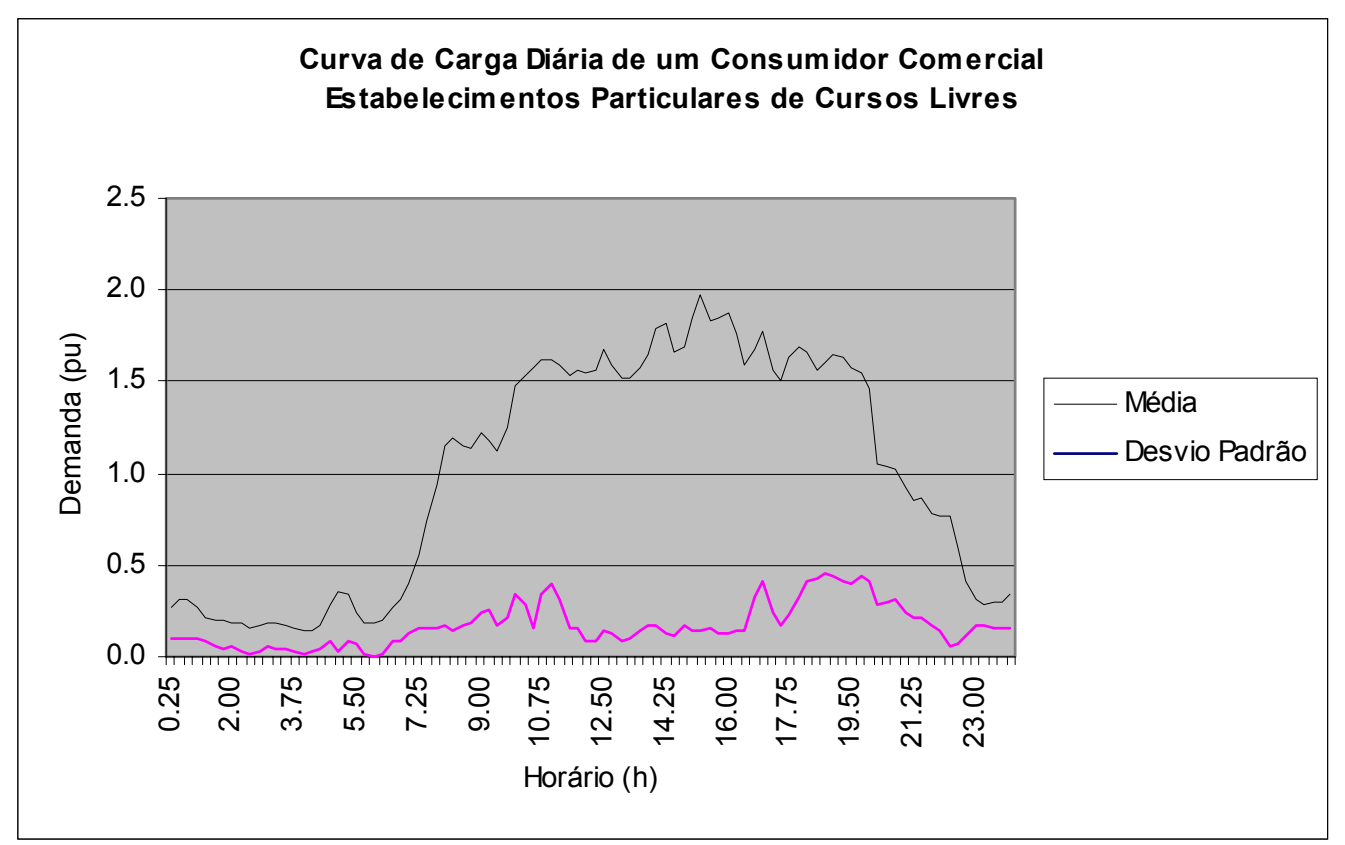

Figura 3.3 - Exemplo de curva de carga típica de consumidor comercial 


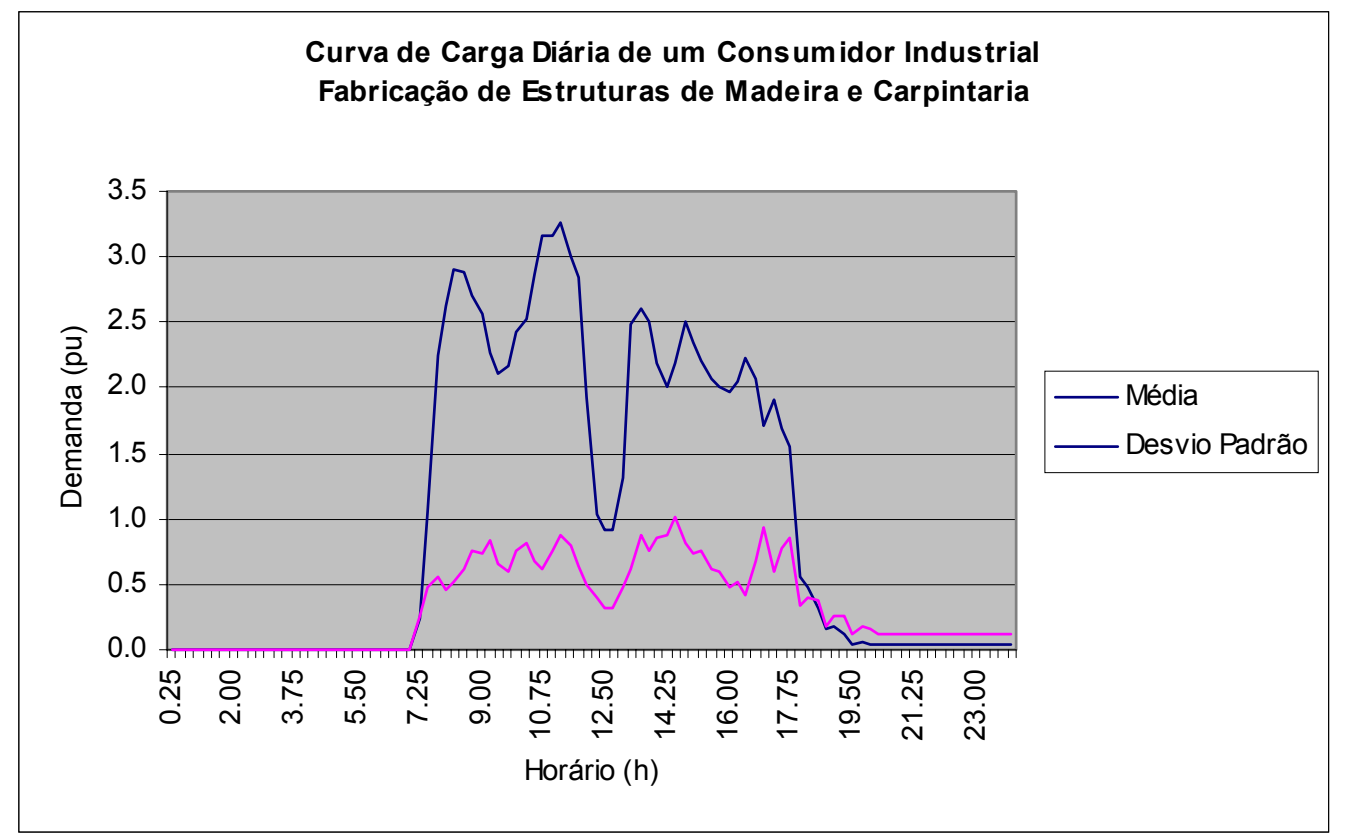

Figura 3.4 - Exemplo de curva de carga típica de consumidor industrial

Deve-se salientar que as curvas típicas de consumidores apresentam, para cada intervalo de 15 minutos, um valor médio e um valor de desvio padrão, totalizando 96 valores para a média e 96 valores para o desvio padrão para o período de 1 dia. $\mathrm{O}$ valor da demanda a ser utilizado em cada instante de tempo é uma variável aleatória, na qual é conhecida a distribuição de probabilidades correspondente, e não um valor determinado. Porém, para avaliar um valor que represente de forma adequada o carregamento da rede com dado grau de confiança, assume-se que a demanda é proporcional ao valor médio adicionado de uma certa porcentagem do desvio padrão global do circuito secundário.

Em suma, neste modelo, utiliza-se a seguinte expressão para a avaliação da demanda, $D_{i, t}$, em cada consumidor:

$$
D_{i, t}=D_{\text {med }_{i, t}}\left(1+\frac{k \sigma_{E T, t}}{D_{\text {med }_{E T, t}}}\right)
$$

onde:

$D_{i, t} \quad$ - é a demanda do consumidor $i$ no instante $t[\mathrm{~kW}]$;

$D_{\text {medi,t }} \quad$ - é a demanda média do consumidor $i$ no instante $t[\mathrm{~kW}]$; 
$\sigma_{E T, t} \quad$ - é o desvio padrão do circuito secundário [kW]. Corresponde à demanda acumulada na ET devido a todos consumidores, avaliada a partir dos desvios padrão de cada consumidor;

$D_{\text {medET,t }}$ - é a demanda média da ET [kW]. É determinada pela soma das médias das demandas de cada consumidor individual, no instante $\mathrm{t}$;

$k \quad$ - é o fator de proporcionalidade que é aplicado ao desvio padrão normalizado. Para distribuição normal (gaussiana), tem-se $k=1,28$ para uma probabilidade de $89,97 \%$ de a demanda não exceder o valor $D_{i, t}$.

Na presente metodologia será utilizado o valor médio, ou seja, $D_{i, t}=D_{\text {medi,t }}$, uma vez que a preocupação principal é o cálculo da perda de energia. Utilizar $k=1,28$ significa aumentar a carga dos consumidores e, consequentemente, a perda de energia. Tal valor seria interessante para gerenciar o carregamento de transformadores, pois, como já foi mencionado, para $k=1,28$, existe uma probabilidade de $89,97 \%$ de a demanda real não exceder o valor de demanda calculado por (3.2).

Os valores médio e de desvio padrão nas curvas de carga típicas estão em pu da potência média mensal. Sendo assim, para obter-se a curva de carga em kW, à cada consumidor associa-se uma curva de carga típica em pu conforme o seu estrato de consumo (consumidor residencial) ou sua atividade desenvolvida (consumidor comercial e industrial). Conhecendo-se a energia mensal consumida $E \mathrm{em} \mathrm{kWh}$ (energia faturada), determina-se a potência média mensal $P(\mathrm{em} \mathrm{kW})$ do consumidor por

$$
P=\frac{E}{N_{h}}[\mathrm{~kW}]
$$

onde:

$N_{h}$ - é o número de horas em um mês [h].

Uma vez determinada a potência média em $\mathrm{kW}$, basta multiplicá-la pela curva de carga típica em pu para obter a curva de carga em $\mathrm{kW}$ do consumidor. Essa curva fornece a demanda instantânea em kW para cada um dos 96 pontos do dia. Este processo deve ser repetido para cada consumidor. 
Conhecendo-se a curva de carga em $\mathrm{kW}$ do consumidor e a tensão a que está submetido, as correntes são calculadas facilmente, utilizando-se o modelo de corrente constante com a tensão, no qual avalia-se a corrente absorvida a partir da demanda instantânea e da sua tensão nominal. Como a curva de carga fornece o valor da potência ativa apenas, deve-se ainda estimar um fator de potência para o cálculo da corrente. Nos exemplos apresentados neste trabalho, o fator de potência estimado foi considerado como constante ao longo do dia.

Para consumidores ligados a duas fases e neutro, assumiu-se como hipótese que sua potência se divide igualmente entre as duas fases. Por isso, dependendo do tipo de ET que alimenta o consumidor bifásico, ele pode ou não apresentar corrente no neutro. Para uma ET trifásica, a corrente no neutro do consumidor bifásico é igual a sua corrente de fase. Para os outros tipos de ET (monofásica, delta aberto ou delta fechado), o consumidor bifásico não apresenta corrente no neutro. Os diversos tipos de ET que podem alimentar a rede secundária serão mais detalhados ainda neste capítulo.

Para os consumidores ligados a três fases e neutro, assume-se que a carga é trifásica equilibrada, dividindo-se sua potência igualmente entre as três fases.

Em outras palavras, supondo que a potência instantânea é $P_{i}$, a potência por fase do consumidor monofásico será $P_{i}$ (figura 3.5). Para os consumidores bifásicos e trifásicos, a potência por fase será, respectivamente, $\frac{P_{i}}{2}$ (figura 3.6) e $\frac{P_{i}}{3}$ (figura 3.7).

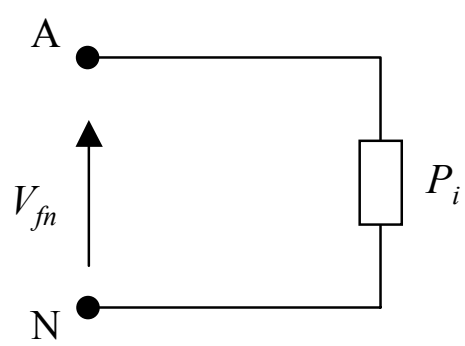

Figura 3.5 - Representação do consumidor monofásico 


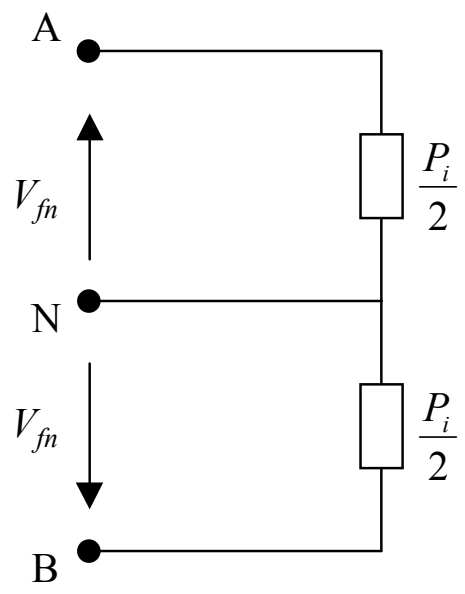

Figura 3.6 - Representação do consumidor bifásico

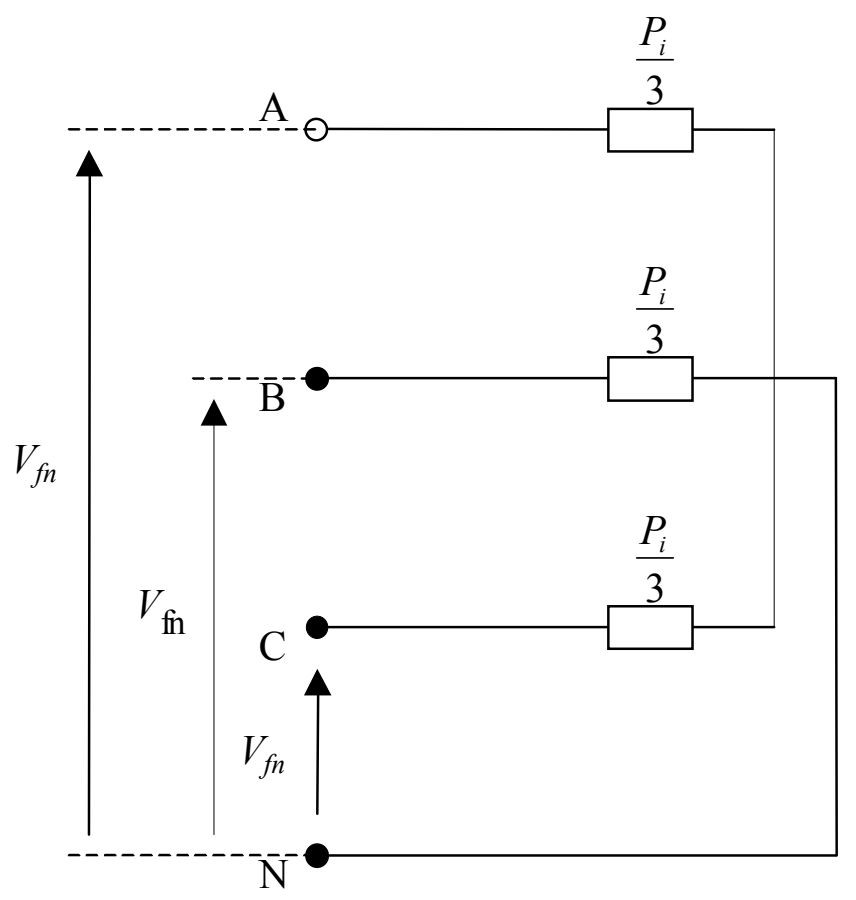

Figura 3.7 - Representação do consumidor trifásico

\subsubsection{Consumidores Primários}

Para os consumidores em que se dispõe de curva de carga típica, determina-se a demanda em cada intervalo de 15 minutos, de maneira análoga àquela apresentada para os consumidores da rede secundária.

Os consumidores primários foram divididos em 6 atividades principais. Caso existam 
consumidores sem curva de carga típica associada, adota-se uma curva de carga típica que não apresenta grandes variações ao longo do dia. Esta curva foi definida em [20], onde os autores mostraram que, em geral, ela representa bem a maioria dos consumidores primários.

Como exemplo de curvas de carga típicas para consumidores primários, as figuras 3.8 e 3.9 representam, respectivamente, um consumidor primário com código de atividade 1010 (aparelhamento de pedras para construção e execução de trabalhos em mármore, ardósia, granito e outras pedras) e um consumidor primário com código de atividade 1106 (produção de fundidos de ferro e aço).

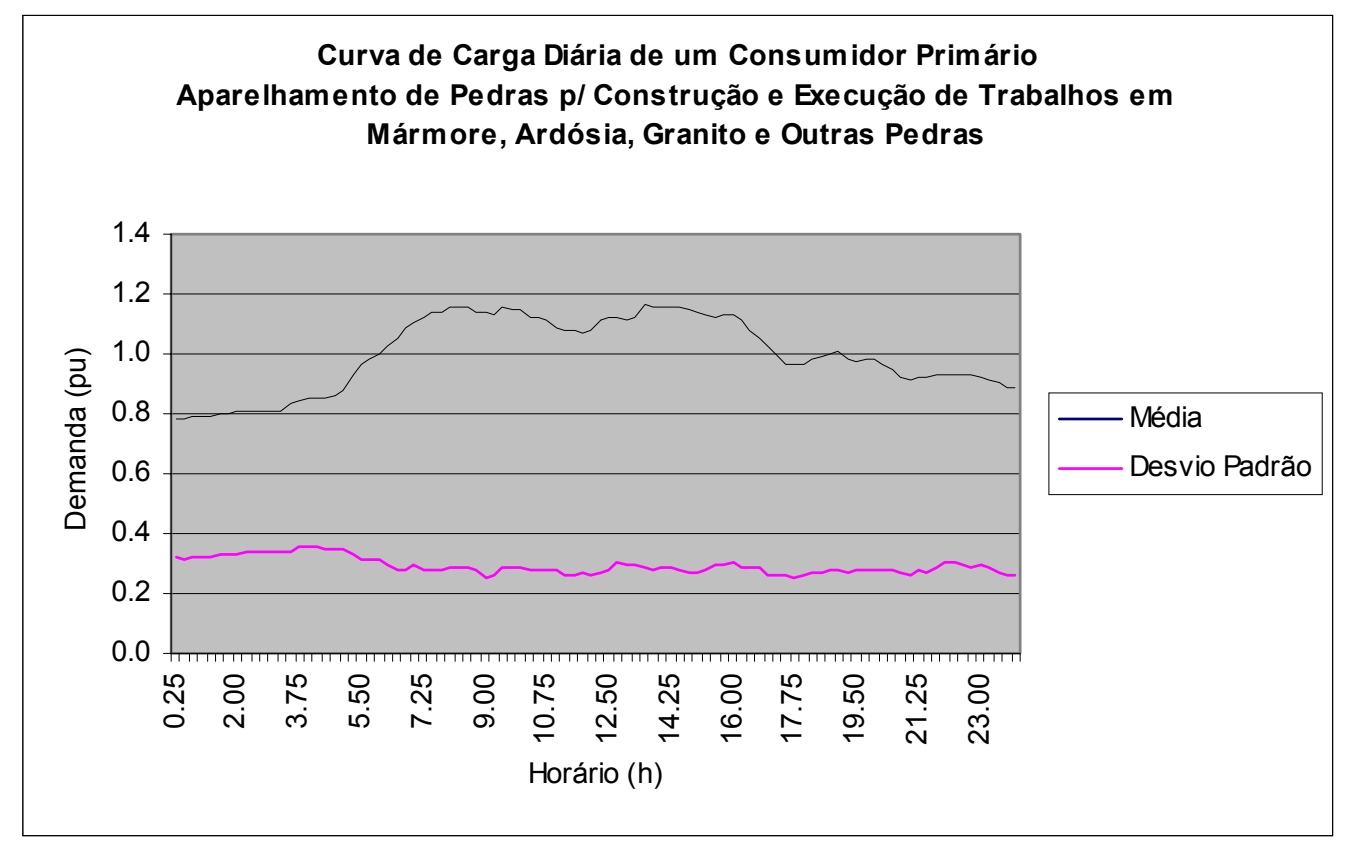

Figura 3.8 - Exemplo de curva de carga típica de consumidor primário

A potência e a corrente em cada ponto do dia são determinadas de forma análoga aos consumidores secundários, ou seja, as curvas de carga típicas dos consumidores primários fornecem apenas o valor de potência ativa, devendo-se fazer uma estimativa do fator de potência, onde assume-se um valor constante ao longo do dia.

Outro ponto a ser considerado é que o consumidor primário é representado por uma carga trifásica e equilibrada. 


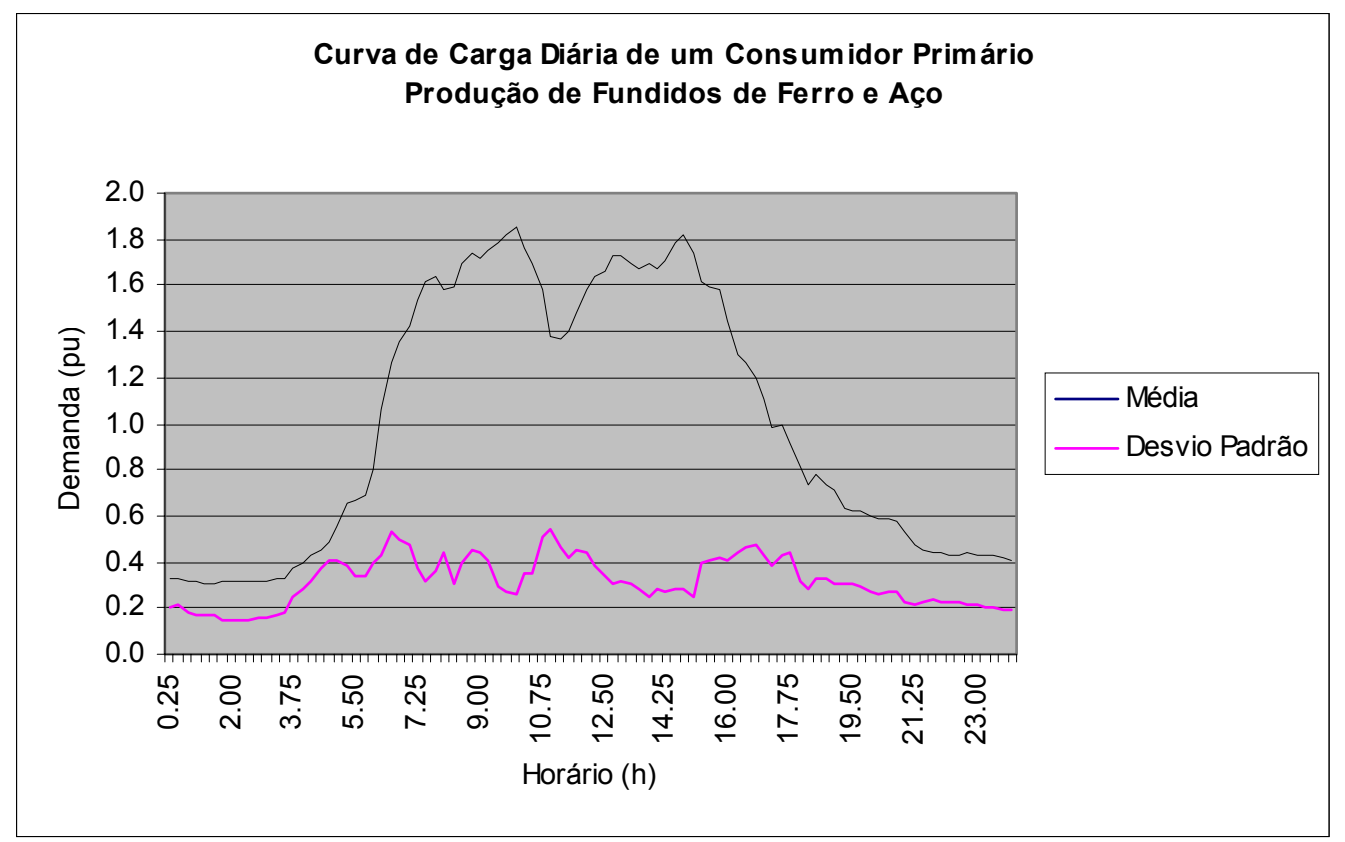

Figura 3.9- Exemplo de curva de carga típica de consumidor primário

\subsubsection{Carga de Iluminação Pública}

A carga de iluminação pública (IP) pode ser alimentada de 3 maneiras diferentes.

Num primeiro caso, a carga de IP está ligada diretamente à rede secundária que também atende consumidores secundários.

Num segundo caso, a carga de IP é alimentada por uma rede exclusiva denominada rede de iluminação pública que se deriva de uma ET que também alimenta consumidores secundários ou de um ponto qualquer da rede secundária.

Também é possível que a rede de IP seja alimentada por um transformador exclusivo de IP.

Qualquer que seja o tipo de alimentação da carga de IP, deve-se apenas tratar adequadamente a sua carga e a perda de energia na rede de IP é calculada da mesma maneira que na rede secundária.

A carga de IP é representada por uma curva de carga em $\mathrm{kW}$ de valor constante nas fases e nos períodos correspondentes do dia. Essas informações são fáceis de serem obtidas, uma vez que se conhece a potência de cada lâmpada, suas fases de ligação e seu ponto geográfico de conexão na rede de IP. Também é feita uma estimativa do fator de 
potência para calcular a corrente absorvida pela carga de IP, assumindo-se um valor constante ao longo do dia.

\subsubsection{Medidor de Energia}

As perdas nos medidores de energia são basicamente devido às perdas no ferro das bobinas de potencial e, desta forma podem ser consideradas aproximadamente constantes, pois independem da carga. De acordo com a revisão bibliográfica realizada no capítulo 2, a literatura técnica apresenta valores médios que variam de 1,2 a 1,5 W por bobina.

Desta forma, a perda de energia nos medidores $\left(e_{m}\right)$ será obtida por:

$$
e_{m}=\frac{p_{m} \cdot N_{m} \cdot\left(i_{1}+2 i_{2}+3 i_{3}\right) \cdot T}{1000}[\mathrm{kWh}]
$$

onde:

$p_{m}$ - é a perda média por elemento medidor de energia [W];

$N_{m}$ - é o número total de medidores;

$i_{1} \quad$ - é a percentagem de medidores monofásicos;

$i_{2} \quad$ é a percentagem de medidores bifásicos;

$i_{3} \quad$ - é a percentagem de medidores trifásicos;

$T$ - é o intervalo de tempo considerado [h];

Cada concessionária deve realizar ensaios de laboratório para determinar o valor da perda média por elemento medidor, pois ela pode variar conforme o tipo e o fabricante do medidor utilizado.

\subsubsection{Ramal de Ligação}

Para o cálculo das perdas nos ramais de ligação, foi definido um ramal típico por classe de consumo, com comprimento e resistência ôhmica dos condutores pré-fixados. A 
título de exemplo, são apresentados na tabela 3.1 alguns valores típicos.

Tabela 3.1 - Ramais de ligação típicos por classe de consumo

\begin{tabular}{lcc}
\hline \multicolumn{1}{c}{ Classe } & Resistência $(\Omega / \mathbf{k m})$ & Comprimento (m) \\
\hline Residencial & 3,08 & 15,0 \\
\hline Comercial & & \\
\cline { 1 - 1 } Industrial & 0,77 & 20,0 \\
\cline { 1 - 1 } Rural & 0 & \\
\cline { 1 - 1 } Outros & & \\
\hline
\end{tabular}

Desta forma, a perda de energia diária $\left(e_{r}\right)$ no ramal de ligação de um consumidor será obtida por:

$$
e_{r}=\frac{k \cdot R \cdot L \cdot \Delta t \cdot \sum_{i=1}^{N_{t}} I_{i}^{2}}{1000}[\mathrm{kWh}]
$$

onde:

$k$ - é o número de condutores do ramal de ligação em que flui corrente;

$R$ - é a resistência ôhmica dos condutores $[\Omega / \mathrm{km}]$;

$L \quad$ - é o comprimento médio do ramal $[\mathrm{km}]$;

$I_{i} \quad$ - é a corrente no ramal no período $i$ do dia $[\mathrm{A}]$;

$\Delta t$ - é a duração do intervalo da curva de carga [h];

$N_{t}$ - é o número de períodos do dia.

O valor da corrente em cada período do dia será obtido a partir do consumo de energia mensal do consumidor e de sua curva diária de carga típica em 96 pontos, o que resulta num intervalo $(\Delta t)$ igual a $0,25 \mathrm{~h}(15 \mathrm{~min})$. A obtenção da demanda em cada ponto do dia foi explicada no item 3.3.1.

Em função da modelagem da carga adotada, o condutor neutro apresentará corrente nula para os consumidores bifásicos (alimentados por ET monofásica ou delta) e trifásicos e, portanto, utiliza-se $k=2$ para consumidores monofásicos e bifásicos alimentados por ET monofásica ou delta e $k=3$ para consumidores trifásicos e consumidores bifásicos alimentados por ET trifásica.

A expressão (3.5) fornece a perda de energia num único ramal de ligação. Vale ressaltar que ela representa a área sob a curva de perda de um ramal de ligação. Conhecendo-se 
as curvas de perda de todos os ramais de ligação pertencentes a um mesmo transformador de distribuição, basta somá-las para obter a curva de perda total. A partir da curva total determina-se a perda máxima de demanda e a perda de energia no conjunto de ramais de ligação pertencentes ao mesmo transformador de distribuição.

A curva de carga em cada ramal de ligação é obtida utilizando-se apenas o valor médio da curva de carga típica. Caso o principal objetivo fosse o cálculo de perdas em cada ramal separadamente, poderia-se estar cometendo erros no cálculo e seria mais adequado considerar também a curva de desvio padrão para determinar a demanda no ramal em cada instante do dia.

No entanto, como o objetivo é calcular as perdas em todos os ramais de ligação pertencentes a uma mesma ET, considerou-se apenas o valor médio da curva de carga típica no cálculo. Além disso, vale lembrar que os dados dos ramais utilizados no cálculo são dados de ramais típicos e que este segmento contribui com uma parcela pequena do total de perdas técnicas no sistema de distribuição, o que dispensa a elaboração de um cálculo mais complexo.

\subsubsection{Rede Secundária}

\subsubsection{Considerações Gerais}

O modelo proposto permite, a partir dos dados adquiridos da concessionária relativos aos consumidores e à topologia da rede secundária e dos dados de curvas típicas de carga de consumidores residenciais, comerciais e industriais, avaliar as perdas em todos os trechos da rede secundária, por fase, bem como o carregamento das ET's.

A metodologia permite a determinação das demandas de cada ponto de carga (poste), em 96 intervalos de 15 minutos que compõem um dia típico de 24 horas, uma vez que são conhecidas as curvas de carga em $\mathrm{kW}$ de todos os consumidores ligados à rede secundária. O procedimento utilizado para obter essas curvas já foi explicado em 3.3.1. Conhecendo-se em qual ponto de carga um determinado consumidor está ligado, é fácil determinar a curva de carga de cada ponto de carga da rede. 


\subsubsection{Representação da Rede}

Para o cálculo elétrico da rede secundária, parte-se do princípio de que a rede é radial e que cada trecho é representado pelos condutores de fase e de neutro (fases $\mathrm{A}, \mathrm{B}, \mathrm{C}$ e neutro N). A figura 3.10 ilustra um trecho de rede secundária, na qual são supostamente conhecidas as correntes nas três fases $\left(I_{A}, I_{B}, I_{C}\right)$ e a corrente de neutro $\left(I_{N}\right)$. Estas correntes são obtidas a partir do conhecimento da carga em cada um dos pontos de carga (postes) da rede secundária, como foi visto no item 3.3.1.1.

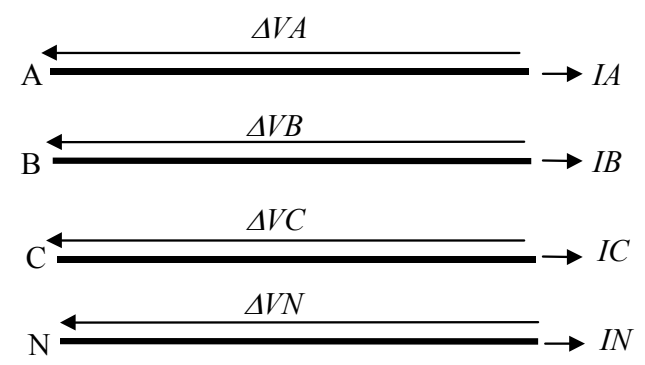

$$
\text { III }
$$

Figura 3.10 - Trecho de rede secundária

Uma vez que o circuito secundário é constituído de trechos de rede como o da figura 3.10, para determinar a corrente num trecho basta acumular as correntes, por fase e neutro, relativas às cargas correspondentes aos trechos a jusante, conforme ilustrado na figura 3.11 .

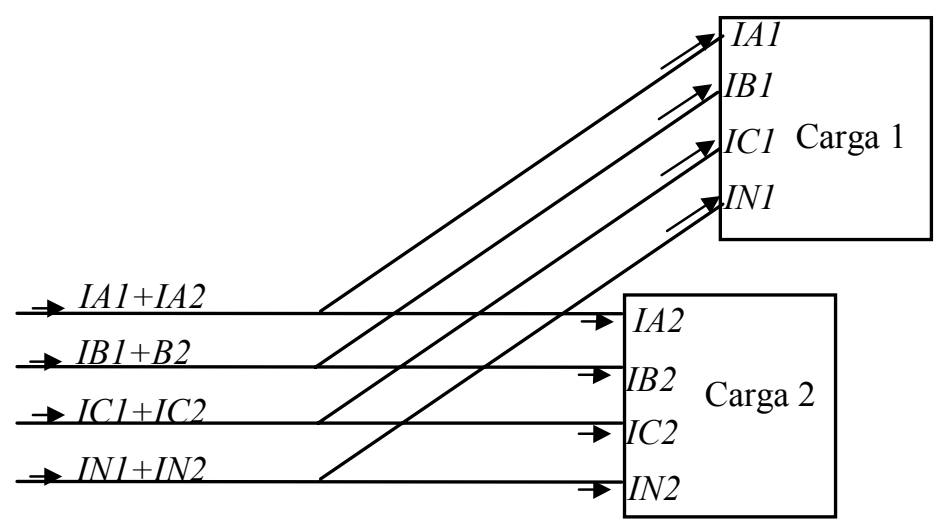

Figura 3.11-Cálculo de correntes nos trechos 
O procedimento de cálculo das correntes nos trechos é realizado dos trechos finais até a ET. Uma vez determinadas as correntes em todos os trechos (fases e neutro), pode-se então calcular as perdas na rede secundária. Para cada trecho de rede, a perda de energia diária $\left(e_{s}\right)$ é calculada por:

$$
e_{s}=\frac{1}{1000} \cdot \sum_{t=1}^{96}\left(\sum_{i=1}^{N_{\text {cond }}}\left(R_{i} \cdot I_{i, t}^{2}\right)\right) \cdot \Delta t[\mathrm{kWh}]
$$

onde:

$R_{i} \quad$ - é a resistência ôhmica do condutor $i[\Omega]$;

$I_{i} \quad$ - é a corrente no condutor $i$ no intervalo de tempo $t[\mathrm{~A}]$;

$\Delta t$ - é a duração de cada intervalo da curva de carga diária [h]. Para uma curva de carga diária com 96 pontos, $\Delta t=0,25 \mathrm{~h}$;

$N_{\text {cond }}$ - é o número de condutores no trecho (incluindo os condutores de fase e o de neutro).

É importante notar que, na expressão acima, são considerados os eventuais desequilíbrios que possam existir na rede secundária, uma vez que se realiza o cálculo elétrico por fase.

\subsubsection{Transformador de Distribuição}

Conforme apresentado no item 3.3.4, o cálculo de corrente nos trechos da rede secundária é realizado dos trechos finais até a ET, determinando-se então as correntes por fase em cada um de seus terminais.

No entanto, uma ET pode apresentar diferentes tipos de montagens e cada qual deve receber um tratamento específico. Neste trabalho, foram considerados os seguintes tipos de montagens para uma ET:

- 1 transformador monofásico;

- 2 transformadores monofásicos na ligação delta aberto;

- 3 transformadores monofásicos na ligação delta fechado; 
- 1 transformador trifásico na ligação delta-estrela.

Em seguida, é mostrada a modelagem adotada para cada uma dessas montagens para que se possa calcular as perdas numa ET.

\subsubsection{Transformador Monofásico}

Para a ET com 1 transformador monofásico (figura 3.12), calcula-se a perda de demanda em cada instante do dia $p_{t, i}$ por

$$
p_{t, i}=S \cdot\left[\frac{r}{2} \cdot\left(i_{t 1, i}^{2}+i_{t 2, i}^{2}\right)+p_{F e}\right][\mathrm{kW}]
$$

onde:

- $S \quad$ - é a potência nominal do transformador [kVA];

- $r \quad$ - é a resistência ou perda no cobre à plena carga do transformador [pu];

- $p_{F e} \quad$ - é perda nominal no ferro do transformador [pu];

- $i_{t 1, i}, i_{t 2, i}$ - são as correntes no enrolamento secundário do transformador no instante $i$ [pu].

Como as correntes $i_{A, i}, i_{B, i}$ e $i_{N, i}$ são resultados de cálculo a partir das correntes absorvidas pelos consumidores, as correntes $i_{t 1, i}$ e $i_{t 2, i}$ são facilmente calculadas utilizando-se a $1^{\text {a }}$ Lei de Kirchoff, ou seja:

$$
\begin{aligned}
& \dot{i}_{t 1, i}=\dot{i}_{A, i} \\
& \dot{i}_{t 2, i}=-\dot{i}_{B, i}
\end{aligned}
$$




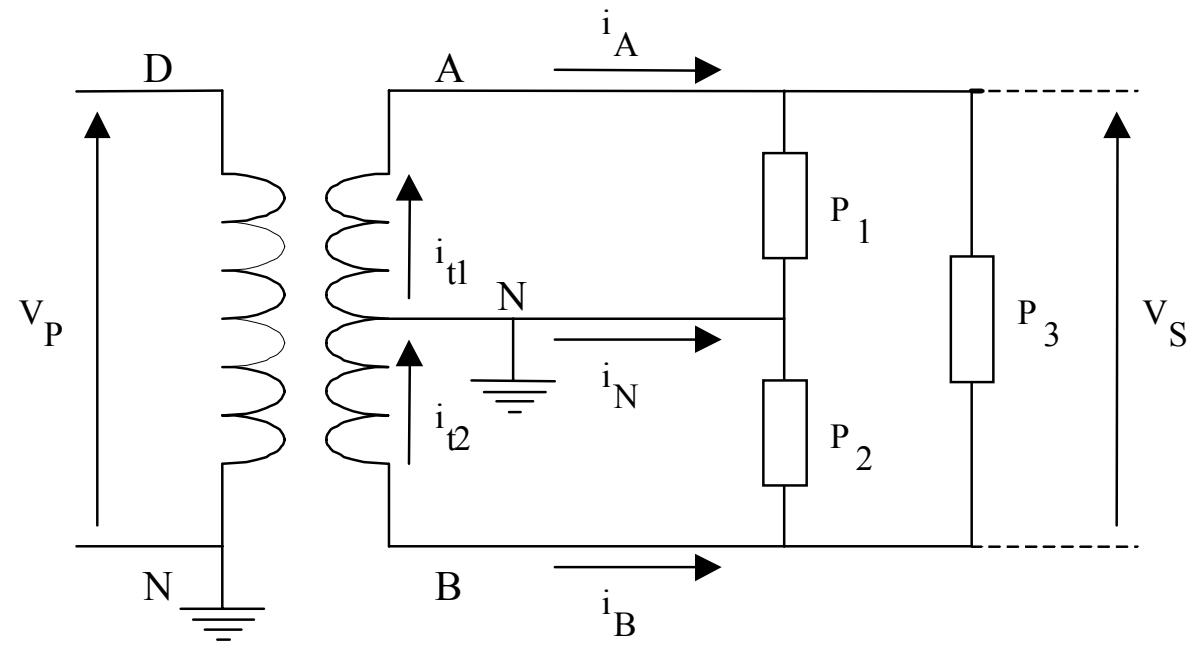

Figura 3.12 - ET com 1 transformador monofásico

\subsubsection{Transformadores Monofásicos na Ligação Delta Aberto}

Neste tipo de montagem, mostrada na figura 3.13, o transformador que alimenta as cargas monofásicas e trifásicas é denominado transformador de luz. $\mathrm{O}$ transformador que alimenta apenas cargas trifásicas é denominado transformador de força.

Para a ET com 2 transformadores monofásicos na ligação delta aberto, calcula-se a perda de demanda em cada instante do dia $p_{t, i}$ por

$$
p_{t, i}=S_{l u z} \cdot\left[\frac{r_{l u z}}{2} \cdot\left(i_{t 1, i}^{2}+i_{t 2, i}^{2}\right)+p_{F e, l u z}\right]+S_{f o r s a} \cdot\left[r_{f o r s a} \cdot i_{C B, i}^{2}+p_{F e, f o r \varsigma a}\right][\mathrm{kW}]
$$

onde:

$S_{l u z} \quad$ - é a potência nominal do transformador de luz [kVA];

$S_{\text {força }} \quad$ - é a potência nominal do transformador de força [kVA];

$r_{l u z} \quad$ - é a resistência ou perda no cobre à plena carga do transformador de luz [pu];

$r_{\text {força }} \quad$ - é a resistência ou perda no cobre à plena carga do transformador de força [pu];

$p_{F e, l u z} \quad$ - é perda nominal no ferro do transformador de luz [pu];

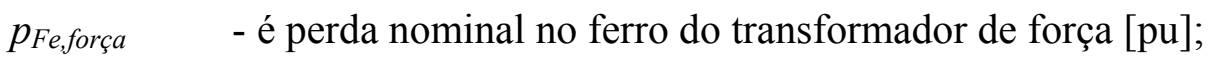


$i_{t 1, i}, i_{t 2, i}, i_{C B, i}$ - são as correntes nos enrolamentos secundários dos transformadores de luz e de força no instante $i[\mathrm{pu}]$.

Como as correntes $i_{A, i}, i_{B, i}, i_{C, i}$ e $i_{N, i}$ são resultados de cálculo a partir das correntes absorvidas pelos consumidores, as correntes $i_{t l, i}, i_{t 2, i}$ e $i_{C B, i}$ são facilmente calculadas utilizando-se a $1^{\text {a }}$ Lei de Kirchoff, ou seja:

$$
\begin{aligned}
& \dot{i}_{t 1, i}=\dot{i}_{A, i} \\
& \dot{i}_{t 2, i}=\dot{i}_{C B, i}-\dot{i}_{B, i} \\
& \dot{i}_{C B, i}=-\dot{i}_{C, t}
\end{aligned}
$$

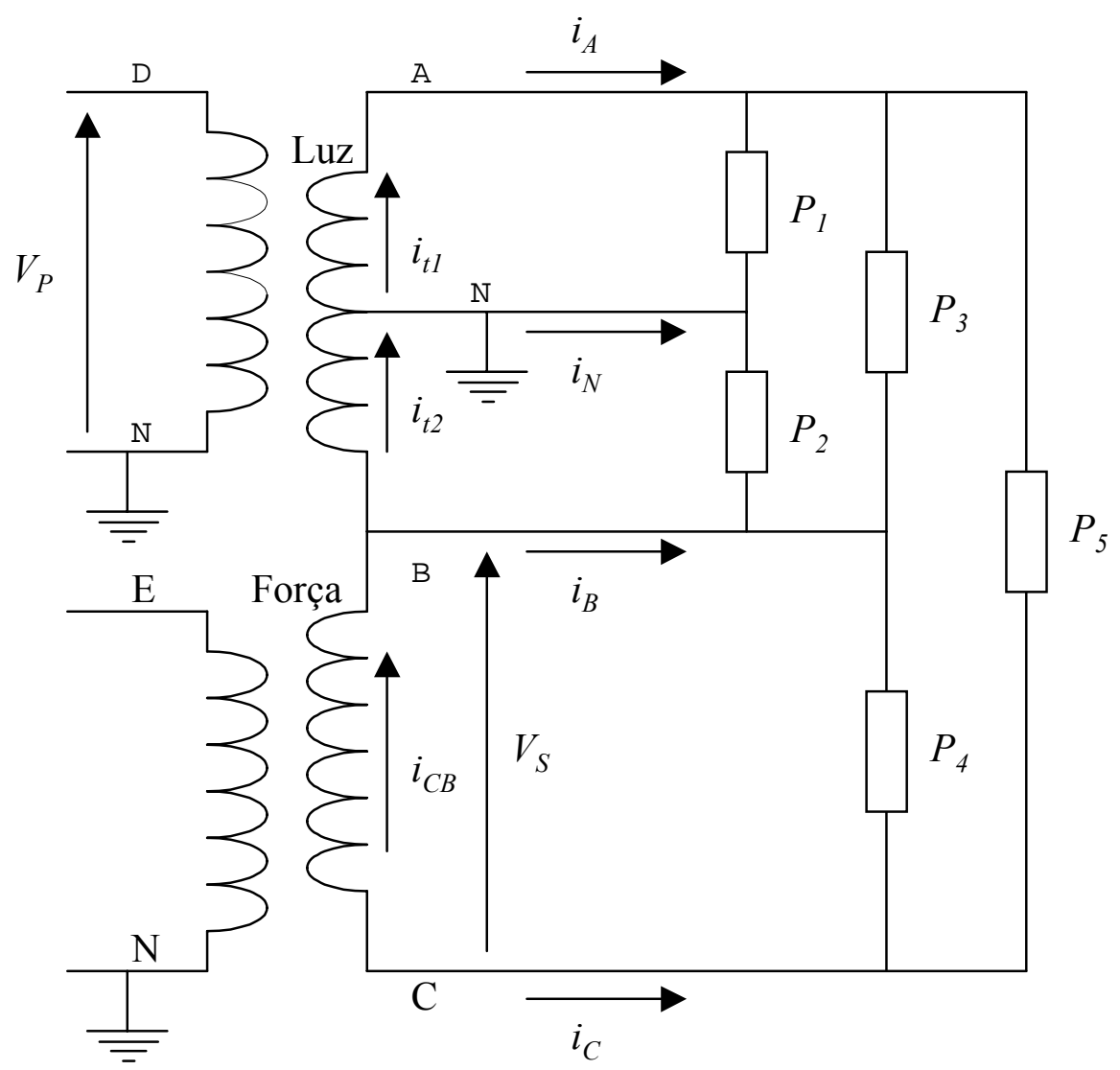

Figura 3.13 - ET com 2 transformadores monofásicos na ligação delta aberto 


\subsubsection{Transformadores Monofásicos na Ligação Delta Fechado}

A diferença entre este tipo de montagem, mostrada na figura 3.14, e a anterior é que na ligação delta fechado aparece mais um transformador de força. Os 2 transformadores de força presentes nesta montagem possuem a mesma capacidade nominal.

Para a ET com 3 transformadores monofásicos na ligação delta fechado, calcula-se a perda de demanda em cada instante do dia $p_{t, i}$ por

$$
p_{t, i}=S_{l u z} \cdot\left[\frac{r_{l u z}}{2} \cdot\left(i_{t 1, i}^{2}+i_{t 2, i}^{2}\right)+p_{F e, l u z}\right]+S_{f o r c a} \cdot\left[r_{f o r c a} \cdot\left(i_{C B, i}^{2}+i_{A C, i}^{2}\right)+p_{F e, f o r c a}\right][\mathrm{kW}]
$$

onde:

$S_{l u z} \quad$ - é a potência nominal do transformador de luz [kVA];

$S_{\text {força }} \quad$ - é a potência nominal dos transformadores de força [kVA];

$r_{l u z} \quad$ - é a resistência ou perda no cobre à plena carga do transformador de luz [pu];

$r_{\text {força }} \quad$ - é a resistência ou perda no cobre à plena carga dos transformadores de força $[\mathrm{pu}]$;

$p_{F e, l u z} \quad$ - é perda nominal no ferro do transformador de luz [pu];

$p_{F e, f o r c ̧ a} \quad$ é perda nominal no ferro dos transformadores de força [pu];

$i_{t 1, i}, i_{t 2, i}, i_{C B, i}$ - são as correntes nos enrolamentos secundários dos transformadores de luz e de força no instante $i[\mathrm{pu}]$.

Neste caso, o conhecimento das correntes de linha não possibilita o cálculo das correntes de fase utilizando-se a $1^{\text {a }}$ Lei de Kirchoff. Para contornar este problema, calcula-se primeiro a corrente $i_{A C}$ por

$$
\dot{i}_{A C}=z_{a} \cdot\left(\dot{i}_{B}-\dot{i}_{A}\right)+0,5 \cdot \dot{i}_{C}[\mathrm{pu}]
$$

onde $z_{a}=\frac{3}{8} \cdot\left(r_{l u z}+j x_{l u z}\right)[\mathrm{pu}]$, sendo $x_{l u z}$ a reatância do transformador de luz [pu]. Em seguida, as outras correntes podem ser facilmente calculadas utilizando-se a $1^{\text {a }}$ Lei de Kirchoff. 

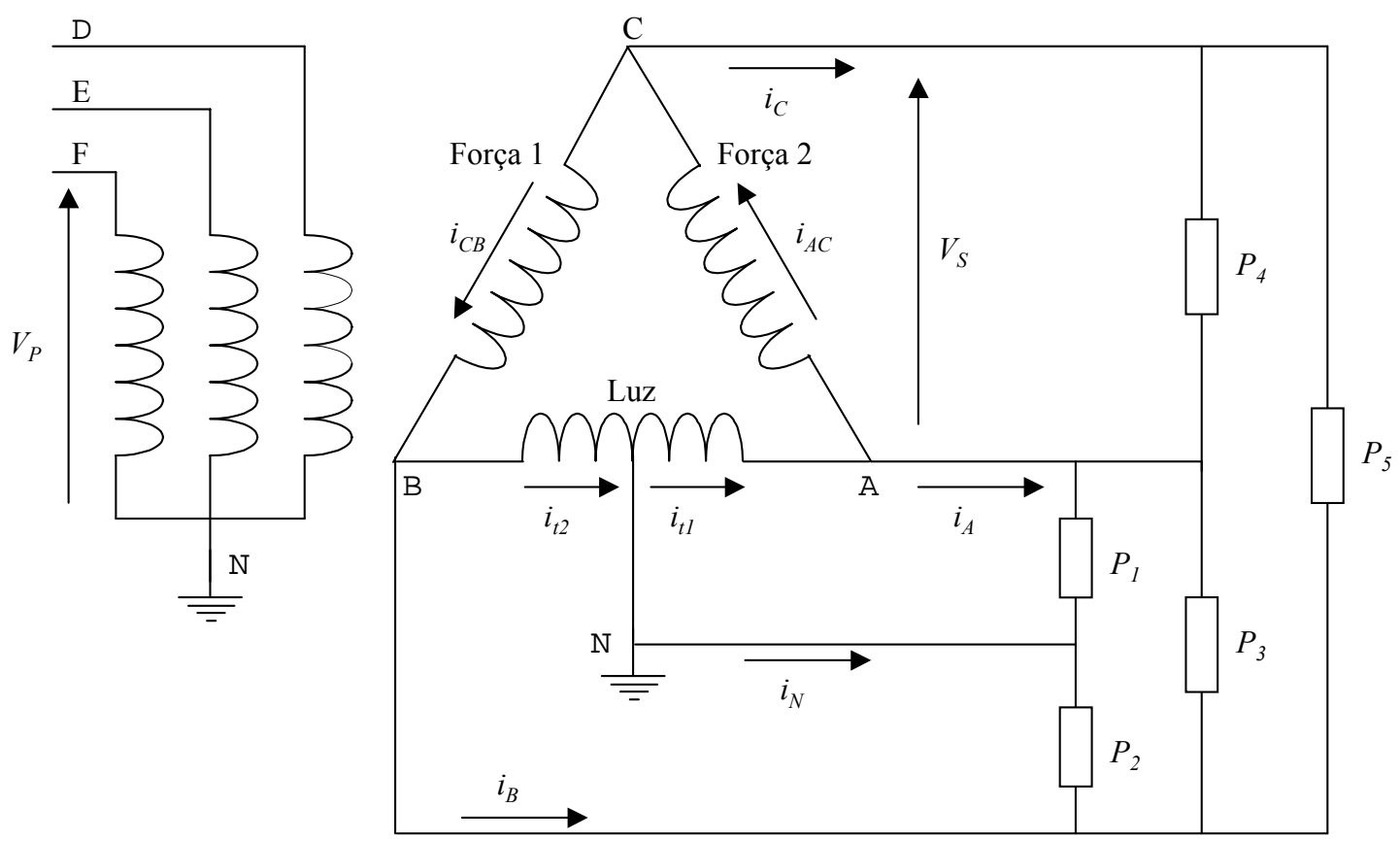

Figura 3.14 - ET com 3 transformadores monofásicos na ligação delta fechado

\subsubsection{Transformador Trifásico na Ligação Delta-Estrela}

Para a ET com 1 transformador trifásico na ligação delta-estrela (figura 3.15), calcula-se a perda de demanda em cada instante do dia $p_{t, i}$ por

$$
p_{t, i}=S \cdot\left[\frac{r}{3} \cdot\left(i_{A, i}^{2}+i_{B, i}^{2}+i_{C, i}^{2}\right)+p_{F e}\right][\mathrm{kW}]
$$

onde:

$S \quad$ - é a potência nominal do transformador [kVA];

$r \quad$ - é a resistência ou perda no cobre à plena carga do transformador [pu];

$p_{F e} \quad$ - é perda nominal no ferro do transformador [pu];

$i_{A, i}, i_{B, i}, i_{C, i}$ - são as correntes no enrolamento secundário do transformador no instante $i$ [pu].

As correntes $i_{A, i}, i_{B, i}, i_{C, i}$ e $i_{N, i}$ são resultados de cálculo a partir das correntes absorvidas pelos consumidores atendidos pelo circuito. 

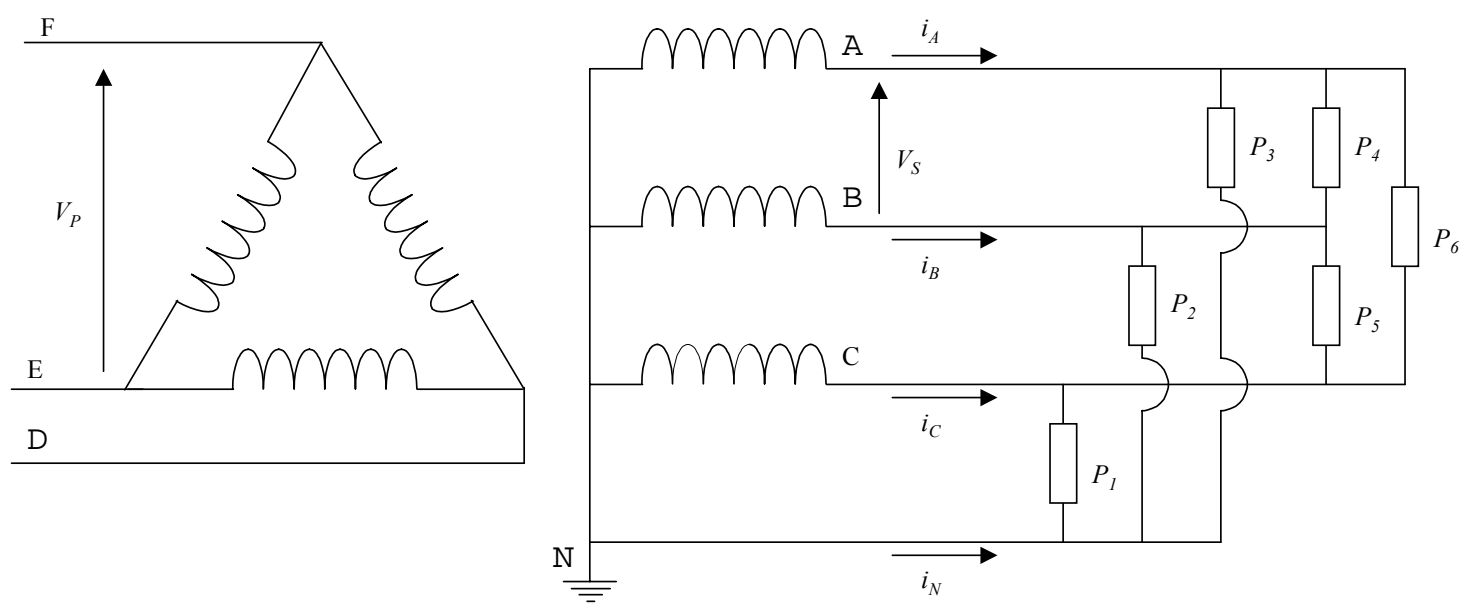

Figura 3.15 - ET com transformador trifásico na ligação delta-estrela

Para cada um dos tipos de montagem descritos acima, pode-se então avaliar a perda de demanda na ET correspondente para cada instante do dia. Finalmente, a perda de energia é calculada por

$$
e_{t}=\sum_{i=1}^{96} p_{t, i} \cdot \Delta t[\mathrm{kWh}]
$$

onde:

$p_{t, i} \quad$ - é a perda de demanda na ET no instante $i$ do dia [kW];

$\Delta t \quad$ - duração do intervalo da curva de carga diária [h].

Vale ressaltar que o tipo de abordagem adotada considera os desequilíbrios de correntes nas ET’s e, portanto, não há a necessidade de estimar um fator de desequilíbrio.

\subsubsection{Rede Primária}

\subsubsection{Considerações Gerais}

A metodologia proposta para o cálculo das perdas na rede primária é análoga àquela apresentada para a rede secundária. Ou seja, parte-se do princípio de que a rede é radial, 
e representa-se a rede trecho a trecho, por meio dos condutores de fase e de neutro (fases $\mathrm{A}, \mathrm{B}, \mathrm{C}$ e neutro $\mathrm{N}$ ). $\mathrm{O}$ cálculo elétrico é feito por meio de fluxo de potência trifásico, com a utilização da metodologia de curvas de carga, com o estabelecimento das correntes em intervalos de 15 minutos.

Para a atribuição da carga às fases da rede primária, são necessários os dados de carregamento dos transformadores de distribuição, dos consumidores primários e da carga de iluminação pública. Para o cálculo do fluxo de potência, é necessário ainda se dispor dos dados de bancos de capacitores, ou seja, ponto de conexão à rede, potência nominal e período de utilização ao longo do dia.

\subsubsection{Transformadores de Distribuição}

A curva de carga diária dos transformadores de distribuição é obtida pela agregação das curvas de carga diárias dos consumidores secundários e é resultado direto do cálculo da rede secundária.

Desta forma, dispondo-se da curva de carga no lado de baixa tensão de cada ET, devese refletir seus valores convenientemente para o lado de média tensão. Para isto, é necessário conhecer:

- o tipo de montagem da ET: monofásica, trifásica na ligação delta-estrela aterrada, banco em delta aberto ou delta fechado;

- as tensões nominais nos lados de média e baixa tensão;

- as fases de ligação nos lados de média e baixa tensão para cada unidade transformadora da ET, caso a ET seja monofásica ou delta.

Olhando para as figuras 3.12 a 3.15, pode-se notar que, uma vez conhecidas as correntes nos enrolamentos secundários dos transformadores, elas podem ser facilmente refletidas para os enrolamentos primários.

A título de exemplo, a figura 3.16 ilustra o procedimento para a obtenção das correntes no lado de média tensão de uma ET trifásica na ligação delta-estrela. 


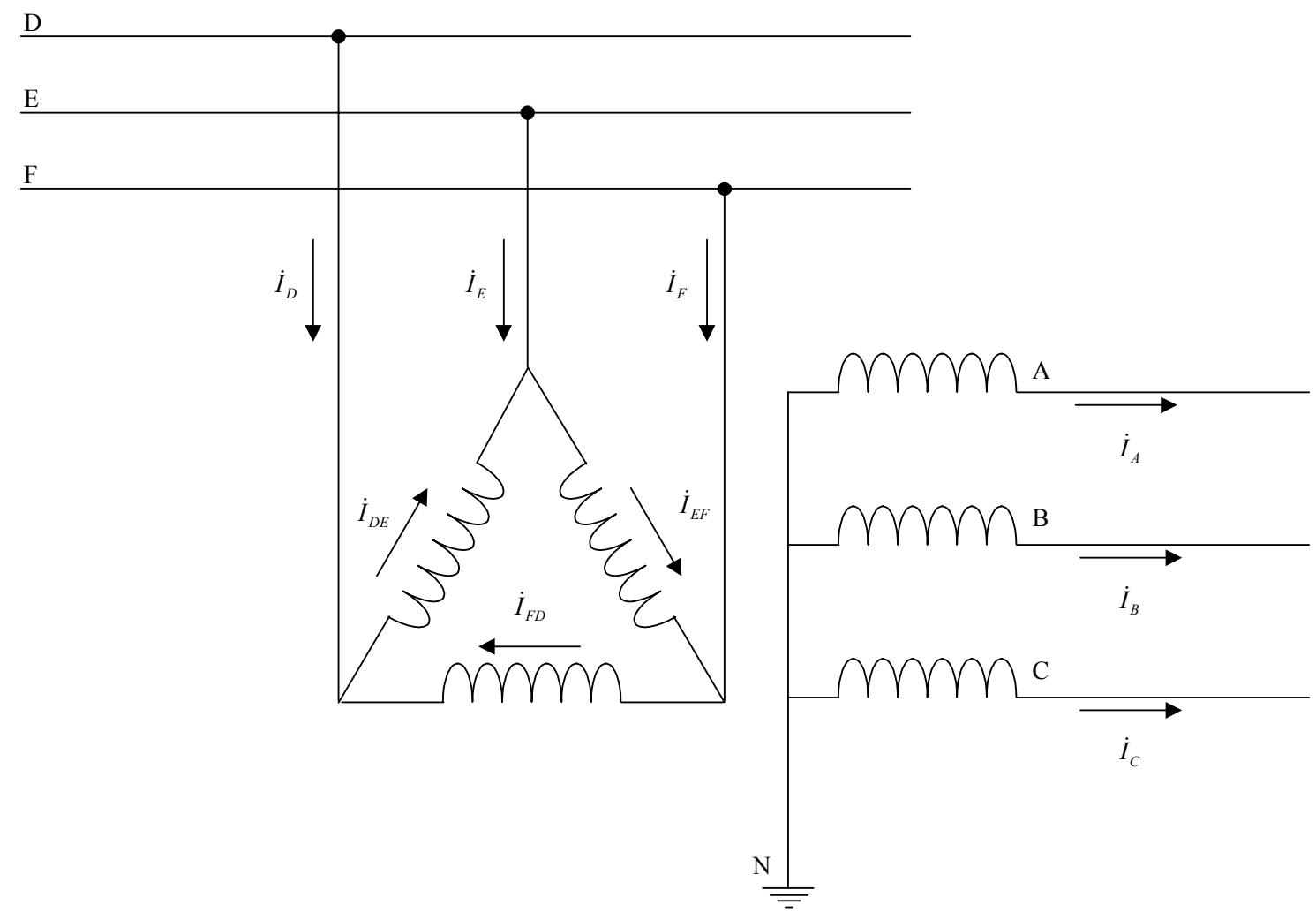

Figura 3.16 - Correntes nos lados de baixa e média tensão

Para um determinado instante de tempo $t$, sejam os seguintes valores de correntes obtidos pela agregação das curvas de carga dos consumidores de baixa tensão supridos pela ET, para as fases A, B e C, respectivamente:

- fase A: $I_{A}$, fase $-\varphi_{A}$;

- fase B: $I_{B}$, fase $-\varphi_{B}$;

- fase $C: I_{C}$, fase $-\varphi_{C}$.

Resultam, para as correntes do lado de baixa tensão, os valores:

$$
\begin{gathered}
\dot{I}_{A}=I_{A} \mid \underline{-\varphi_{\mathrm{A}}} \\
\dot{I}_{B}=I_{B} \mid \underline{-120-\varphi_{\mathrm{B}}} \\
\dot{I}_{C}=I_{C} \mid 120-\varphi_{\mathrm{C}}
\end{gathered}
$$


Para a obtenção destes valores de corrente, sendo as tensões nominais no primário e secundário iguais a $V_{N 1}$ e $V_{N 2}$, respectivamente, foram assumidos os seguintes valores de tensões no lado de baixa tensão do transformador:

$$
\begin{gathered}
\dot{V}_{A N}=\frac{V_{N 2}}{\sqrt{3}} \mid \underline{0^{\circ}} \\
\dot{V}_{B N}=\frac{V_{N 2}}{\sqrt{3}} \mid \underline{-120^{\circ}} \\
\dot{V}_{C N}=\frac{V_{N 2}}{\sqrt{3}} \mid \underline{120^{\circ}}
\end{gathered}
$$

Considerando-se o transformador ideal, resultam os seguintes valores de fase no lado de média tensão da ET:

$$
\begin{aligned}
& \dot{I}_{D E}=\dot{I}_{A}\left(\frac{V_{N 2} / \sqrt{3}}{V_{N 1}}\right) \\
& \dot{I}_{E F}=\dot{I}_{B}\left(\frac{V_{N 2} / \sqrt{3}}{V_{N 1}}\right) \\
& \dot{I}_{F D}=\dot{I}_{C}\left(\frac{V_{N 2} / \sqrt{3}}{V_{N 1}}\right)
\end{aligned}
$$

Finalmente, os valores de linha no lado de média tensão são obtidos por:

$$
\begin{aligned}
& \dot{I}_{D}=\dot{I}_{D E}-\dot{I}_{F D} \\
& \dot{I}_{E}=\dot{I}_{E F}-\dot{I}_{D E} \\
& \dot{I}_{F}=\dot{I}_{F D}-\dot{I}_{E F}
\end{aligned}
$$

\subsubsection{Transformador Exclusivo de Iluminação Pública}

A curva de carga nos transformadores exclusivos de IP é obtida da mesma forma que nos transformadores de distribuição. A diferença é que a carga de IP é representada por 
uma carga de valor constante nas fases e nos períodos indicados, conforme já foi explicado no item 3.3.1.3.

\subsubsection{Consumidor Primário}

A determinação das curvas de carga em $\mathrm{kW}$ dos consumidores primários é feita de forma análoga aos consumidores secundários e já foi explicado em 3.3.1.2.

\subsubsection{Banco de Capacitor}

Para determinar a curva de carga num banco de capacitor, basta conhecer a sua capacidade nominal e o seu tipo de controle, que pode ser do tipo fixo (ligado 24 horas por dia) ou do tipo chaveado (ligado, por exemplo, das 18 horas às 21 horas).

Em seguida, para calcular a corrente drenada por um banco de capacitor em cada instante do dia, adota-se a tensão nominal do circuito. Admite-se que a corrente absorvida pelo banco é trifásica e equilibrada.

Assim como na rede secundária, o tipo de abordagem adotada no cálculo da rede primária considera os desequilíbrios de correntes, não havendo necessidade de estimar um fator de desequilíbrio.

\subsubsection{Subestação de Distribuição}

Ao término do cálculo elétrico da rede primária, dispor-se-á da curva de carga diária (em termos de corrente por fase) do alimentador. A composição das curvas de carga de todos os alimentadores resulta na curva de carga dos transformadores da subestação.

Conhecendo-se o transformador em que cada circuito de uma SE está ligado, determinase a curva de carga em termos de corrente (por fase) para cada transformador. Em seguida, calcula-se a potência aparente por fase de cada transformador, uma vez que é 
conhecida a tensão nominal. Assim, obtém-se a curva de potência total trifásica passante em cada transformador da SE.

Para cada transformador, conhecendo-se a sua potência nominal, a perda nominal no ferro e a perda nominal no cobre à plena carga, calcula-se a perda de demanda em cada instante do dia de um transformador de $\mathrm{SE} p_{T, i}$ por

$$
p_{T, i}=p_{F e}+p_{C u, p c} \cdot\left(\frac{S_{i}}{S}\right)^{2}[\mathrm{~kW}]
$$

onde:

$S \quad$ - é a potência nominal do transformador [MVA];

$S_{i} \quad$ - é a potência aparente trifásica no instante $i$ [MVA];

$p_{F e} \quad$ é a perda nominal no ferro do transformador $[\mathrm{kW}]$;

$p_{C u, p c} \quad$ - é a perda nominal à plena carga no cobre do transformador [kW]

e a perda de energia é calculada por

$$
e_{T}=\Delta t \cdot \sum_{i=1}^{96} p_{T, i}[\mathrm{kWh}]
$$

onde $\Delta t$ é a duração do intervalo da curva de carga [h].

Finalmente, para saber o total de perda de energia na subestação, basta somar as perdas de energia de seus respectivos transformadores.

\subsubsection{Sistema de Alta Tensão}

A seguir serão apresentados 3 procedimentos diferentes para calcular as perdas no sistema de alta tensão. A utilização de um ou outro procedimento depende da disponibilidade de dados de cada concessionária. 


\subsubsection{Cálculo das Perdas por Medição}

Um dos procedimentos para determinar a perda de energia no sistema de alta tensão é por meio de medições nos pontos de fronteira e nas entradas das subestações de distribuição, uma vez que a quantidade de redes de alta tensão é pequena se comparada com os outros segmentos. Dessa forma, a perda de energia no sistema de alta tensão é calculada por:

$$
\varepsilon_{p}=\varepsilon_{c}+\varepsilon_{g}-\varepsilon_{v}-\varepsilon_{S E}
$$

onde:

$\varepsilon_{c} \quad$ é o valor das compras de energia de outras empresas;

$\varepsilon_{g}$ - é a geração própria, descontando-se o consumo interno das unidades geradoras;

$\varepsilon_{v}$ - é o valor das vendas de energia a outras empresas e aos consumidores atendidos em alta tensão;

$\varepsilon_{S E}$ - é a quantidade de energia medida na entrada de todas as subestações de distribuição do sistema.

\subsubsection{Cálculo das Perdas por Fluxo de Potência}

Em não se dispondo das medições necessárias para aplicar a expressão (3.21), as perdas poderiam ser calculadas a partir de um programa de fluxo de potência, de forma análoga ao cálculo das redes secundárias e primárias, utilizando-se a curva de carga calculada de cada subestação de distribuição e os dados da rede de alta tensão.

Entretanto, se a concessionária não possuir uma base de dados onde são armazenados os dados das redes de alta tensão, a perda de energia na rede de alta tensão deve ser calculada por meio de um balanço de energia a partir do nível percentual de perda de energia a ser determinado por um cálculo de fluxo de potência utilizando-se os dados de planejamento. Para este tipo de cálculo é importante que os dados de planejamento da rede de alta tensão sejam os mesmos que os dados operativos da rede.

A perda de energia percentual apresenta pequenas variações ao longo do tempo e, 
portanto, pode ser utilizada como referência para calcular a perda de energia em MWh em função da energia que entra no segmento, que pode apresentar grandes variações conforme o período considerado.

Neste caso, o cálculo de fluxo de potência deve ser feito periodicamente para atualizar o nível percentual de perda de energia no sistema de alta tensão.

\subsubsection{Cálculo das Perdas com Estimador de Estado}

Uma terceira opção para calcular as perdas no sistema de alta tensão consiste em utilizar os dados provenientes de medições combinados com um estimador de estado.

A Estimação de Estado [22] é o processo de atribuir um valor a uma variável de estado desconhecida de acordo com alguns critérios e baseado em medições do sistema. Geralmente, o processo envolve dados de medições, que são redundantes e que podem apresentar erros. O processo de estimar os estados do sistema é baseado em critérios estatísticos que estimam o valor verdadeiro das variáveis de estado para maximizar ou minimizar os critérios selecionados.

Um exemplo clássico de aplicação do processo de estimação de estado diz respeito a um sistema de potência, onde as variáveis de estado são os módulos e as fases das tensões em cada barra do sistema. O estimador é desenvolvido para produzir a "melhor estimativa" dos módulos e fases das tensões levando-se em consideração que existem erros nas medições e que elas podem ser redundantes.

Utilizando o exemplo de fluxo de potência DC no sistema da figura 3.17, a partir de seu equacionamento, pode-se verificar que são necessárias medições de potência ativa em apenas 2 das 3 linhas que compõem o sistema para determinar as fases das tensões em cada barra. A medição na terceira linha é redundante. Porém, como as medições contêm erros, deve-se utilizar as medições nas 3 linhas para obter a melhor estimativa das fases das tensões em cada barra e do fluxo de potência ativa em cada linha. 


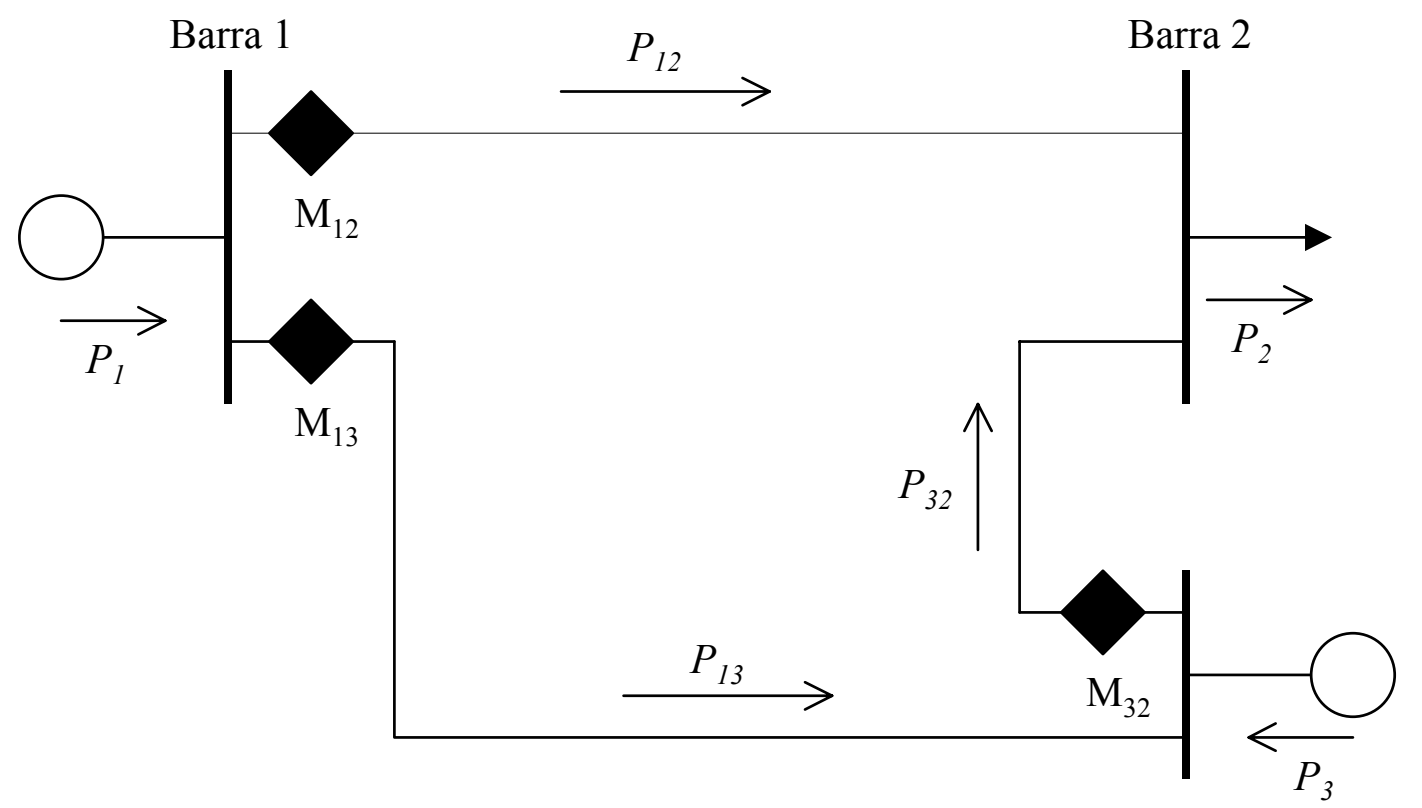

Barra 3

Figura 3.17 - Estimador de estado em um sistema de potência

O desenvolvimento das técnicas de estimação de estado teve duas grandes motivações.

O primeiro motivo diz respeito aos transdutores para medições em sistemas de potência, equipamentos que estão sujeitos a erros. Se os erros são pequenos, eles podem passar despercebidos e provocar má interpretação por parte do operador que está lendo os valores medidos para tomar decisões. Por outro lado, se os erros são grandes, os valores medidos tornam-se inúteis.

O segundo motivo diz respeito aos equipamentos de comunicação utilizados para transmitir os dados das medições. Tais equipamentos podem passar por períodos com problemas nas comunicações e privar o operador do sistema de informações de parte da rede.

O estimador de estado desenvolvido pode, então, diminuir os pequenos erros de medição, identificar os grandes erros e preencher os dados de medições ausentes devido às falhas de comunicação.

Para utilizar o estimador de estado na determinação das perdas de energia no sistema de alta tensão, seria necessário que as medições fornecessem os dados de correntes em cada instante do dia. Uma vez conhecidas as correntes medidas e as resistências das linhas, pode-se desenvolver um estimador de estado que considere as medições e seus possíveis erros para se obter uma melhor estimativa das correntes em cada linha. 


\subsection{Metodologia para Balanço de Energia no Sistema de Distribuição}

O balanço de energia no sistema de distribuição tem dois principais objetivos:

- estimar as perdas técnicas por segmento a partir do cálculo detalhado de uma parcela representativa do sistema;

- estimar as perdas não técnicas.

\subsubsection{Estimativa das Perdas Técnicas por Segmento}

Para se efetuar o balanço de energia no sistema de distribuição, foram consideradas as seguintes parcelas de perdas técnicas:

- perdas nos medidores de energia dos consumidores de baixa tensão;

- perdas nos ramais de ligação dos consumidores de baixa tensão;

- perdas nos condutores das redes secundárias;

- perdas nos transformadores de distribuição;

- perdas nos condutores das redes primárias;

- perdas nos transformadores das subestações de distribuição;

- perdas nas linhas do sistema de alta tensão;

- perdas em outros segmentos do sistema.

O índice de perdas de um determinado segmento do sistema é definido pela expressão (3.22) onde as letras minúsculas foram utilizadas para se referir a grandezas em \% e as letras maiúsculas para grandezas em MWh.

$$
e_{p}=\frac{E_{p}}{E_{\text {montante }}} \cdot 100=\frac{E_{p}}{E_{\text {jusante }}+E_{p}} \cdot 100[\%]
$$

ou 


$$
E_{p}=\frac{0,01 \cdot e_{p} \cdot E_{\text {jusante }}}{1-0,01 \cdot e_{p}}[\mathrm{MWh}]
$$

onde:

$E_{p} \quad$ - é a energia de perdas do segmento [MWh];

$E_{\text {montante }}$ - é a energia a montante do segmento (energia que entra no segmento) [MWh];

$E_{\text {jusante }}$ - é a energia a jusante do segmento (energia que sai do segmento) [MWh];

$e_{p} \quad$ - é a perda de energia do segmento [\%].

A figura 3.18 apresenta uma ilustração do fluxo de energia num sistema de distribuição considerando os vários segmentos tratados neste trabalho. Nesta figura, apresentam-se os valores correspondentes às parcelas de $E_{p}, E_{\text {jusante }}$ e $E_{\text {montante }}$ de cada segmento, e que serão utilizadas nas expressões subseqüentes.

Desta forma, conhecendo-se o índice de perdas dos diversos segmentos do sistema, os valores de energia adquiridos pela empresa (energia nos pontos de fronteira) e a energia vendida aos consumidores (energia faturada) por nível de tensão, obtém-se uma boa estimativa do fluxo de energia, conforme ilustrado na figura 3.18.

A partir dos índices de perdas, calculam-se as perdas de energia e as energias a montante de cada segmento como a seguir:

a) perdas em medidor de energia: o índice $e_{p, m e d}$ é obtido pela expressão (3.22) para todos os medidores de energia cujo cálculo de perdas já foi efetuado.

$$
\begin{aligned}
& E_{p, \text { med }}=\frac{0,01 \cdot e_{p, \text { med }} \cdot E_{c o n, \mathrm{sec}}}{1-0,01 \cdot e_{p, \text { med }}} \\
& E_{\text {med }}=E_{p, \text { med }}+E_{c o n, \mathrm{sec}}
\end{aligned}
$$




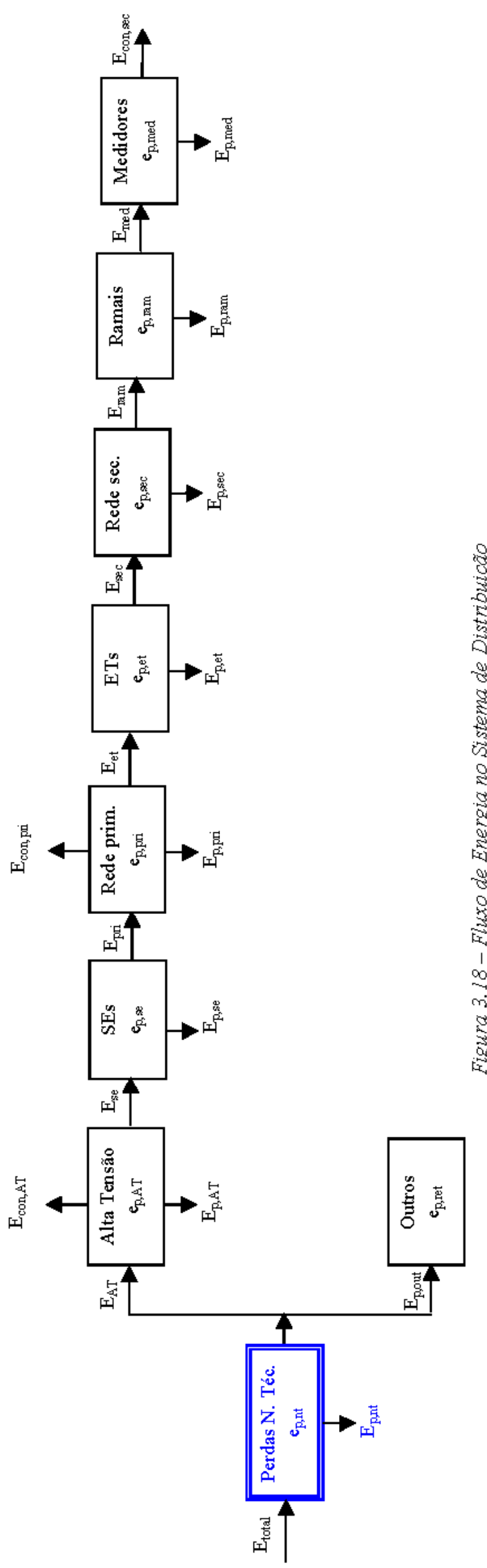


b) perdas em ramal de ligação: o índice $e_{p \text {,ram }}$ é obtido pela expressão (3.22) para todos os ramais de ligação cujo cálculo de perdas já foi efetuado.

$$
\begin{aligned}
& E_{p, \text { ram }}=\frac{0,01 \cdot e_{p, r a m} \cdot E_{\text {med }}}{1-0,01 \cdot e_{p, r a m}} \\
& E_{\text {ram }}=E_{p, r a m}+E_{\text {med }}
\end{aligned}
$$

c) perdas em rede secundária: o índice $e_{p, s e c}$ é obtido pela expressão (3.22) para todas as redes secundárias cujo cálculo de perdas já foi efetuado.

$$
\begin{aligned}
& E_{p, \mathrm{sec}}=\frac{0,01 \cdot e_{p, \mathrm{sec}} \cdot E_{\mathrm{ram}}}{1-0,01 \cdot e_{p, \mathrm{sec}}} \\
& E_{\mathrm{sec}}=E_{p, \mathrm{sec}}+E_{\mathrm{ram}}
\end{aligned}
$$

d) perdas em transformador de distribuição: o índice $e_{p, e t}$ é obtido pela expressão (3.22) para todos os transformadores de distribuição cujo cálculo de perdas já foi efetuado.

$$
\begin{aligned}
& E_{p, e t}=\frac{0,01 \cdot e_{p, e t} \cdot E_{\mathrm{sec}}}{1-0,01 \cdot e_{p, e t}} \\
& E_{e t}=E_{p, e t}+E_{\mathrm{sec}}
\end{aligned}
$$

e) perdas em rede primária: o índice $e_{p, p r i}$ é obtido pela expressão (3.22) para todos os circuitos primários cujo cálculo de perdas já foi efetuado.

$$
\begin{aligned}
& E_{p, p r i}=\frac{0,01 \cdot e_{p, p r i} \cdot\left(E_{e t}+E_{c o n, p r i}\right)}{1-0,01 \cdot e_{p, p r i}} \\
& E_{p r i}=E_{p, p r i}+E_{e t}+E_{c o n, p r i}
\end{aligned}
$$


f) perdas em subestação de distribuição: o índice $e_{p, s e}$ é obtido pela expressão (3.22) para todas as subestações de distribuição cujo cálculo de perdas já foi efetuado.

$$
\begin{aligned}
& E_{p, s e}=\frac{0,01 \cdot e_{p, s e} \cdot E_{p r i}}{1-0,01 \cdot e_{p, s e}} \\
& E_{s e}=E_{p, s e}+E_{p r i}
\end{aligned}
$$

g) perdas em sistema de alta tensão: o índice $e_{p, s u b}$ é obtido pela expressão (3.22), conforme foi explicado em 3.3.8.

$$
\begin{aligned}
& E_{p, A T}=\frac{0,01 \cdot e_{p, A T} \cdot\left(E_{s e}+E_{c o n, A T}\right)}{1-0,01 \cdot e_{p, A T}} \\
& E_{A T}=E_{p, A T}+E_{s e}+E_{c o n, A T}
\end{aligned}
$$

h) perdas em outros segmentos do sistema: o índice $e_{p, o u t}$ foi especificado, a partir das referências bibliográficas consultadas [1-6], em $10 \%$ do total das perdas nos outros segmentos, ou seja:

$$
E_{p, \text { out }}=e_{p, \text { out }} \cdot\left(E_{p, \text { med }}+E_{p, \text { ram }}+E_{p, \text { sec }}+E_{p, e t}+E_{p, p r i}+E_{p, s e}+E_{p, A T}\right)
$$

\subsubsection{Estimativa das Perdas Não Técnicas}

A partir dos valores obtidos para as perdas técnicas nos diversos segmentos do sistema de distribuição, conforme equações (3.24) a (3.31), obtém-se a equação de balanço de energia:

$$
E_{\text {total }}=E_{c o n}+E_{p, t}+E_{p, n t}
$$

onde: 
$E_{\text {total }}$ - é a energia total adquirida pelo sistema, ou seja, a energia nos pontos de fronteira da empresa;

$E_{c o n}$ - energia total faturada, obtida pela soma dos consumidores secundários, primários e de alta tensão, respectivamente, $E_{c o n, s e c}, E_{c o n, p r i}$ e $E_{c o n, A T}$;

$E_{p, t} \quad$ - é o total de perdas técnicas de energia em todo o sistema de distribuição, obtida pela soma das parcelas de perdas técnicas em cada segmento;

$E_{p, n t} \quad$ - é o total de perdas não técnicas de energia em todo o sistema de distribuição.

As equações (3.32) e (3.33) permitem obter o valor das perdas não técnicas $E_{p, n t}$ e seu índice percentual $e_{p, n t}$.

$$
e_{p, n t}=\frac{E_{p, n t}}{E_{\text {total }}} \cdot 100
$$

O índice $e_{p, n t}$ também pode ser calculado por (vide figura 3.18):

$$
e_{p, n t}=\frac{E_{p, n t}}{E_{A T}+E_{\text {out }}} \cdot 100
$$




\subsection{Conclusões}

Neste capítulo foi proposta uma nova metodologia para realizar o cálculo das perdas técnicas de energia num sistema de distribuição utilizando curvas de carga típicas dos consumidores.

$\mathrm{Na}$ metodologia apresentada neste capítulo, as perdas são calculadas de forma detalhada, através de cálculo elétrico específico para cada componente de um determinado segmento do sistema, eliminando as simplificações existentes nos modelos encontrados na bibliografia pesquisada.

Entre as vantagens dessa metodologia está o fato de não se depender de uma série de aproximações como, por exemplo, uma estimativa do fator de perdas a partir do fator de carga, que pode influir de forma significativa nos resultados do cálculo. O cálculo das perdas de energia é efetuado diretamente a partir da curva de carga.

Outro ponto favorável à metodologia apresentada é a representação por fase de cada trecho da rede e a representação por fase dos transformadores. Os desequilíbrios de correntes são considerados ao realizar o cálculo por fase e, portanto, não há a necessidade de estimar um fator de desequilíbrio, o que torna os resultados dos cálculos mais precisos.

No capítulo seguinte será apresentado o sistema computacional que foi desenvolvido para utilizar a metodologia proposta. 


\section{CAPÍTULO 4}

\section{SISTEMA COMPUTACIONAL DESENVOLVIDO PARA APLICAÇÃO DA METODOLOGIA}

\subsection{Introdução}

O capítulo anterior apresentou uma proposição de metodologia para calcular as perdas técnicas de energia por segmento do sistema de distribuição.

Como a metodologia proposta realiza um cálculo detalhado em cada componente de cada segmento do sistema de distribuição, foi desenvolvido um sistema computacional para tornar viável a aplicação da metodologia.

Este sistema computacional é composto por dois módulos.

O primeiro, denominado PERTEC - Cálculo de Perdas Técnicas por Segmento -, realiza o cálculo detalhado das perdas técnicas em cada componente do sistema de distribuição. É no PERTEC que está implementada a metodologia proposta no capítulo 3 para cálculo de perdas técnicas.

O Módulo PERTEC é uma ferramenta que possibilita a quantificação das perdas técnicas de energia e de demanda por segmento do sistema de distribuição. Tal quantificação permite identificar as áreas e/ou componentes que apresentam maior contribuição e, consequentemente, priorizar ações para sua redução.

Neste módulo são calculadas as perdas técnicas nos seguintes segmentos: medidor de energia, ramal de ligação, rede secundária, transformador de distribuição (ET), rede primária e subestação de distribuição (SE).

O segundo módulo, denominado Módulo de Balanço de Energia, permite calcular as perdas técnicas de energia em cada segmento a partir das perdas percentuais calculadas pelo PERTEC e permite avaliar as perdas não técnicas globais do sistema, conforme a metodologia proposta no capítulo 3 para realização de balanço de energia no sistema de distribuição. Por esse módulo, é possível fazer o balanço de energia da concessionária e 
obter o fluxo de energia através do sistema de distribuição e também uma visão geral das perdas técnicas em cada segmento.

Este capítulo apresenta o sistema computacional desenvolvido e as ferramentas que ele disponibiliza para a apresentação dos resultados calculados. 


\subsection{Estrutura Geral do Sistema Computacional}

A figura 4.1 apresenta a estrutura geral do sistema computacional que foi desenvolvido.

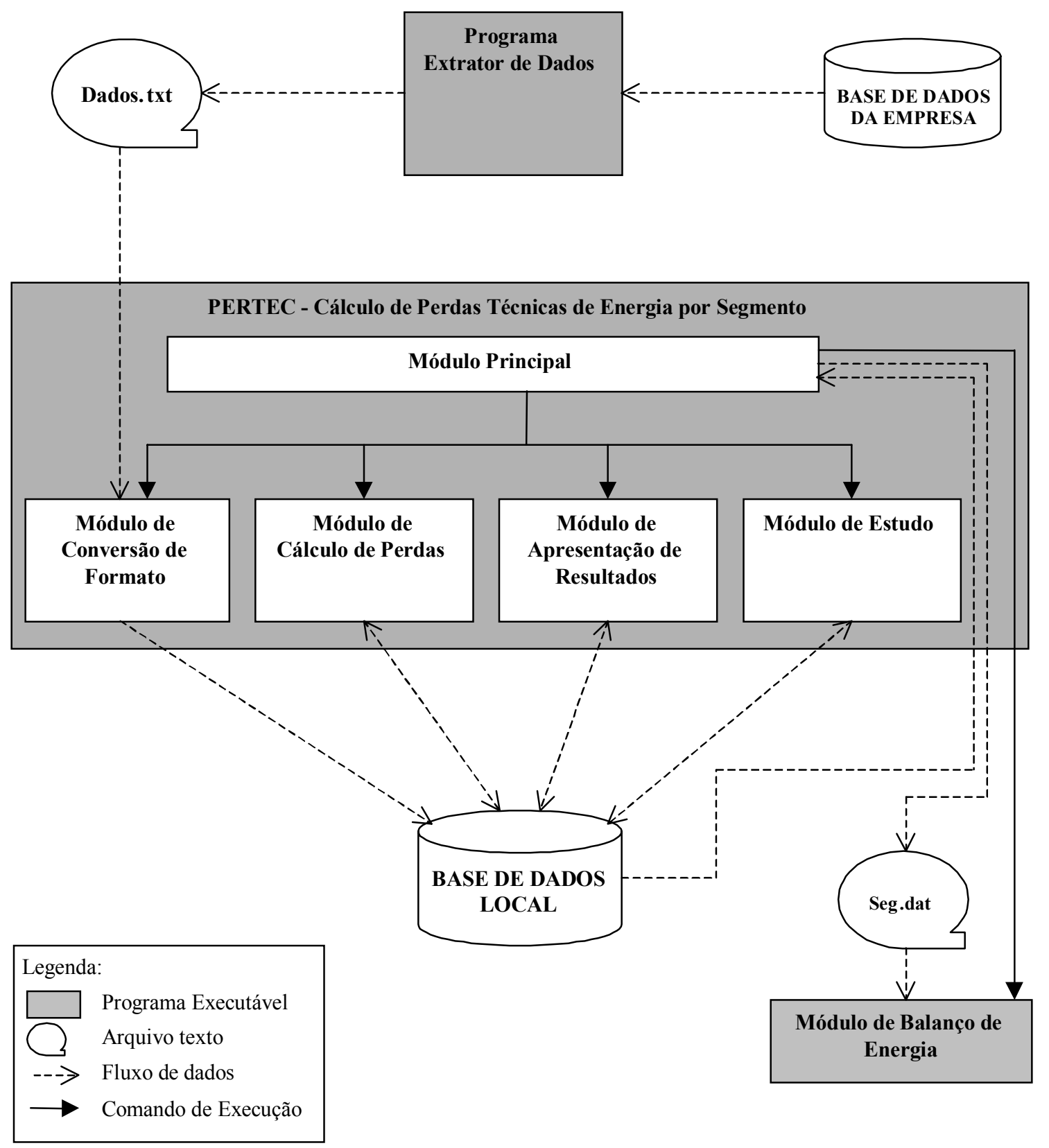

Figura 4.1. Estrutura geral do sistema computacional

Pela figura 4.1, fica claro que o Módulo PERTEC interage com uma Base de Dados Local e possui 5 módulos internos. Essa figura é muito importante para a compreensão do sistema. 
O Programa Extrator de Dados adquire as informações necessárias da Base de Dados da Empresa e grava um arquivo texto contendo o conjunto de informações que compõem um circuito primário: dados gerais do circuito, trechos de rede primária, todos os transformadores de distribuição (ET's) supridos pelo circuito, todas as redes secundárias (trecho a trecho) supridas pelos transformadores de distribuição (ET's) e todos os consumidores supridos pelo respectivo circuito.

A partir do arquivo texto gerado pelo Programa Extrator, o Módulo de Conversão de Formato monta uma base de dados local da qual os dados da rede são lidos pelo Módulo de Cálculo de Perdas.

Os resultados do cálculo são gravados na base de dados e podem ser acessados pelo Módulo de Apresentação de Resultados e pelo Módulo de Estudo.

O Módulo de Apresentação de Resultados, como o próprio nome diz, é responsável por consultar os resultados na base de dados e elaborar diversos tipos de relatórios. Já o Módulo de Estudo auxilia o usuário a "simular" a execução de algumas ações na rede visando a diminuição das perdas.

A Base de Dados Local armazena 3 tipos de dados:

- dados da rede;

- dados dos resultados do cálculo;

- dados de cabos, circuitos, subestações e transformadores de subestações.

O terceiro item corresponde a um cadastro que contém os dados dos cabos utilizados nas redes secundária e primária, os dados das subestações com seus respectivos transformadores e os circuitos que se derivam de cada um deles.

Tal cadastro contém um conjunto de informações necessárias ao cálculo de perdas nas SE's e nas redes primária e secundária.

Para cada SE, sabe-se quais são os transformadores que nela estão instalados e quais são os circuitos que dela se derivam e em qual transformador eles estão ligados. São informações importantes para compor a curva de carga correta em cada transformador da SE.

Para cada trecho de rede primária ou secundária sabe-se o código do cabo utilizado. Pelo cadastro de cabos obtém-se a resistência por unidade de comprimento de cada cabo. Como o Módulo de Cálculo de Perdas utiliza diretamente os valores de resistência 
fornecidos pelo cadastro de cabos, esses valores são os de resistência em corrente alternada para as temperaturas normais de operação.

O Módulo Principal comanda a execução dos módulos internos do PERTEC e também acessa a base de dados de forma a determinar as perdas percentuais de energia de cada segmento. Os resultados são armazenados em um arquivo texto, que é lido pelo Módulo de Balanço de Energia. O PERTEC ainda pode disparar um comando para executar o Módulo de Balanço de Energia.

As perdas de energia calculadas pelo PERTEC referem-se ao período de 1 mês. Consequentemente, as perdas percentuais determinadas por ele também estão em base mensal. Assim, o cálculo pode ser executado mês a mês de forma a se obter as perdas percentuais por segmento em cada mês do ano, o que permite verificar como as perdas evoluem ao longo do ano.

O sistema computacional será explicado mais detalhadamente nos itens seguintes deste capítulo.

\subsection{Apresentação do Módulo PERTEC}

A figura 4.2 apresenta a tela principal do PERTEC.

A tela principal permite o acesso a todos os módulos internos ao PERTEC (figura 4.1).

O usuário pode especificar o valor da perda de demanda por elemento medidor de energia e definir as resistências e os comprimentos médios do ramal típico de ligação do consumidor para cada classe de consumo.

Pode-se definir também o fator de potência médio que deve ser utilizado pelo Módulo de Cálculo de Perdas. 


\subsubsection{Cálculo das Perdas Técnicas por Segmento}

O cálculo das perdas por segmento pode ser realizado de diversas maneiras como será mostrado a seguir.

A tela mostrada na figura 4.3 apresenta, na guia ET / Rede Secundária, uma lista das ET's disponíveis na base de dados e permite selecionar quais as ET's que se deseja calcular as perdas. Quando decide-se calcular uma determinada ET, são calculadas não só as perdas em cada unidade transformadora da ET como também as perdas na rede secundária, na rede de iluminação pública e nos ramais de ligação. Também é determinado o número de medidores de energia monofásicos, bifásicos e trifásicos ligados em cada ET para que, posteriormente, possam ser calculadas as perdas associadas a eles. 


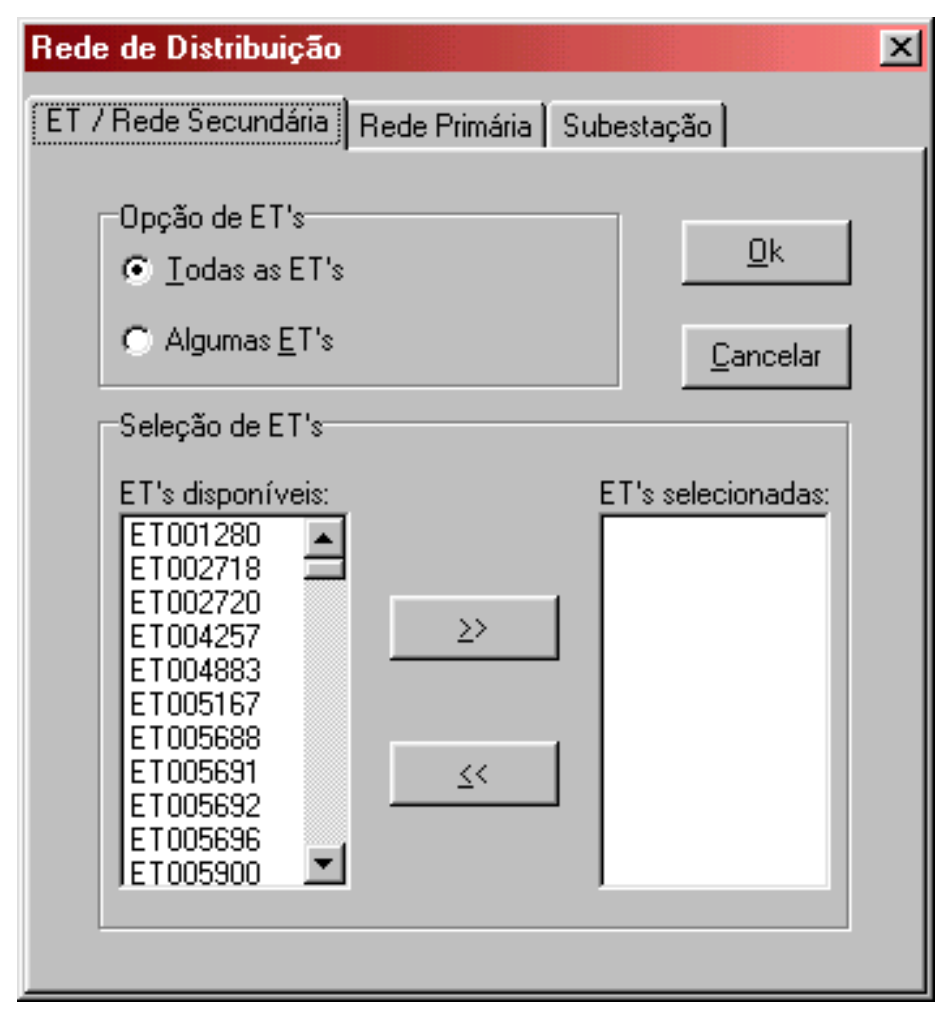

Figura 4.3 - Guia ET / Rede Secundária da tela Rede de Distribuição

Da mesma forma que na guia ET / Rede Secundária, a guia Rede Primária possui uma tela semelhante. Pode-se escolher quais os circuitos que se deseja calcular as perdas. Ao iniciar o cálculo, primeiro é realizado o cálculo em todas as ET's dos circuitos selecionados para, em seguida, realizar o cálculo dos circuitos primários. Isso deve-se ao fato de ser necessário conhecer as curvas de carga de todas as ET's de um circuito para realizar seu cálculo e as curvas de carga das ET's são obtidas realizando-se o cálculo em cada uma delas.

Ao decidir calcular as perdas no segmento rede primária, automaticamente são calculadas as perdas de todos os segmentos que estão a jusante da rede primária.

Finalmente, de forma idêntica às guias anteriores, na guia Subestação pode-se escolher quais SE's se deseja realizar o cálculo de perdas. Para o cálculo no segmento SE, devese conhecer as curvas de carga de todos os circuitos daquela SE e, para conhecer as curvas de carga de cada circuito, é necessário conhecer as curvas de carga de todas as ET's daquela SE. Então, ao iniciar o cálculo de uma SE, são calculadas as perdas em nos segmentos ramal de ligação, rede secundária (inclusive rede de iluminação pública), transformador de distribuição (inclusive transformador exclusivo de iluminação pública), rede primária e subestação de distribuição. Também é determinado o número 
de medidores de energia monofásicos, bifásicos e trifásicos para posterior cálculo das perdas nos medidores de energia.

\subsubsection{Apresentação dos Resultados do Cálculo}

O Módulo de Apresentação de Resultados permite obter relatórios para cada um dos segmentos abaixo:

- Medidor de Energia;

- Ramal de Ligação;

- Rede Secundária;

- Transformador de Distribuição;

- Rede Primária;

- Subestação de Distribuição.

Dependendo do segmento escolhido, pode-se escolher um dos seguintes tipos de relatórios abaixo:

- Relatório Detalhado: mostra o resultado de perdas para cada componente dentro do segmento escolhido.

- Relatório por Circuito: mostra o resultado de perdas para os componentes agrupados segundo o circuito primário ao qual pertencem. Não disponível para perdas em circuitos primários e em subestações de distribuição.

- Relatório por SE: mostra o resultado de perdas para os componentes agrupados segundo a subestação à qual pertencem. Não disponível para perdas em subestações.

- Relatório por Regional: mostra o resultado de perdas para os componentes agrupados segundo a regional à qual pertencem.

- Relatório Geral: mostra o resultado de perdas para o segmento escolhido. O relatório apresenta os valores de perda percentual máxima e mínima com suas respectivas ocorrências, a perda percentual média e o total de perda de energia no segmento. 
Com exceção do Relatório Geral, todos os outros relatórios são apresentados em uma tela, mostrada na figura 4.4 .

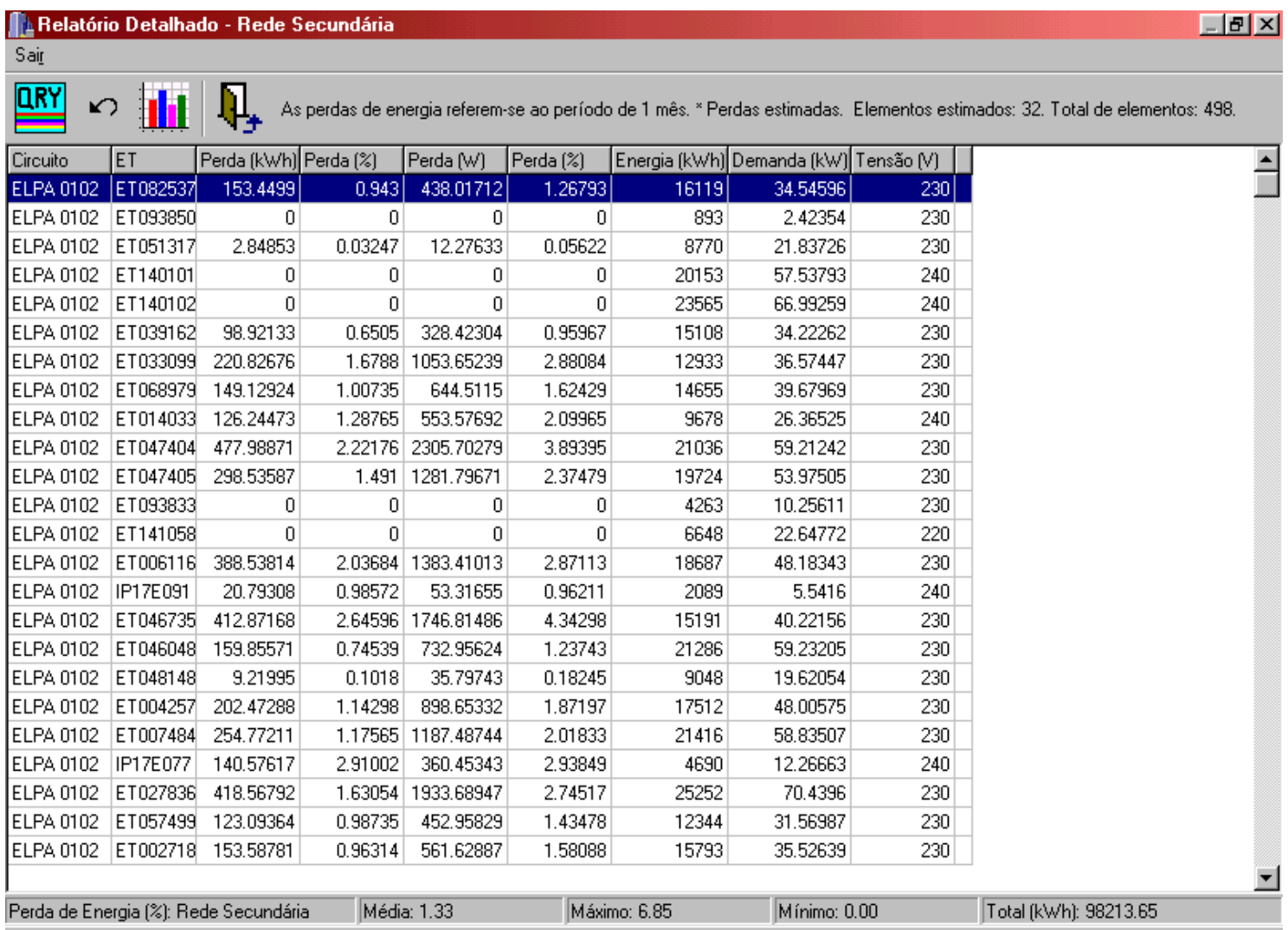

Figura 4.4 - Relatório detalhado para perdas em Redes Secundárias

A tela mostrada na figura 4.4 apresenta a tabela de resultados de perdas em redes secundárias. Nessa tabela, nota-se a presença de alguns campos importantes.

O campo ET informa o código da ET da qual se deriva a rede secundária e o campo Circuito, o código do circuito a que a ET pertence. Já para o relatório detalhado de ramal de ligação, que apresenta uma tela semelhante à mostrada na figura 4.4, o campo ET informa o código da ET na qual estão ligados os ramais de ligação de todos os consumidores que estão ligados naquela ET. Em outras palavras, para o relatório detalhado de ramal de ligação, o registro correspondente a uma determinada ET fornece o resultado de perdas em todos os ramais de ligação conectados àquela ET. O mesmo raciocínio vale para o segmento medidor de energia.

No campo Perda (kWh) está a perda mensal de energia em kWh. Em seguida, no primeiro campo Perda (\%), está a perda mensal de energia em \% da soma da energia suprida com a perda de energia no componente. O campo Perda (W) e o segundo 
campo Perda (\%) apresentam, respectivamente, a perda máxima de demanda em $\mathrm{W}$ e a perda máxima de demanda em \% da demanda máxima na ET. No campo Energia está a energia suprida (energia dos consumidores + energia de iluminação pública) por aquele componente, no campo Demanda, a demanda máxima naquele componente e, no campo Tensão, o nível de tensão em V.

Para o segmento Medidor de Energia, as perdas são calculadas no momento em que se escolhe o tipo de relatório. Portanto, é possível estudar como outros valores de perda por elemento medidor influem no resultado final sem ter que solicitar um novo cálculo. Para isso, basta alterar o valor de perda por elemento medidor e pedir o tipo de relatório desejado novamente.

O programa também dispõe de algumas ferramentas para facilitar a visualização dos resultados.

Uma primeira ferramenta possibilita localizar todos os componentes que estão dentro de uma determinada faixa de perdas de energia.

A segunda ferramenta elabora um gráfico e o apresenta na tela de gráficos, mostrada na figura 4.5. O gráfico mostrado é um histograma da distribuição dos componentes em função da faixa de perdas de energia em que se encontram. Por ele, pode-se visualizar qual a porcentagem de componentes que estão dentro de uma determinada faixa de perda. Pela figura 4.5 , pode-se ver que $71,2 \%$ das redes secundárias estão com perdas de energia entre 0 e $1 \%$. Os limites inferiores e superiores de cada barra podem ser alterados.

O Relatório por Nível de Tensão apresenta o resultado de perdas para os segmentos medidor de energia, ramal de ligação, rede secundária e rede primária agrupados segundo o nível de tensão a que os componentes de cada segmento pertencem. 


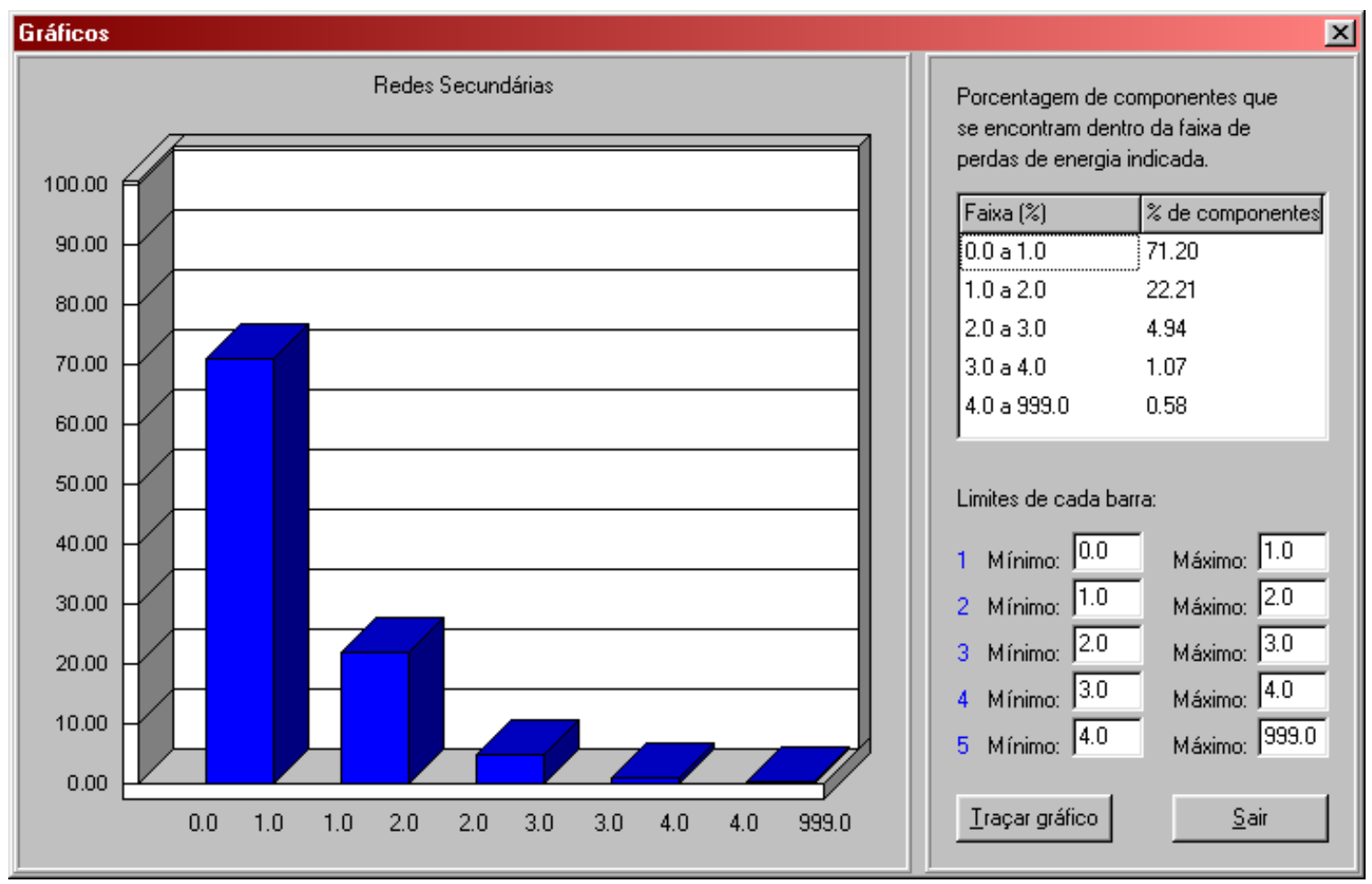

Figura 4.5 - Tela de Gráficos

Como pode ser visto, as ferramentas disponibilizadas pelo Módulo PERTEC possibilitam identificar as regiões ou mesmo componentes específicos cujas perdas estão altas.

\subsection{Apresentação do Módulo de Balanço de Energia}

Cada vez que o Módulo PERTEC termina um processamento, ele determina os valores de perda de energia percentual para os segmentos subestação de distribuição, rede primária, transformador de distribuição, rede secundária, ramal de ligação e medidor de energia com base nos resultados calculados. Esses valores são gravados em um arquivo texto (seg.dat) que é um arquivo de entrada para o Módulo de Balanço de Energia, conforme mostra a figura 4.1 .

A tela principal do Módulo de Balanço de Energia está mostrada na figura 4.6.

Para realizar o balanço de energia, deve-se fornecer os seguintes dados:

- Energia total faturada em baixa tensão (BT) [MWh]; 
- Energia total faturada em média tensão (MT) [MWh];

- Energia total faturada em alta tensão (AT) [MWh];

- Energia total faturada em nível reticulado ${ }^{1}[\mathrm{MWh}]$;

- Energia total dos pontos de fronteira (energia total que entra no sistema) ou energia total de perdas não técnicas [MWh];

- Níveis de perda de energia percentual para cada segmento.

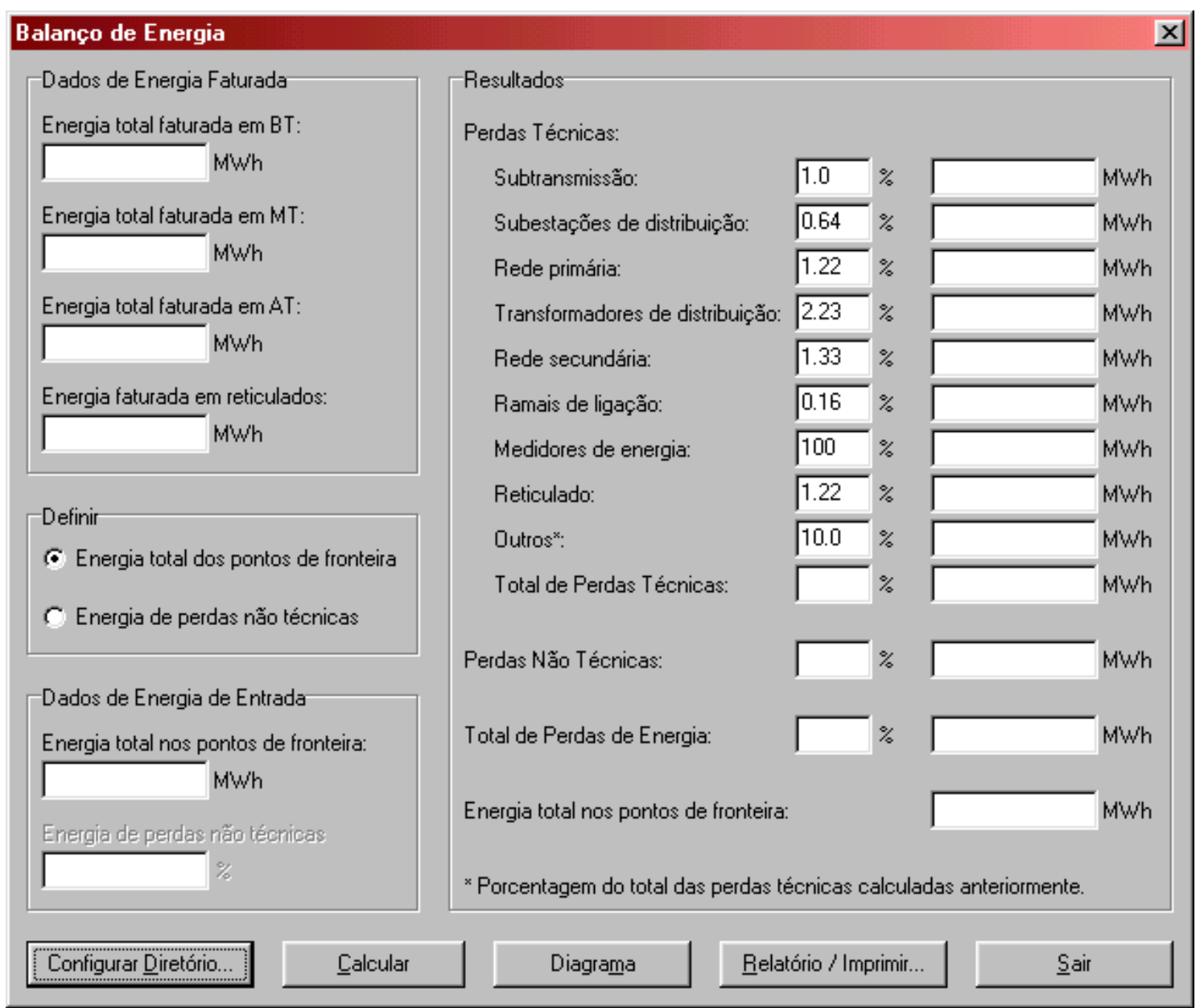

Figura 4.6 - Tela principal do módulo de Balanço de Energia

\footnotetext{
${ }^{1} \mathrm{O}$ sistema reticulado é uma particularidade da concessionária e que o sistema computacional foi implantado.
} 
O Módulo de Balanço de Energia calcula a perda de energia em 9 segmentos, como pode ser visto pela figura 4.6. Desses 9 segmentos, apenas 3 necessitam que o nível de perda de energia percentual seja digitado pelo usuário. Os valores mostrados para esses 3 segmentos são valores adotados pelo programa. São eles: sistema de alta tensão, sistema reticulado e outros, que são os segmentos não calculados pelo PERTEC. Os demais segmentos têm seu nível de perda de energia percentual lido do arquivo seg.dat. Entretanto, esses valores percentuais podem ser alterados.

É importante notar que o nível de perda de energia percentual para o segmento outros refere-se ao total de perdas técnicas de energia e não ao total da energia que entra no sistema.

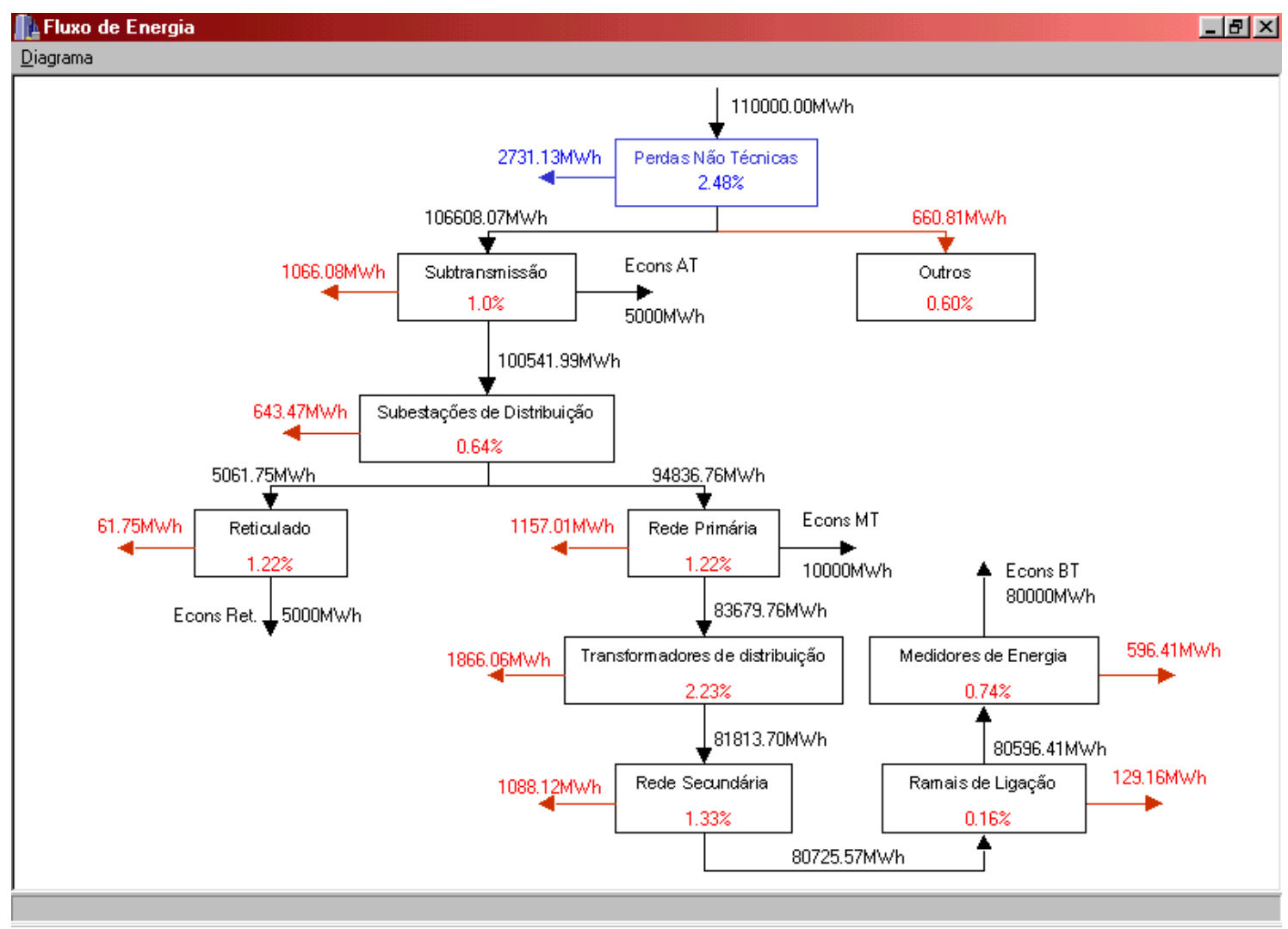

Figura 4.7 - Tela com o fluxo de energia no sistema

Os resultados do cálculo podem ser visualizados num fluxograma, conforme mostra a figura 4.7. $\mathrm{Na}$ tela que é apresentada (figura 4.7) tem-se um diagrama detalhando o fluxo de energia dentro do sistema de distribuição. 


\subsection{Conclusões}

Neste capítulo foi apresentado o sistema computacional que foi desenvolvido para aplicar a metodologia proposta no capítulo 3. Pode-se observar que o sistema como um todo constitui uma ferramenta poderosa quando se deseja não só um cálculo de perdas técnicas de energia e de demanda por segmento na área de concessão de uma concessionária, mas quando se deseja também calcular as perdas em algumas regiões da área de concessão. Nesse sentido, o sistema desenvolvido possibilita identificar as regiões cujas perdas num determinado segmento estão muito altas. Além disso, ele permite também identificar componentes específicos de um determinado segmento cujas perdas estão altas.

Identificados os componentes cujas perdas estão altas, pode-se estudar o impacto de algumas ações na redução das perdas, tais como recondutoramento e troca de transformadores.

Outra vantagem desse sistema é a possibilidade de se determinar as perdas não técnicas de energia por meio de um balanço de energia. Assim, identificados os segmentos que têm uma contribuição maior para o total de perdas de energia no sistema de distribuição, pode-se elaborar um plano de ações para a redução das perdas de energia, priorizandose os segmentos de maior contribuição.

No capítulo seguinte será apresentado um exemplo de aplicação do sistema computacional desenvolvido. Também será apresentado um estudo comparando o cálculo direto e o cálculo indireto pelo uso de fatores típicos (fator de carga e fator de perdas), além de uma comparação entre os resultados obtidos pela aplicação da metodologia proposta e de algumas metodologias apresentadas na revisão bibliográfica. 


\section{CAPÍTULO 5}

\section{APLICAÇÃO DA METODOLOGIA E ANÁLISES COMPLEMENTARES}

\subsection{Introdução}

O capítulo 4 apresentou o sistema computacional que foi desenvolvido para tornar viável a utilização da metodologia proposta neste trabalho.

Este capítulo apresenta um exemplo de aplicação desse sistema, mostrando como podem ser utilizadas as ferramentas que ele dispõe.

Primeiro, apresenta-se um exemplo de aplicação do Módulo PERTEC, mostrando as ferramentas que ele disponibiliza para apresentar, localizar e agrupar os resultados calculados em cada segmento. Também é realizada uma comparação com medições em campo.

Em seguida, apresenta-se um exemplo de aplicação do Módulo de Balanço de Energia. Para ilustrar a aplicação deste sistema computacional, foram calculadas as perdas técnicas de energia em uma parte de um sistema de distribuição. Os dados utilizados no cálculo são dados de redes de distribuição reais, cujos códigos de identificação foram alterados para preservar os dados da empresa.

Ao final deste capítulo, é feita uma análise da influência do fator de perdas no cálculo indireto das perdas de energia e também compara-se os resultados obtidos com a metodologia proposta neste trabalho com aqueles obtidos com algumas das metodologias apresentadas no capítulo 2 . 


\subsection{Aplicação do Módulo PERTEC para o Cálculo de Perdas}

Para exemplificar a utilização do PERTEC, foram calculadas as perdas em uma parte de um sistema de distribuição real.

Nesse cálculo, admitiu-se que as resistências e os comprimentos dos ramais de ligação por classe de consumidor são aqueles apresentados na tabela 3.1 e foi utilizado um fator de potência de 0,95 para o cálculo da demanda aparente de consumidores primários e secundários.

\subsubsection{Resultados Obtidos}

O PERTEC pode apresentar os resultados de diversas maneiras, como já foi explicado no capítulo anterior. No relatório detalhado são mostradas as perdas calculadas para cada componente do segmento. As figuras 5.1 e 5.2 mostram, respectivamente, as telas de relatório detalhado para os segmentos transformador de distribuição (ou ET Estação Transformadora) e ramal de ligação.

Tomando-se como exemplo a figura 5.1, nota-se que a ET082537 apresenta uma perda de energia de $381,35 \mathrm{kWh}$ ou $2,31 \%$. Olhando agora a figura 5.2 , os valores de perda de energia para a ET082537, respectivamente 29,74 kWh e 0,18\% são as perdas de energia nos ramais de ligação de todos os consumidores ligados naquela ET.

Da mesma forma, nota-se que a ET082537 apresenta uma perda de demanda de 757,64 W ou 2,19\% e que seus respectivos ramais de ligação apresentam uma perda de demanda de $137,37 \mathrm{~W}$ ou $0,40 \%$.

Nota-se também que, na parte inferior da tela de relatório detalhado, são apresentados os valores médio, mínimo e máximo de perda percentual de energia que ocorrem no segmento, além do total de perda de energia em $\mathrm{kWh}$ no segmento.

Resumindo, pelo relatório detalhado pode-se observar, para cada segmento, as perdas calculadas em cada componente, o mínimo e o máximo de perda de energia percentual observado e o total de perdas de energia. 


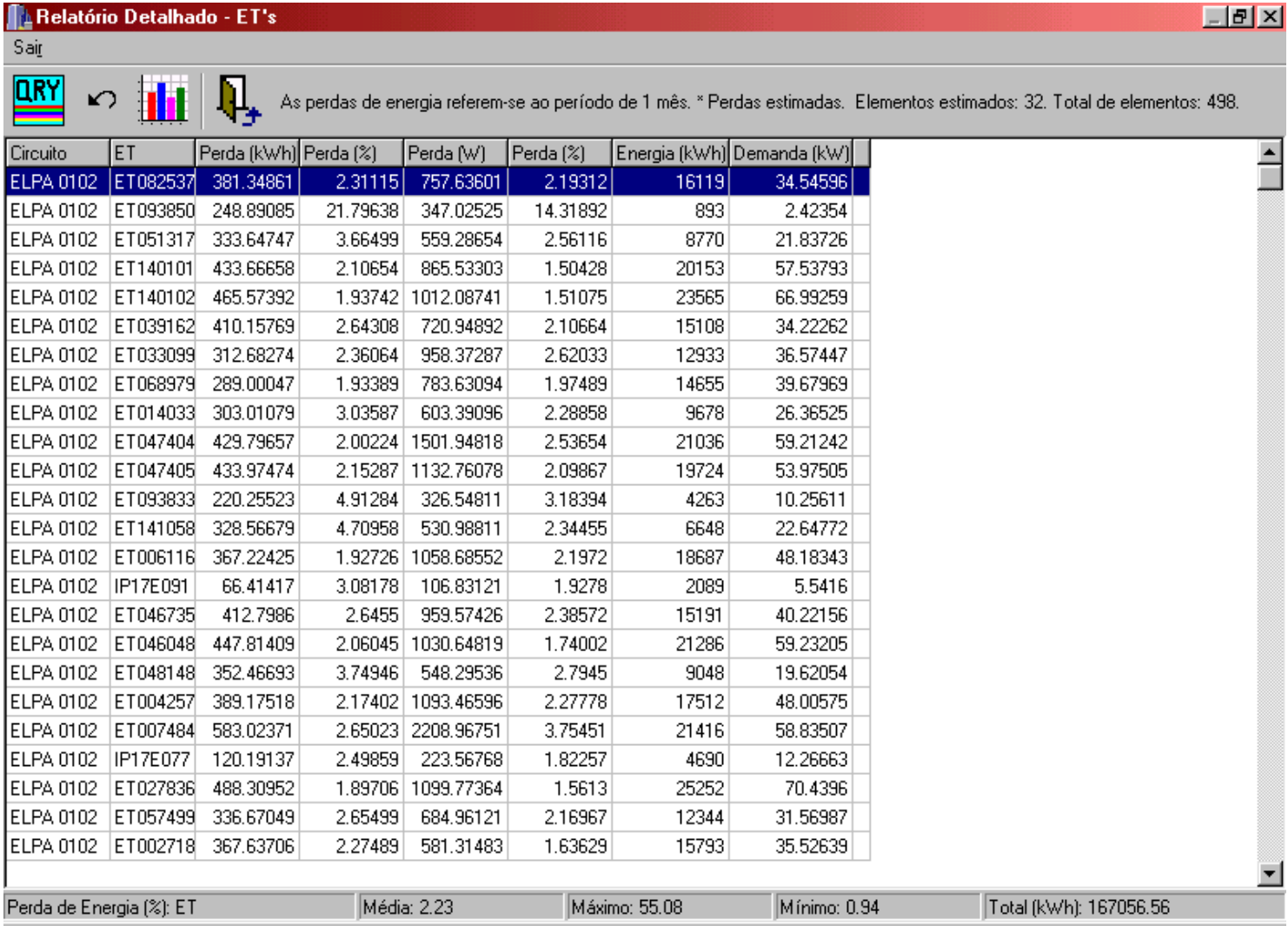

Figura 5.1 - Relatório detalhado para transformador de distribuição

Thelatório Detalhado - Ramais de Ligação

Sais

QRY $\curvearrowleft$ :

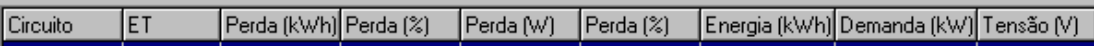

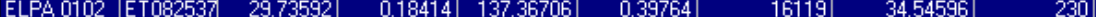

\begin{tabular}{|l|l|l|r|r|r|r|r|r|}
\hline ELPA 0102 & ET093850 & 0.88358 & 0.09885 & 7.07236 & 0.29182 & 893 & 2.42354 & 230 \\
\hline
\end{tabular}

\begin{tabular}{|l|l|r|r|r|r|r|r|r|r|}
\hline ELPA 0102 & ET051317 & 37.40511 & 0.4247 & 221.03041 & 1.01217 & 8770 & 21.83726 & 230 \\
\hline
\end{tabular}

\begin{tabular}{|l|l|l|l|l|l|l|l|l|}
\hline ELPA 0102 & ET140101 & 18.95013 & 0.09394 & 179.00955 & 0.31112 & 20153 & 57.53793 & 240 \\
\hline
\end{tabular}

\begin{tabular}{|l|l|l|l|l|l|l|l|l|}
\hline ELPA 0102 & ET140102 & 35.54175 & 0.1506 & 354.17143 & 0.52867 & 23565 & 66.99259 & 240 \\
\hline
\end{tabular}

\begin{tabular}{|l|l|l|l|l|l|l|l|l|}
\hline ELPA 0102 & ET039162 & 22.04786 & 0.14572 & 126.68574 & 0.37018 & 15108 & 34.22262 & 230 \\
\hline
\end{tabular}

\begin{tabular}{|l|l|l|l|l|l|l|l|l|}
\hline ELPA 0102 & ET033099 & 11.87869 & 0.09176 & 110.63503 & 0.30249 & 12933 & 36.57447 & 230 \\
\hline
\end{tabular}

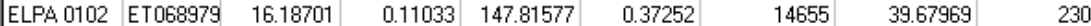

\begin{tabular}{|l|l|l|r|r|r|r|r|r|r|}
\hline ELPA. 0102 & ET014033 & 10.17272 & 0.105 & 95.81827 & 0.36343 & 9678 & 26.36525 & 240 \\
\hline
\end{tabular}

\begin{tabular}{|l|l|l|r|r|r|r|r|r|}
\hline ELPA 0102 & ET047404 & 21.02501 & 0.09985 & 200.42877 & 0.33849 & 21036 & 59.21242 & 230 \\
\hline
\end{tabular}

\begin{tabular}{|l|l|l|l|r|r|r|r|r|r|}
\hline ELPA 0102 & ET047405 & 16.30654 & 0.08261 & 148.5774 & 0.27527 & 19724 & 53.97505 & 230 \\
\hline
\end{tabular}

\begin{tabular}{|l|l|l|l|l|l|l|l|l|}
\hline ELPA 0102 & ET093833 & 9.99103 & 0.23382 & 54.49795 & 0.53137 & 4263 & 10.25611 & 230 \\
\hline
\end{tabular}

\begin{tabular}{|l|l|r|r|r|r|r|r|r|r|}
\hline ELPA 0102 & ET141058 & 39.26002 & 0.58709 & 323.86193 & 1.43 & 6648 & 22.64772 & 220 \\
\hline
\end{tabular}

\begin{tabular}{|l|l|l|l|l|l|r|r|r|}
\hline ELPA 0102 & ET006116 & 24.73785 & 0.1322 & 195.21783 & 0.40516 & 18687 & 48.18343 & 230 \\
\hline
\end{tabular}

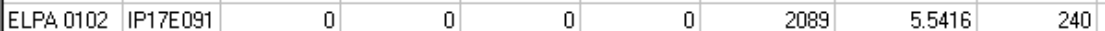

\begin{tabular}{|l|l|r|r|r|r|r|r|r|r|}
\hline ELPA 0102 & ET046735 & 15.85796 & 0.10428 & 141.5016 & 0.35181 & 15191 & 40.22156 & 230 \\
\hline
\end{tabular}

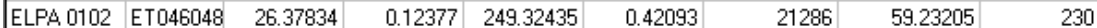

\begin{tabular}{|l|l|l|r|r|r|r|r|r|r|}
\hline ELPA 0102 & ET048148 & 10.71671 & 0.1183 & 44.08882 & 0.22471 & 9048 & 19.62054 & 230 \\
\hline
\end{tabular}

\begin{tabular}{|l|l|l|l|l|l|l|l|l|}
\hline ELPA 0102 & ET004257 & 18.53576 & 0.10573 & 176.34969 & 0.36735 & 17512 & 48.00575 & 230 \\
\hline
\end{tabular}

\begin{tabular}{|l|l|r|r|r|r|r|r|r|r|r|}
\hline ELPA 0102 & ET007484 & 21.8949 & 0.10213 & 206.6715 & 0.35127 & 21416 & 58.83507 & 230 \\
\hline
\end{tabular}

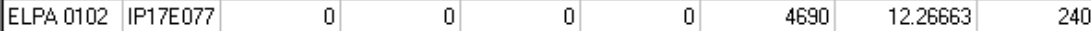

\begin{tabular}{|l|l|l|r|r|r|r|r|r|r|}
\hline ELPA 0102 & ET027836 & 23.36399 & 0.09244 & 218.78539 & 0.3106 & 25252 & 70.4396 & 230 \\
\hline
\end{tabular}

\begin{tabular}{|l|l|l|l|l|l|l|l|l|}
\hline ELPA 0102 & ET057499 & 17.61434 & 0.14249 & 116.92507 & 0.37037 & 12344 & 31.56987 & 230 \\
\hline
\end{tabular}

\begin{tabular}{|l|l|l|l|l|l|r|r|r|r|}
\hline ELPA 0102 & ET002718 & 20.63311 & 0.13048 & 105.57775 & 0.29718 & 15793 & 35.52639 & 230 \\
\hline
\end{tabular}

\begin{tabular}{|l||l||l||l|l|l|l|l}
\hline Perda de Energia (\%): Ramal de Ligação & Média: 0.16 & Máximo: 2.52 & Mínimo: 0.04 & Total (kWh): 11692.13 \\
\hline
\end{tabular}

Figura 5.2 - Relatório detalhado para ramal de ligação 
Os relatórios de perdas apresentam os valores de perdas calculadas no último processamento realizado. A única exceção é o segmento medidor de energia, cujas perdas são calculadas no momento em que se solicita um dos relatórios disponíveis.

Dessa forma, para o segmento medidor de energia é possível verificar qual o impacto que o valor da perda por elemento medidor tem sobre o resultado das perdas. Para isso, é só alterar o valor de perda por elemento medidor na tela de opções do PERTEC. A tabela 5.1 apresenta, de forma resumida, os resultados obtidos para 3 valores diferentes de perda por elemento medidor.

Tabela 5.1 - Perda nos Medidores de Energia X Perda por Elemento Medidor

\begin{tabular}{ccccc}
\hline \multirow{2}{*}{$\begin{array}{c}\text { Perda por Elemento } \\
\text { Medidor }(\mathbf{W})\end{array}$} & \multicolumn{2}{c}{ Perda de Energia } & \multicolumn{2}{c}{ Perda de Demanda } \\
\cline { 2 - 5 } & $\mathbf{k W h}$ & $\mathbf{\%}$ & $\mathbf{k W}$ & $\mathbf{\%}$ \\
\hline 1,20 & $6.691 .101,12$ & 0,56 & $9.293,20$ & 0,29 \\
\hline 1,35 & $7.527 .488,76$ & 0,63 & $10.454,85$ & 0,33 \\
\hline 1,50 & $8.363 .876,40$ & 0,70 & $11.616,50$ & 0,36 \\
\hline
\end{tabular}

A tabela 5.2 apresenta, de uma forma resumida, as perdas técnicas obtidas em cada segmento em parte de um sistema de distribuição real. Os índices percentuais obtidos servirão de entrada para o Módulo de Balanço de Energia. A perda de demanda apresentada é a perda de demanda não coincidente.

Tabela 5.2 - Perdas Técnicas por Segmento

\begin{tabular}{lcccc}
\hline \multirow{2}{*}{\multicolumn{1}{c}{ Segmento }} & \multicolumn{2}{c}{ Perda de Energia } & \multicolumn{2}{c}{ Perda de Demanda } \\
\cline { 2 - 5 } & $\mathbf{k W h}$ & $\mathbf{\%}$ & $\mathbf{k W}$ & $\mathbf{\%}$ \\
\hline Medidor de Energia* & $6.691 .101,12$ & 0,56 & $9.293,20$ & 0,29 \\
\hline Ramal de Ligação & $3.300 .121,31$ & 0,27 & $26.522,86$ & 0,83 \\
\hline Rede Secundária & $11.574 .650,73$ & 0,95 & $47.293,30$ & 1,47 \\
\hline Transformador de Distribuição & $34.406 .246,67$ & 2,75 & $78.655,32$ & 2,45 \\
\hline Rede Primária & $17.558 .344,22$ & 0,94 & $52.758,68$ & 1,43 \\
\hline Subestação de Distribuição & $11.006 .444,45$ & 0,59 & $21.311,19$ & 0,57 \\
\hline \multicolumn{4}{c}{ *Perda por elemento medidor igual a 1,2 W } \\
\end{tabular}

Como o relatório detalhado é extenso, o PERTEC dispõe de uma ferramenta para realizar buscas neste relatório e possibilita agregar os resultados do relatório detalhado de um determinado segmento segundo o circuito a que cada um de seus componentes pertencem, como já foi explicado no capítulo anterior.

As tabelas 5.3, 5.4, 5.5 e 5.6 apresentam, respectivamente, as perdas técnicas nos 
segmentos medidor de energia, ramal de ligação, rede secundária e transformador de distribuição agrupadas por circuito primário. Como a quantidade de circuitos é grande, foram colocados os resultados de apenas alguns circuitos.

Tabela 5.3 - Perdas em Medidor de Energia por Circuito

\begin{tabular}{ccccc}
\hline \multirow{2}{*}{ Circuito } & \multicolumn{2}{c}{ Perda de Energia } & \multicolumn{2}{c}{ Perda de Demanda } \\
\cline { 2 - 5 } & $\mathbf{k W h}$ & $\mathbf{\%}$ & $\mathbf{k W}$ & $\mathbf{\%}$ \\
\hline ELPB-0102 & 210,82 & 0,21 & 0,29 & 0,11 \\
\hline ELPB-0103 & 783,65 & 0,40 & 1,09 & 0,22 \\
\hline ELPB-0104 & $3.222,72$ & 0,83 & 4,48 & 0,42 \\
\hline ELPB-0105 & $1.927,58$ & 0,19 & 2,68 & 0,11 \\
\hline ELPB-0106 & $10.800,86$ & 0,59 & 15,00 & 0,32 \\
\hline ELPB-0107 & $17.057,95$ & 0,60 & 23,69 & 0,32 \\
\hline
\end{tabular}

Tabela 5.4 - Perdas em Ramal de Ligação por Circuito

\begin{tabular}{ccccc}
\hline \multirow{2}{*}{ Circuito } & \multicolumn{2}{c}{ Perda de Energia } & \multicolumn{2}{c}{ Perda de Demanda } \\
\cline { 2 - 5 } & $\mathbf{k W h}$ & $\mathbf{\%}$ & $\mathbf{k W}$ & $\mathbf{\%}$ \\
\hline ELPC-0102 & 931,05 & 1,52 & 7,79 & 4,06 \\
\hline ELPC-0103 & $2.489,39$ & 0,17 & 17,80 & 0,47 \\
\hline ELPC-0104 & $7.789,48$ & 0,34 & 69,87 & 1,10 \\
\hline ELPC-0105 & $7.318,39$ & 0,61 & 63,87 & 1,80 \\
\hline ELPC-0106 & $1.413,09$ & 0,75 & 11,95 & 1,56 \\
\hline ELPC-0107 & $1.048,37$ & 0,97 & 7,13 & 2,29 \\
\hline
\end{tabular}

Tabela 5.5 - Perdas em Rede Secundária por Circuito

\begin{tabular}{ccccc}
\hline \multirow{2}{*}{ Circuito } & \multicolumn{2}{c}{ Perda de Energia } & \multicolumn{2}{c}{ Perda de Demanda } \\
\cline { 2 - 5 } & $\mathbf{k W h}$ & $\mathbf{\%}$ & $\mathbf{k W}$ & $\mathbf{\%}$ \\
\hline ELPD-0102 & $3.366,33$ & 2,99 & 12,05 & 3,57 \\
\hline ELPD-0103 & 364,72 & 0,39 & 1,08 & 0,43 \\
\hline ELPD-0104 & $6.732,31$ & 0,81 & 27,65 & 1,29 \\
\hline ELPD-0105 & $28.394,22$ & 1,56 & 108,51 & 2,34 \\
\hline ELPD-0106 & $17.524,75$ & 1,00 & 72,48 & 1,56 \\
\hline ELPD-0107 & $46.382,50$ & 2,41 & 178,05 & 3,67 \\
\hline
\end{tabular}

Tabela 5.6 - Perdas em Transformador de Distribuição por Circuito

\begin{tabular}{ccccc}
\hline \multirow{2}{*}{ Circuito } & \multicolumn{2}{c}{ Perda de Energia } & \multicolumn{2}{c}{ Perda de Demanda } \\
\cline { 2 - 5 } & $\mathbf{k W h}$ & $\mathbf{\%}$ & $\mathbf{k W}$ & $\mathbf{\%}$ \\
\hline ELPE-0102 & $10.419,27$ & 3,70 & 19,04 & 2,75 \\
\hline ELPE-0103 & $6.820,21$ & 5,05 & 11,24 & 3,16 \\
\hline ELPE-0104 & $26.456,33$ & 2,46 & 62,39 & 2,36 \\
\hline ELPE-0105 & $41.495,86$ & 2,13 & 109,08 & 2,10 \\
\hline ELPE-0106 & $62.199,12$ & 2,82 & 148,67 & 2,42 \\
\hline ELPE-0107 & $32.063,22$ & 1,80 & 77,08 & 1,54 \\
\hline
\end{tabular}


Nota-se que, agregando-se o relatório detalhado por circuito, pode-se identificar quais os circuitos que apresentam maiores perdas nos segmentos medidor de energia, ramal de ligação, rede secundária e transformador de distribuição.

Da mesma forma que o circuito ELPE-0103 é o circuito que apresenta maior perda de energia percentual no segmento transformador de distribuição, o circuito ELPD-0102 é o circuito que apresenta maior perda de energia no segmento rede secundária. Para o segmento transformador de distribuição, o valor observado no circuito ELPE-0103 é $5,05 \%$ enquanto o valor médio encontrado no segmento é 2,75\%. Para o segmento rede secundária, o valor observado no circuito ELPD-0102 é 2,99\% enquanto o valor médio encontrado no segmento é $0,95 \%$.

Os relatórios detalhados também podem ser agrupados por subestação ou por regional, conforme já foi explicado no capítulo anterior. Dessa forma, pode-se identificar não somente os circuitos, mas também as subestações ou regionais que mais contribuem para as perdas técnicas num determinado segmento.

As tabelas 5.7, 5.8, 5.9, 5,10 e 5.11 apresentam, respectivamente, as perdas técnicas nos segmentos medidor de energia, ramal de ligação, rede secundária, transformador de distribuição e rede primária agrupadas por subestação. Como a quantidade de subestações é grande, foram colocados os resultados de algumas delas.

Em seguida, as tabelas 5.12, 5.13, 5.14, 5,15, 5.16 e 5.17 apresentam, respectivamente, as perdas técnicas nos segmentos medidor de energia, ramal de ligação, rede secundária, transformador de distribuição, rede primária e subestação de distribuição agrupadas por regional.

Tabela 5.7 - Perdas em Medidor de Energia por Subestação

\begin{tabular}{ccccc}
\hline \multirow{2}{*}{ Subestação } & \multicolumn{2}{c}{ Perda de Energia } & \multicolumn{2}{c}{ Perda de Demanda } \\
\cline { 2 - 5 } & $\mathbf{k W h}$ & $\mathbf{\%}$ & $\mathbf{k W}$ & $\mathbf{\%}$ \\
\hline ELAB & $35.241,70$ & 0,61 & 48,95 & 0,32 \\
\hline ELAC & $55.488,67$ & 0,47 & 77,07 & 0,25 \\
\hline ELAD & $125.640,29$ & 0,74 & 174,50 & 0,40 \\
\hline ELAE & $30.837,02$ & 0,55 & 42,83 & 0,32 \\
\hline ELAF & $27.844,13$ & 0,25 & 38,67 & 0,13 \\
\hline ELAG & $64.738,66$ & 0,84 & 89,91 & 0,43 \\
\hline
\end{tabular}


Tabela 5.8 - Perdas em Ramal de Ligação por Subestação

\begin{tabular}{ccccc}
\hline \multirow{2}{*}{ Subestação } & \multicolumn{2}{c}{ Perda de Energia } & \multicolumn{2}{c}{ Perda de Demanda } \\
\cline { 2 - 5 } & $\mathbf{k W h}$ & $\mathbf{\%}$ & $\mathbf{k W}$ & $\mathbf{\%}$ \\
\hline ELAH & $13.070,08$ & 0,26 & 113,11 & 0,78 \\
\hline ELAI & $60.852,35$ & 0,42 & 555,59 & 1,40 \\
\hline ELAJ & $30.774,12$ & 0,16 & 242,86 & 0,47 \\
\hline ELAL & $11.853,09$ & 0,59 & 92,09 & 1,60 \\
\hline ELAM & $36.090,28$ & 0,19 & 302,85 & 0,56 \\
\hline ELAN & $33.138,52$ & 0,21 & 248,05 & 0,59 \\
\hline
\end{tabular}

Tabela 5.9 - Perdas em Rede Secundária por Subestação

\begin{tabular}{ccccc}
\hline \multirow{2}{*}{ Subestação } & \multicolumn{2}{c}{ Perda de Energia } & \multicolumn{2}{c}{ Perda de Demanda } \\
\cline { 2 - 5 } & $\mathbf{k W h}$ & $\mathbf{\%}$ & $\mathbf{k W}$ & $\mathbf{\%}$ \\
\hline ELAO & $82.311,38$ & 1,02 & 328,65 & 1,57 \\
\hline ELAP & $397.568,76$ & 2,42 & $1.420,13$ & 3,37 \\
\hline ELAQ & $39.440,34$ & 0,44 & 158,00 & 0,68 \\
\hline ELAR & 753,39 & 0,83 & 15,29 & 1,16 \\
\hline ELAS & $239.083,30$ & 1,22 & $1.007,93$ & 1,94 \\
\hline ELAT & $147.274,45$ & 1,35 & 600,89 & 2,10 \\
\hline
\end{tabular}

Tabela 5.10 - Perdas em Transformador de Distribuição por Subestação

\begin{tabular}{ccccc}
\hline \multirow{2}{*}{ Subestação } & \multicolumn{2}{c}{ Perda de Energia } & \multicolumn{2}{c}{ Perda de Demanda } \\
\cline { 2 - 5 } & $\mathbf{k W h}$ & $\mathbf{\%}$ & $\mathbf{k W}$ & $\mathbf{\%}$ \\
\hline ELAU & $334.320,24$ & 2,37 & 835,97 & 2,31 \\
\hline ELAV & $192.371,50$ & 2,81 & 443,04 & 2,52 \\
\hline ELAX & $189.640,54$ & 3,26 & 344,32 & 2,56 \\
\hline ELAZ & $17.759,75$ & 3,02 & 44,13 & 3,19 \\
\hline ELBA & $230.626,27$ & 2,55 & 546,66 & 2,37 \\
\hline ELBB & $537.874,77$ & 2,67 & $1.392,25$ & 2,63 \\
\hline
\end{tabular}

Tabela 5.11 - Perdas em Rede Primária por Subestação

\begin{tabular}{ccccc}
\hline \multirow{2}{*}{ Subestação } & \multicolumn{2}{c}{ Perda de Energia } & \multicolumn{2}{c}{ Perda de Demanda } \\
\cline { 2 - 5 } & $\mathbf{k W h}$ & $\mathbf{\%}$ & $\mathbf{k W}$ & $\mathbf{\%}$ \\
\hline ELBC & $223.695,89$ & 1,00 & 655,27 & 1,54 \\
\hline ELBD & $34.425,70$ & 1,40 & 104,21 & 2,06 \\
\hline ELBE & $44.454,24$ & 0,46 & 99,14 & 0,57 \\
\hline ELBF & $23.439,19$ & 0,32 & 112,96 & 0,61 \\
\hline ELBG & $48.339,34$ & 0,95 & 221,43 & 1,30 \\
\hline ELBH & $125.797,53$ & 2,47 & 532,43 & 3,36 \\
\hline
\end{tabular}


Tabela 5.12 - Perdas em Medidor de Energia por Regional

\begin{tabular}{ccccc}
\hline \multirow{2}{*}{ Regional } & \multicolumn{2}{c}{ Perda de Energia } & \multicolumn{2}{c}{ Perda de Demanda } \\
\cline { 2 - 5 } & $\mathbf{k W h}$ & $\mathbf{\%}$ & $\mathbf{k W}$ & $\mathbf{\%}$ \\
\hline $\mathrm{A}$ & $1.323 .226,37$ & 0,62 & $1.837,81$ & 0,33 \\
\hline $\mathrm{B}$ & $99.975,17$ & 0,38 & 138,85 & 0,21 \\
\hline $\mathrm{C}$ & $965.732,54$ & 0,71 & $1.341,30$ & 0,36 \\
\hline $\mathrm{D}$ & $1.040 .742,43$ & 0,59 & $1.445,48$ & 0,31 \\
\hline
\end{tabular}

Tabela 5.13 - Perdas em Ramal de Ligação por Regional

\begin{tabular}{ccccc}
\hline \multirow{2}{*}{ Regional } & \multicolumn{2}{c}{ Perda de Energia } & \multicolumn{2}{c}{ Perda de Demanda } \\
\cline { 2 - 5 } & $\mathbf{k W h}$ & $\mathbf{\%}$ & $\mathbf{k W}$ & $\mathbf{\%}$ \\
\hline $\mathrm{A}$ & $529.024,12$ & 0,25 & $3.945,21$ & 0,70 \\
\hline $\mathrm{B}$ & $99.264,73$ & 0,37 & 682,21 & 1,03 \\
\hline $\mathrm{C}$ & $243.197,88$ & 0,18 & $1.964,27$ & 0,53 \\
\hline $\mathrm{D}$ & $395.737,70$ & 0,22 & $3.201,99$ & 0,67 \\
\hline
\end{tabular}

Tabela 5.14 - Perdas em Rede Secundária por Regional

\begin{tabular}{ccccc}
\hline \multirow{2}{*}{ Regional } & \multicolumn{2}{c}{ Perda de Energia } & \multicolumn{2}{c}{ Perda de Demanda } \\
\cline { 2 - 5 } & $\mathbf{k W h}$ & $\mathbf{\%}$ & $\mathbf{k W}$ & $\mathbf{\%}$ \\
\hline $\mathrm{A}$ & $2.774 .175,44$ & 1,28 & $11.071,55$ & 1,92 \\
\hline $\mathrm{B}$ & $131.417,66$ & 0,49 & 452,18 & 0,68 \\
\hline $\mathrm{C}$ & $1.517 .850,21$ & 1,10 & $6.434,78$ & 1,69 \\
\hline $\mathrm{D}$ & $1.790 .823,98$ & 1,00 & $7.339,37$ & 1,52 \\
\hline
\end{tabular}

Tabela 5.15 - Perdas em Transformador de Distribuição por Regional

\begin{tabular}{ccccc}
\hline \multirow{2}{*}{ Regional } & \multicolumn{2}{c}{ Perda de Energia } & \multicolumn{2}{c}{ Perda de Demanda } \\
\cline { 2 - 5 } & $\mathbf{k W h}$ & $\mathbf{\%}$ & $\mathbf{k W}$ & $\mathbf{\%}$ \\
\hline $\mathrm{A}$ & $5.780 .148,30$ & 2,60 & $13.464,74$ & 2,28 \\
\hline $\mathrm{B}$ & $836.027,62$ & 3,03 & $7.736,92$ & 2,54 \\
\hline $\mathrm{C}$ & $3.510 .343,48$ & 2,48 & $8.490,96$ & 2,19 \\
\hline $\mathrm{D}$ & $5.056 .606,17$ & 2,74 & $11.823,45$ & 2,39 \\
\hline
\end{tabular}

Tabela 5.16 - Perdas em Rede Primária por Regional

\begin{tabular}{ccccc}
\hline \multirow{2}{*}{ Regional } & \multicolumn{2}{c}{ Perda de Energia } & \multicolumn{2}{c}{ Perda de Demanda } \\
\cline { 2 - 5 } & $\mathbf{k W h}$ & $\mathbf{\%}$ & $\mathbf{k W}$ & $\mathbf{\%}$ \\
\hline $\mathrm{A}$ & $3.801 .077,90$ & 1,02 & $10.388,59$ & 1,46 \\
\hline $\mathrm{B}$ & $348.393,76$ & 0,79 & $1.307,66$ & 1,14 \\
\hline $\mathrm{C}$ & $2.100 .436,31$ & 1,21 & $6.572,12$ & 1,98 \\
\hline $\mathrm{D}$ & $2.833 .877,25$ & 1,04 & $9.011,36$ & 1,62 \\
\hline
\end{tabular}


Tabela 5.17 - Perdas em Subestação de Distribuição por Regional

\begin{tabular}{ccccc}
\hline \multirow{2}{*}{ Regional } & \multicolumn{2}{c}{ Perda de Energia } & \multicolumn{2}{c}{ Perda de Demanda } \\
\cline { 2 - 5 } & $\mathbf{k W h}$ & $\mathbf{\%}$ & $\mathbf{k W}$ & $\mathbf{\%}$ \\
\hline $\mathrm{A}$ & $1.909 .090,84$ & 0,51 & $3.560,53$ & 0,50 \\
\hline $\mathrm{B}$ & $681.710,64$ & 1,52 & $1.054,87$ & 0,91 \\
\hline $\mathrm{C}$ & $910.471,94$ & 0,52 & $2.085,24$ & 0,63 \\
\hline $\mathrm{D}$ & $1.634 .548,92$ & 0,60 & $3.712,62$ & 0,66 \\
\hline
\end{tabular}

O PERTEC ainda disponibiliza uma ferramenta gráfica que permite visualizar, de forma simplificada, a distribuição dos componentes de um determinado segmento dentro de algumas faixas de perdas de energia. A figura 5.3 mostra a tela que apresenta o histograma da perda de energia para o segmento rede secundária. Nota-se que a maior parte das redes secundárias calculadas $(71,2 \%)$ apresentam perda de energia entre $0,0 \mathrm{e}$ 1,0\%. Da mesma forma, fica claro notar que as redes secundárias que apresentam perda entre 2,0 e 3,0\% representam $4,94 \%$ do total das redes secundárias.

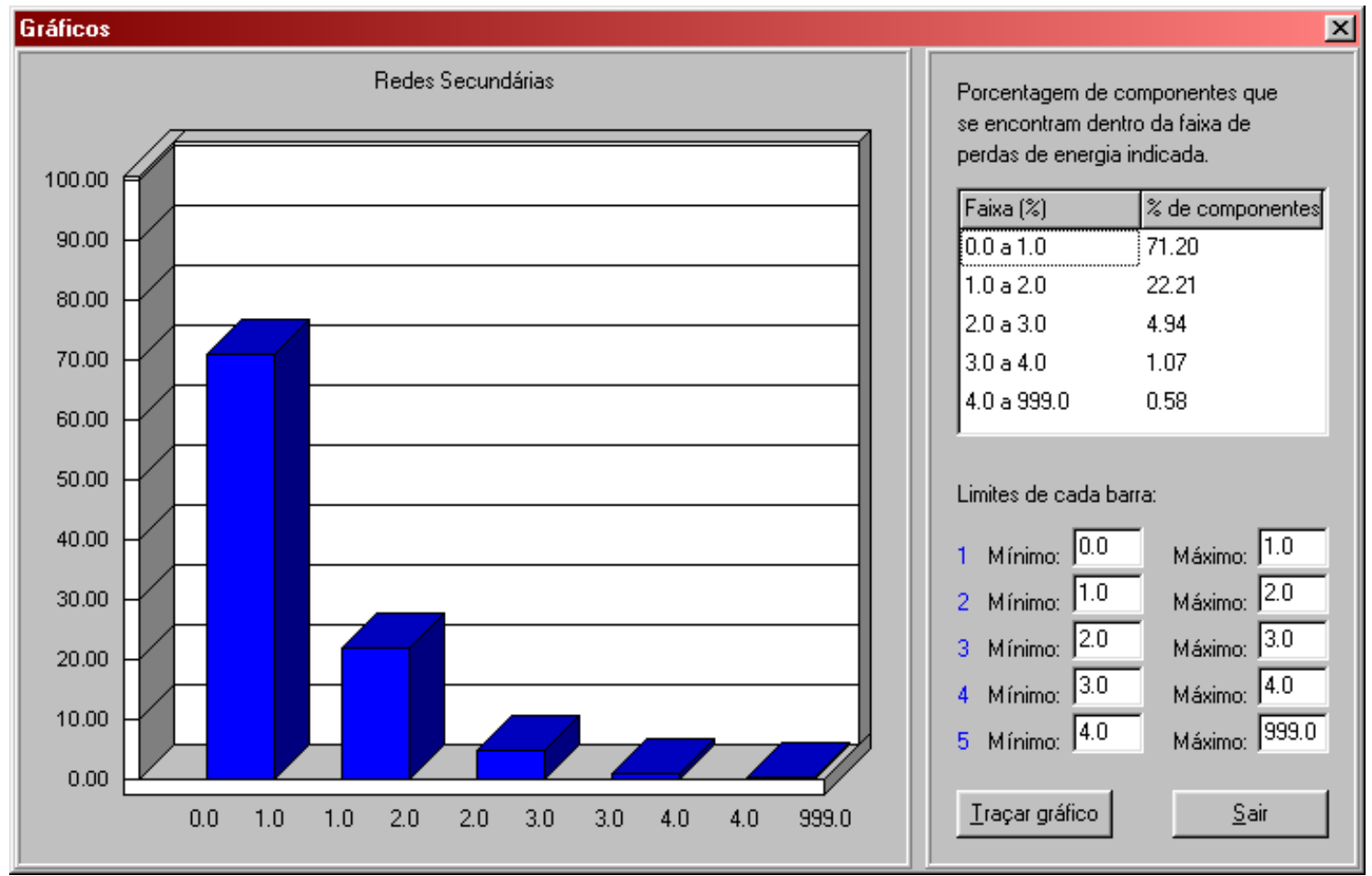

Figura 5.3 - Histograma da perda de energia no segmento rede secundária

As tabelas 5.18, 5.19, 5.20, 5.21, 5.22 e 5.23 apresentam o histograma das perdas de energia para os segmentos medidor de energia, ramal de ligação, rede secundária, transformador de distribuição, rede primária e subestação de distribuição, respectivamente. 
Tabela 5.18 - Histograma da perda de energia nos medidores de energia

\begin{tabular}{cc}
\hline $\begin{array}{c}\text { Faixa de Perdas de } \\
\text { Energia (\%) }\end{array}$ & $\begin{array}{c}\text { Porcentagem de } \\
\text { componentes (\%) }\end{array}$ \\
\hline $0,0-0,5$ & 46,60 \\
\hline $0,5-1,0$ & 46,56 \\
\hline $1,0-1,5$ & 5,52 \\
\hline $1,5-2,0$ & 0,59 \\
\hline Acima de 2,0 & 0,73 \\
\hline
\end{tabular}

Tabela 5.19 - Histograma da perda de energia nos ramais de ligação

\begin{tabular}{cc}
\hline $\begin{array}{c}\text { Faixa de Perdas de } \\
\text { Energia (\%) }\end{array}$ & $\begin{array}{c}\text { Porcentagem de } \\
\text { componentes (\%) }\end{array}$ \\
\hline $0,00-0,25$ & 80,97 \\
\hline $0,25-0,50$ & 12,97 \\
\hline $0,50-1,00$ & 4,53 \\
\hline $1,0-2,0$ & 1,32 \\
\hline Acima de 2,0 & 0,21 \\
\hline
\end{tabular}

Tabela 5.20 - Histograma da perda de energia nas redes secundárias

\begin{tabular}{cc}
\hline $\begin{array}{c}\text { Faixa de Perdas de } \\
\text { Energia (\%) }\end{array}$ & $\begin{array}{c}\text { Porcentagem de } \\
\text { componentes (\%) }\end{array}$ \\
\hline $0,0-1,0$ & 71,20 \\
\hline $1,0-2,0$ & 22,21 \\
\hline $2,0-3,0$ & 4,94 \\
\hline $3,0-4,0$ & 1,07 \\
\hline Acima de 4,0 & 0,58 \\
\hline
\end{tabular}

Tabela 5.21 - Histograma da perda de energia nos transformadores de distribuição

\begin{tabular}{cc}
\hline $\begin{array}{c}\text { Faixa de Perdas de } \\
\text { Energia (\%) }\end{array}$ & $\begin{array}{c}\text { Porcentagem de } \\
\text { componentes (\%) }\end{array}$ \\
\hline $0,0-1,0$ & 2,87 \\
\hline $1,0-2,0$ & 15,23 \\
\hline $2,0-3,0$ & 39,44 \\
\hline $3,0-4,0$ & 18,90 \\
\hline Acima de 4,0 & 23,56 \\
\hline
\end{tabular}

Tabela 5.22 - Histograma da perda de energia nas redes primárias

\begin{tabular}{cc}
\hline $\begin{array}{c}\text { Faixa de Perdas de } \\
\text { Energia (\%) }\end{array}$ & $\begin{array}{c}\text { Porcentagem de } \\
\text { componentes (\%) }\end{array}$ \\
\hline $0,0-1,0$ & 77,62 \\
\hline $1,0-2,0$ & 17,55 \\
\hline $2,0-3,0$ & 3,14 \\
\hline $3,0-4,0$ & 0,97 \\
\hline Acima de 4,0 & 0,72 \\
\hline
\end{tabular}


Tabela 5.23 - Histograma da perda de energia nas subestações de distribuição

\begin{tabular}{cc}
\hline $\begin{array}{c}\text { Faixa de Perdas de } \\
\text { Energia (\%) }\end{array}$ & $\begin{array}{c}\text { Porcentagem de } \\
\text { componentes (\%) }\end{array}$ \\
\hline $0,0-0,5$ & 24,56 \\
\hline $0,5-1,0$ & 68,42 \\
\hline $1,0-2,0$ & 3,51 \\
\hline $2,0-3,0$ & 0,00 \\
\hline Acima de 3,0 & 3,51 \\
\hline
\end{tabular}

\subsubsection{Comparação com Medições em Campo}

Para aferir os resultados obtidos com o PERTEC, foram realizadas algumas medições em campo. O principal objetivo dessa aferição era comparar a curva de carga calculada pelo PERTEC com a curva de carga medida.

Em alguns casos foram verificados valores inconsistentes.

Num destes casos, verificou-se que a curva de carga medida não possuía semelhança alguma com a curva de carga calculada. A discrepância observada deveu-se ao fato de que as ET's escolhidas para medição também atendiam muitos consumidores clandestinos. A existência desses consumidores explica o fato de a energia medida na saída da ET ser maior que a energia fornecida pelo sistema de faturamento da concessionária. Também explica a diferença entre o perfil da curva de carga medida e o perfil da curva de carga calculada pelo PERTEC.

A seguir serão apresentados alguns resultados de uma ET selecionada na qual se sabia que não existiam consumidores clandestinos. Essa estação transformadora é monofásica e tem capacidade nominal de $50 \mathrm{kVA}$. Ela alimenta 63 consumidores, sendo 62 residenciais e 1 comercial, suprindo uma energia total de $17165 \mathrm{kWh}$ num período de aproximadamente 1 mês.

Foi instalado um aparelho de medição, no lado de baixa tensão, durante 12 dias (período de 02/02/2000 a 13/02/2000). Para esses 12 dias de medição, foram calculadas as curvas média e de desvio padrão representativas do carregamento dessa ET (valores em kVA). Essas curvas podem ser visualizadas na figura 5.4 onde pode-se verificar:

- ao longo dos 12 dias de medição, o carregamento da ET teve um bom comportamento, com o desvio padrão não superior a $25 \%$ do valor da média na pior condição; 
- ao longo de um dia, o carregamento apresenta uma ponta de carga (em torno de 43,5 kVA, com um desvio padrão de 5,5 kVA) por volta das $20 \mathrm{~h}$, com o perfil permanecendo praticamente constante (em torno de $28 \mathrm{kVA}$ ) entre 6 e $17 \mathrm{~h}$. A demanda média do carregamento do transformador é de $26,8 \mathrm{kVA}$, resultando num fator de carga de 0,617 ;

- admitindo-se uma distribuição normal para o carregamento da ET e aplicando-se $k=$ 3 na expressão (3.2), seria de se esperar um carregamento máximo de cerca de 60 kVA (43,5 + 3 x 5,5 kVA), com uma probabilidade de 99,7\% de não ser excedida;

- a energia mensal suprida por essa ET, assumindo-se um fator de potência de 0,95 e aplicando-se a curva de carga média para todos os dias do mês, seria $18068 \mathrm{kWh}$. Para efeito de comparação, este valor é bem próximo (107\%) do consumo do mês registrado no sistema da concessionária (17165kWh).

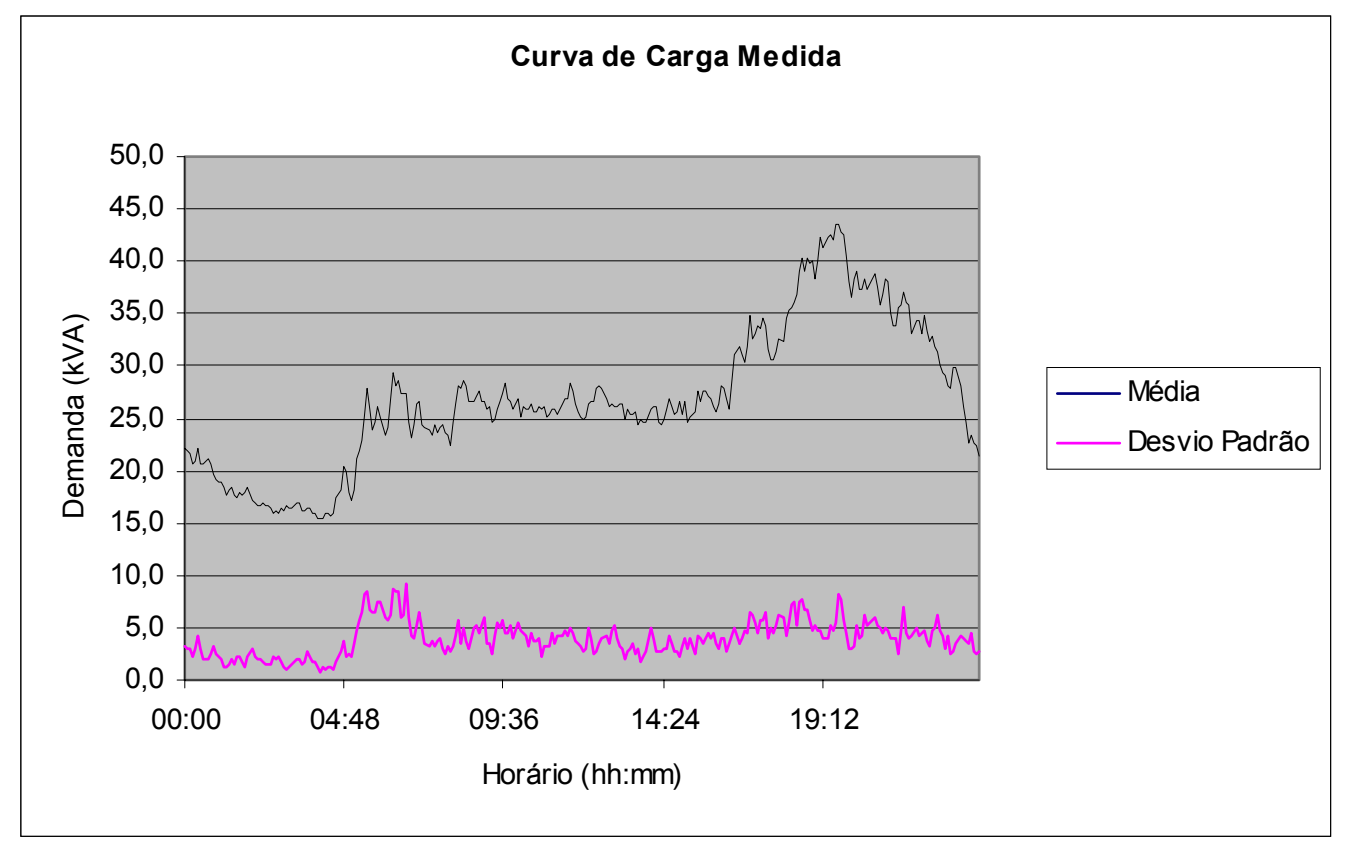

Figura 5.4 - Curva de carga da ET obtida por medição

A curva de carga calculada para a mesma ET pelo PERTEC está apresentada na figura 5.5 .

Analisando essa figura verifica-se:

- o perfil da curva de carga da ET obtida na medição (figura 5.4) é semelhante ao perfil obtido na curva de carga calculada pelo PERTEC (figura 5.5); 
- pela curva de carga calculada, o carregamento máximo na ET resultou no valor de 49,8 kVA, dentro do intervalo esperado para o valor do carregamento obtido nas medições. A demanda média do carregamento do transformador é de $25,1 \mathrm{kVA}$, resultando num fator de carga de 0,504 .

A figura 5.6 apresenta um gráfico comparativo com as duas curvas médias (medida e calculada) de carga do transformador, onde pode-se verificar a semelhança de comportamento das duas curvas.

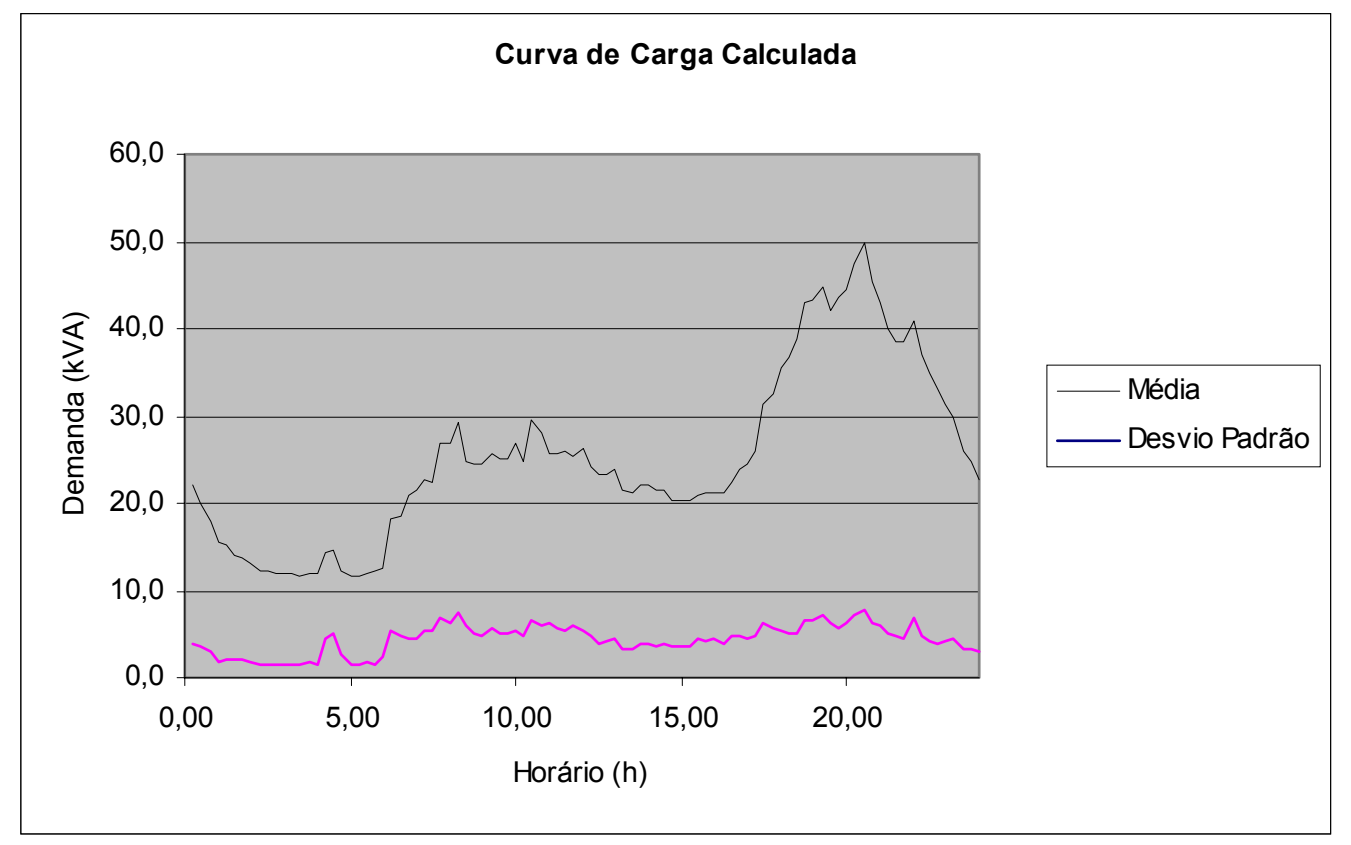

Figura 5.5 - Curva de carga da ET obtida por cálculo com o PERTEC 


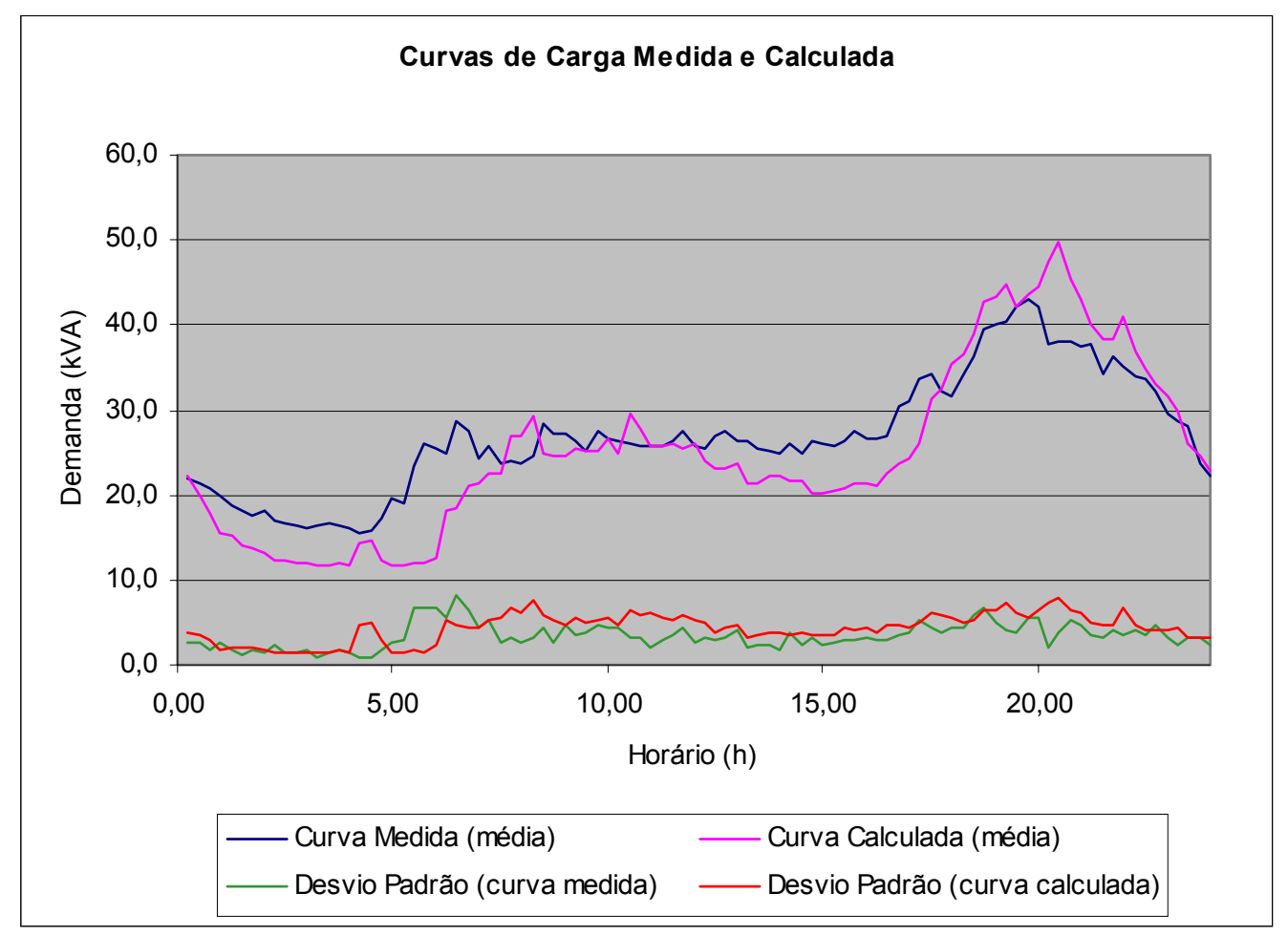

Figura 5.6 - Comparação entre curvas de carga medida e calculada

\subsection{Aplicação do Módulo de Balanço de Energia}

Após realizar o cálculo das perdas técnicas em uma parte de um sistema de distribuição,

o PERTEC determina as perdas de energia percentuais para os segmentos a seguir:

- medidor de energia;

- ramal de ligação;

- rede secundária;

- transformador de distribuição;

- rede primária;

- $\quad$ subestação de distribuição.

Os valores percentuais de perdas de energia nos segmentos citados acima foram determinados pelo PERTEC, utilizando-se os resultados por ele calculados. Os valores percentuais que foram utilizados para os segmentos sistema de alta tensão, rede reticulada e outros são valores adotados pelo Módulo de Balanço de Energia. A rede 
reticulada, como já foi explicado no capítulo anterior, é uma particularidade da concessionária onde o sistema foi implantado. As tabelas 5.24 e 5.25 apresentam os dados que foram utilizados neste exemplo.

Tabela 5.24 - Perdas de Energia por Segmento

\begin{tabular}{lc}
\hline \multicolumn{1}{c}{ Segmento } & Perda de Energia (\%) \\
\hline Sistema de Alta Tensão & 1,00 \\
\hline Subestação de Distribuição & 0,60 \\
\hline Rede Primária & 0,94 \\
\hline Transformador de Distribuição & 2,80 \\
\hline Rede Secundária & 1,00 \\
\hline Ramal de Ligação & 0,26 \\
\hline Medidor de Energia & 0,56 \\
\hline Rede Reticulada & 1,00 \\
\hline Outros & $10,0 *$ \\
\hline
\end{tabular}

Tabela 5.25 - Energia Faturada por nível de faturamento

\begin{tabular}{lc}
\hline \multicolumn{1}{c}{ Níveis de Faturamento } & Energia Faturada (MWh) \\
\hline Baixa Tensão & 80.000 \\
\hline Média Tensão & 10.000 \\
\hline Alta Tensão & 5.000 \\
\hline Rede Reticulada & 5.000 \\
\hline
\end{tabular}

Vale lembrar que os dados apresentados nas tabelas 5.24 e 5.25 são dados hipotéticos apenas para exemplificar o uso do Módulo de Balanço de Energia.

$\mathrm{O}$ balanço de energia foi feito de duas maneiras diferentes. Na primeira, admitiu-se que a energia total adquirida nos pontos de fronteira era um dado conhecido. Nesse caso, utilizou-se uma energia de entrada de 110000 MWh. Na segunda maneira, admitiu-se que o nível de perdas não técnicas era o dado conhecido. Nesse caso, adotou-se um valor de 5,0\% para as perdas não técnicas.

Como já foi explicado na capítulo 3, o Módulo de Balanço de Energia calcula as perdas de energia em MWh em cada segmento assumindo que o nível percentual de perda de energia é expresso em função da energia que entra no segmento. As únicas exceções são o segmento outros e as perdas não técnicas.

No segmento outros, o nível percentual de perda de energia é expresso em função do total de perdas técnicas. O programa também calcula esse valor em função da energia que entra no sistema.

Para as perdas não técnicas, o valor percentual de entrada definido pelo usuário ou 
calculado pelo programa é expresso em função da energia que entra no sistema.

As tabelas 5.26 e 5.27 apresentam, respectivamente, os resultados do cálculo efetuado pelo Módulo de Balanço de Energia quando se conhece a energia total adquirida nos pontos de fronteira e quando se conhece o valor percentual das perdas não técnicas. Nessas tabelas estão as perdas de energia calculadas em cada segmento, os totais de perdas técnicas e não técnicas e o total de perdas de energia em MWh. Também são mostrados os valores percentuais das perdas de energia expressos em função da energia que entra no segmento e em função da energia que entra no sistema.

Tabela 5.26 - Resultados obtidos para energia de entrada de $110000 \mathrm{MWh}$

\begin{tabular}{lccc}
\hline \multirow{2}{*}{ Segmento } & & \multicolumn{2}{c}{ Perda de Energia (\%) X } \\
& Energia... \\
\cline { 2 - 4 } & & \multicolumn{2}{c}{$\begin{array}{c}\text { E. } \\
\text { montante do ...de entrada no } \\
\text { sistema }\end{array}$} \\
\hline Sistema de Alta Tensão & $1.064,29$ & 0,60 & 0,97 \\
\hline Subestação de Distribuição & 602,19 & 0,94 & 0,55 \\
\hline Rede Primária & 890,30 & 2,80 & 0,81 \\
\hline Transformador de Distribuição & $2.347,02$ & 1,00 & 2,13 \\
\hline Rede Secundária & 814,75 & 0,26 & 0,74 \\
\hline Ramal de Ligação & 209,72 & 0,56 & 0,19 \\
\hline Medidor de Energia & 450,52 & 1,00 & 0,41 \\
\hline Rede Reticulada & 50,51 & 0,58 & 0,05 \\
\hline Outros & 642,93 & - & 0,58 \\
\hline Perdas Técnicas & $7.072,22$ & 6,43 \\
\hline Perdas Não Técnicas & $2.927,78$ & - & 2,66 \\
\hline Total de Perdas de Energia & $10.000,00$ & 9,09 \\
\hline
\end{tabular}

Tabela 5.27 - Resultados obtidos para perdas não técnicas de 5,0\%

\begin{tabular}{lccc}
\hline \multirow{2}{*}{ Segmento } & & \multicolumn{2}{c}{$\begin{array}{c}\text { Perda de Energia (\%) X } \\
\text { Energia... }\end{array}$} \\
\cline { 2 - 4 } & Perda de Energia (MWh) & $\begin{array}{c}\text {... } \\
\text { montante do ...de entrada no } \\
\text { segmento }\end{array}$ & sistema \\
\hline Sistema de Alta Tensão & $1.064,29$ & 1,00 & 0,94 \\
\hline Subestação de Distribuição & 602,19 & 0,60 & 0,53 \\
\hline Rede Primária & 890,30 & 0,94 & 0,79 \\
\hline Transformador de Distribuição & $2.347,02$ & 2,80 & 2,08 \\
\hline Rede Secundária & 814,75 & 1,00 & 0,72 \\
\hline Ramal de Ligação & 209,72 & 0,26 & 0,19 \\
\hline Medidor de Energia & 450,52 & 0,56 & 0,40 \\
\hline Rede Reticulada & 50,51 & 1,00 & 0,04 \\
\hline Outros & 642,93 & 0,57 & 0,57 \\
\hline Perdas Técnicas & $7.072,22$ & - & 6,27 \\
\hline Perdas Não Técnicas & $5.635,38$ & - & 5,00 \\
\hline Total de Perdas de Energia & $12.707,60$ & - & 11,27 \\
\hline
\end{tabular}


No segundo caso, em que se conhece as perdas não técnicas (em \%), a energia de entrada calculada foi 112707,60 MWh.

Nota-se que nos dois casos, as perdas técnicas em MWh são as mesmas, mudando apenas os valores percentuais expressos em função da energia que entra no sistema.

\subsection{Análise da Influência do Fator de Perdas}

Como já foi mostrado no capítulo 2, a maioria dos autores pesquisados apresentam metodologias que calculam as perdas de energia de forma indireta, ou seja, a partir da perda de demanda no horário de ponta e do fator de perdas, sendo que o fator de perdas é estimado a partir do fator de carga pela expressão (3.1).

A partir dos resultados obtidos utilizando-se a metodologia proposta neste trabalho, que realiza o cálculo das perdas de energia de forma direta, ou seja, a partir da curva de carga em cada componente, será mostrado como o cálculo indireto pode introduzir erros no resultado final das perdas de energia. Em outras palavras, será mostrado como o fator de perdas pode influir nos resultados do cálculo das perdas de energia quando se realiza o cálculo indireto.

A análise de influência foi realizada para os segmentos rede secundária, transformador de distribuição e rede primária.

Para cada segmento, conhecendo-se os resultados do cálculo para diversos componentes, foi possível calcular para cada componente:

- o fator de carga e o fator de perdas e, consequentemente, o valor de $k$ a ser utilizado na expressão (3.1) de forma que o cálculo indireto produza o mesmo resultado do cálculo direto;

- a perda de energia por cálculo indireto a partir da perda de demanda (resultado do cálculo direto com a metodologia proposta neste trabalho), utilizando-se $k$ igual a 0,15 e $k$ igual a 0,30 (valores usuais utilizados no setor elétrico brasileiro);

- o erro percentual da perda de energia obtida por cálculo indireto em relação à perda de energia obtida por cálculo direto;

- o valor médio de $k$ para o segmento. 


\subsubsection{Rede Secundária}

Neste segmento, foram consideradas 22678 redes secundárias na análise. A tabela 5.28 mostra os resultados obtidos para algumas dessas redes.

Tabela 5.28 - Perdas de Energia para Rede Secundária

\begin{tabular}{|c|c|c|c|c|c|c|}
\hline \multirow{3}{*}{$\begin{array}{c}\text { Rede } \\
\text { Secundária }\end{array}$} & \multicolumn{3}{|c|}{ Perdas de Energia (kWh) } & \multirow{3}{*}{$\begin{array}{c}\text { Valor } \\
\text { Correto de } \\
k\end{array}$} & \multirow{2}{*}{\multicolumn{2}{|c|}{$\begin{array}{c}\text { Erros } \\
(\%)\end{array}$}} \\
\hline & \multirow{2}{*}{$\begin{array}{l}\text { Cálculo } \\
\text { Direto }\end{array}$} & \multicolumn{2}{|c|}{ Cálculo Indireto } & & & \\
\hline & & $k=0,15$ & $k=\mathbf{0 , 3 0}$ & & $k=0,15$ & $k=\mathbf{0 , 3 0}$ \\
\hline 1 & 604,36 & 720,50 & 768,96 & $-0,21$ & 19,22 & 27,24 \\
\hline 2 & 193,50 & 203,64 & 220,09 & 0,06 & 5,24 & 13,74 \\
\hline 3 & 266,42 & 203,98 & 225,15 & 0,59 & $-23,44$ & $-15,49$ \\
\hline 4 & 219,11 & 207,43 & 223,06 & 0,26 & $-5,33$ & 1,80 \\
\hline 5 & 482,86 & 488,05 & 520,80 & 0,13 & 1,08 & 7,86 \\
\hline 6 & 96,41 & 110,93 & 119,57 & $-0,10$ & 15,06 & 24,02 \\
\hline 7 & 113,67 & 48,06 & 59,38 & 1,02 & $-57,72$ & $-47,77$ \\
\hline
\end{tabular}

É interessante notar como o valor de $k$ varia de componente para componente, aparecendo até valores menores que zero e maiores que 1,0, o que indica que o fator de perdas $f_{p}$ não se encontra na faixa $f_{c}^{2} \leq f_{p} \leq f_{c}$, onde $f_{c}$ é o fator de carga. Isso se deve ao fato de que esta conclusão $\left(f_{c}^{2} \leq f_{p} \leq f_{c}\right)$ só é válida para cada trecho de uma rede, e não para a rede toda.

$\mathrm{Na}$ realidade, cada trecho de rede secundária possui um fator de perdas diferente, pois cada trecho está submetido a uma diferente curva de carga. Ao calcular o fator de perdas a partir da expressão (3.1), comete-se erros, pois esta expressão não poderia se aplicada para todo o circuito, e sim, trecho a trecho.

As figuras a seguir ilustram melhor os resultados obtidos para as 22678 redes secundárias consideradas nesta análise. A figura 5.7 mostra um gráfico de dispersão onde estão os valores de $k$ para cada rede secundária e a figura 5.8 mostra como esses valores se distribuem ao longo de 20 faixas. 


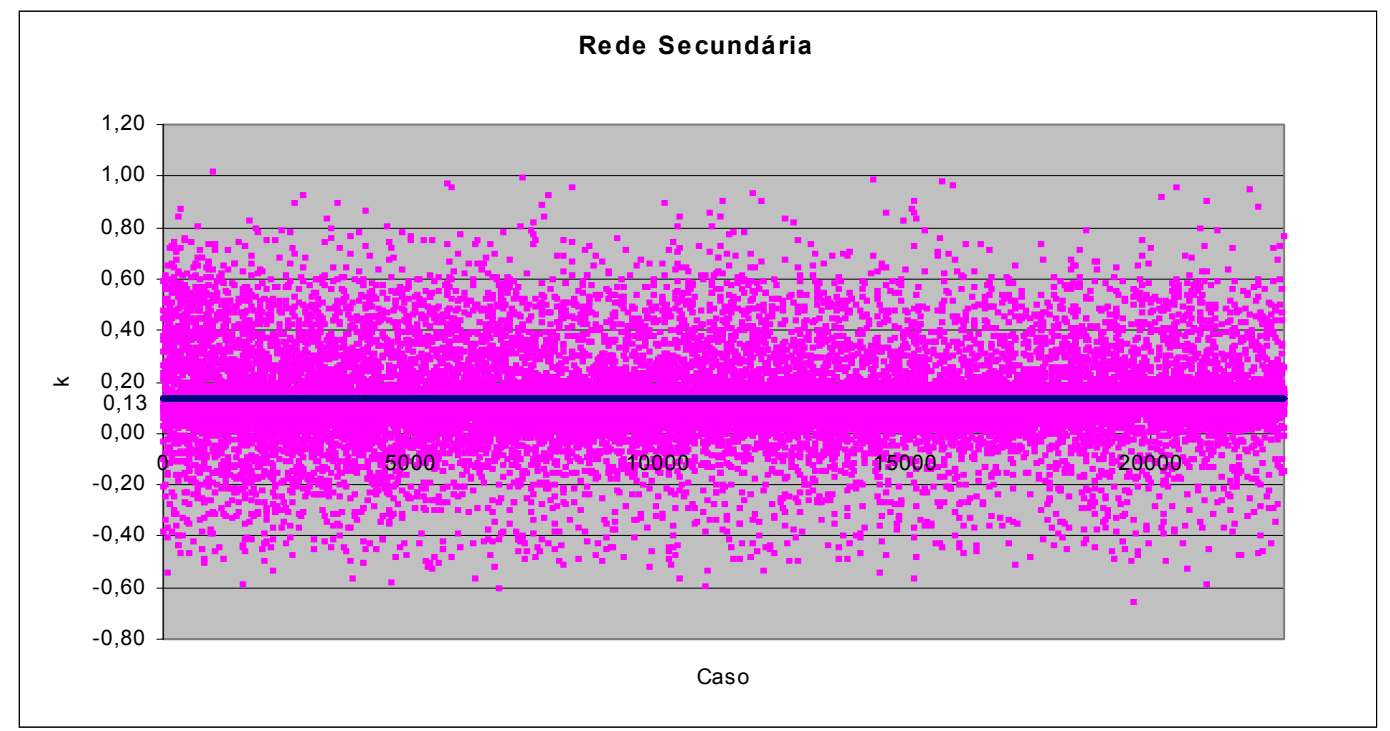

Figura 5.7 - Gráfico de dispersão (valores de $\mathrm{k}$ para cada rede secundária)

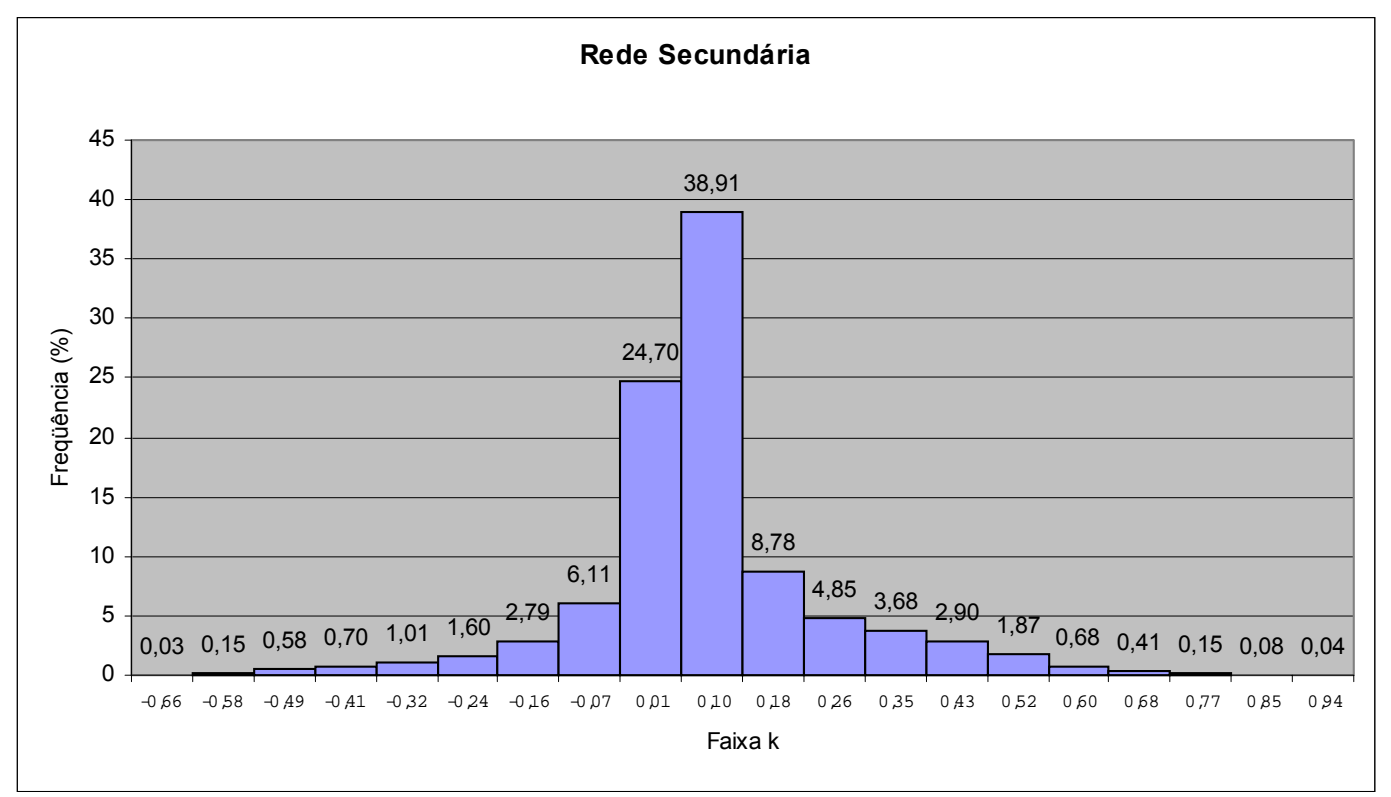

Figura 5.8 - Distribuição dos valores de $\mathrm{k}$ ao longo de 20 faixas

Na figura 5.7, a linha azul indica o valor médio de $k$ para o segmento rede secundária. Considerando as redes analisadas, o valor médio observado foi 0,13 com desvio padrão de 0,17 . A figura 5.8 mostra melhor a dispersão observada e nota-se que os valores mais freqüentes de $k$ encontram-se entre 0,10 e 0,18 , representando $38,91 \%$ das redes secundárias analisadas. 


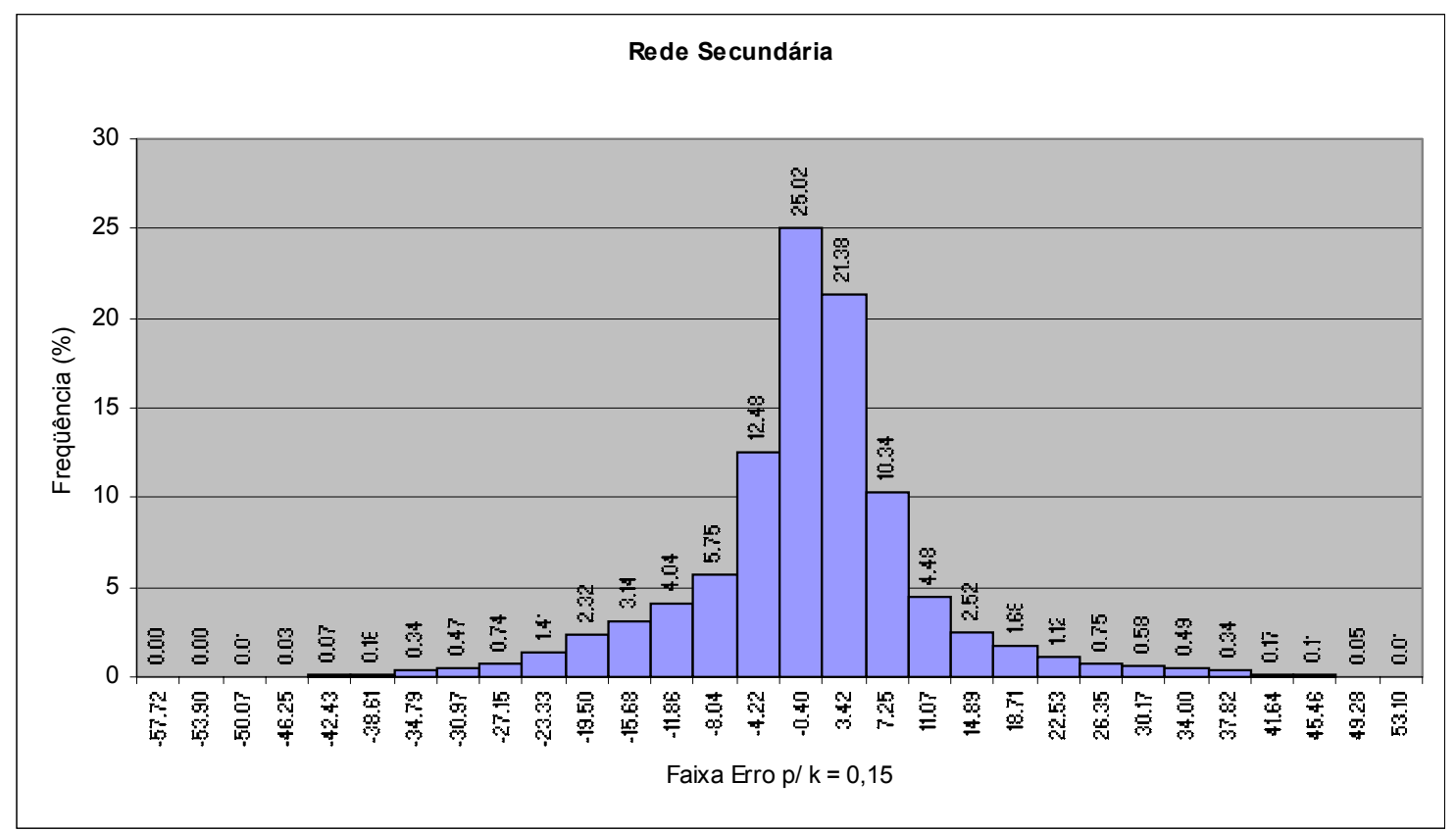

Figura 5.9 - Distribuição dos erros para $\mathrm{k}=0,15$ ao longo de 30 faixas

Também foi traçado o histograma dos erros percentuais do cálculo indireto em relação ao cálculo direto quando se utiliza $k$ igual a 0,15 e 0,30 . Esses histogramas são apresentados nas figuras 5.9 e 5.10 .

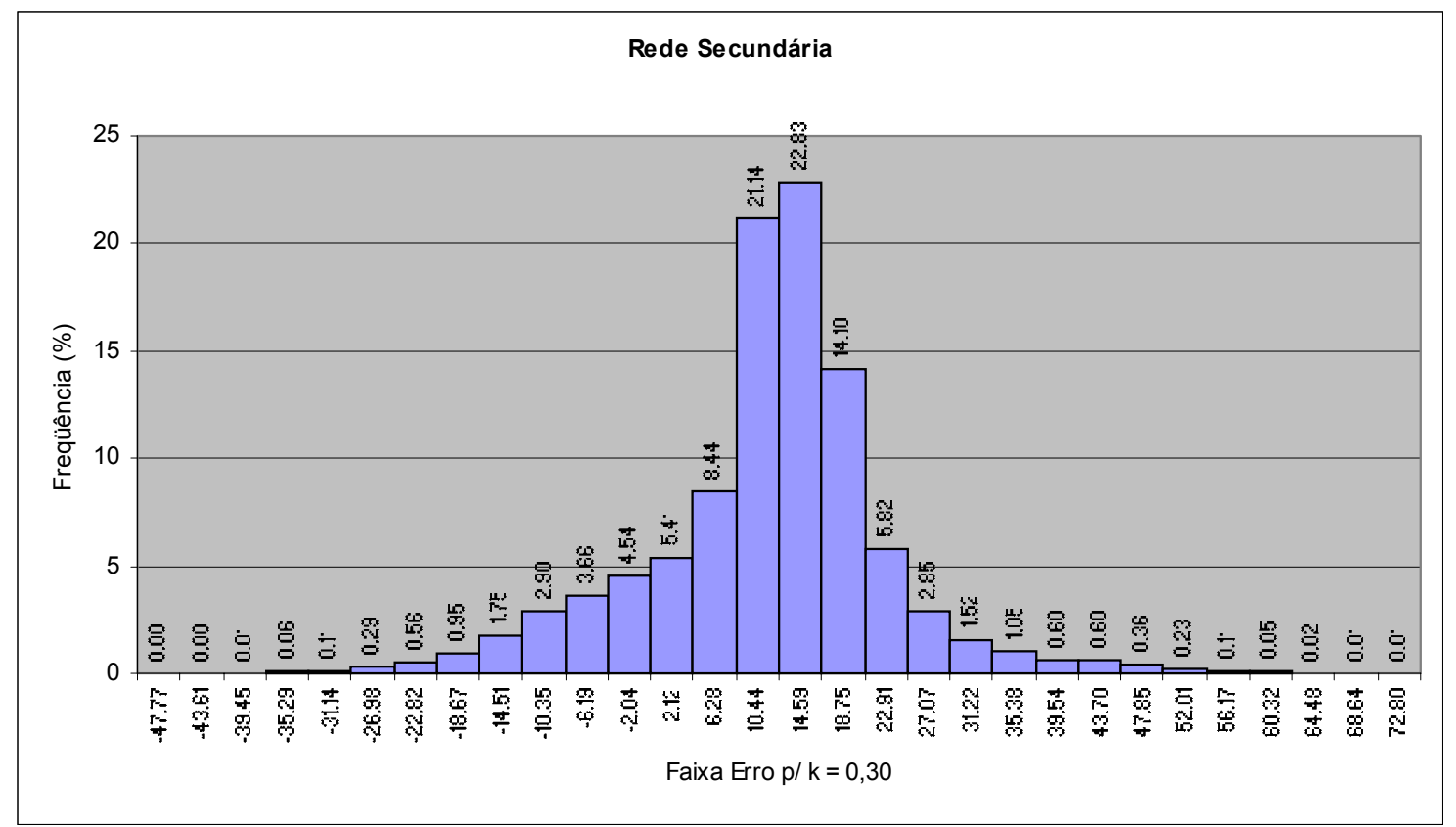

Figura 5.10 - Distribuição dos erros para $\mathrm{k}=0,30$ ao longo de 30 faixas

Pode-se observar pela figura 5.9 que grande quantidade das redes secundárias $(64,63 \%)$ apresentam erros razoavelmente pequenos, entre $-8,04 \%$ e $7,25 \%$, quando se utiliza $k$ 
igual a 0,15 no cálculo indireto das perdas de energia. $\mathrm{O}$ restante das redes secundárias $(35,37 \%)$ apresentam erros mais elevados, entre $-8,04 \%$ e $-57,72 \%$ ou entre $7,25 \%$ e $56,93 \%$.

De forma análoga, pode-se observar pela figura 5.10 que apenas $24,95 \%$ das redes secundárias apresentam erros entre $-10,35 \%$ e $10,44 \%$ quando se utiliza $k$ igual a 0,30 no cálculo indireto das perdas de energia. A maioria delas $(75,05 \%)$ apresentam erros elevados, entre $-10,35 \%$ e $-47,77 \%$ ou entre $10,44 \%$ e $76,96 \%$. Isso já era esperado, uma vez que o valor médio de $k$ encontrado entre os casos analisados foi 0,13 .

Nota-se que ao utilizar $k$ igual a 0,15 comete-se erros menores. No entanto, deve-se notar que em muitos casos o erro observado não é desprezível.

\subsubsection{Transformador de Distribuição}

Neste segmento, foram considerados 21993 transformadores de distribuição na análise. A tabela 5.29 mostra os resultados obtidos para alguns desses transformadores. Vale ressaltar que os resultados obtidos referem-se apenas às perdas no cobre dos transformadores, uma vez que as perdas no ferro são constantes e possuem fator de perdas igual a 1,0 .

Tabela 5.29 - Perdas de Energia para Transformador de Distribuição

\begin{tabular}{|c|c|c|c|c|c|c|}
\hline \multirow{3}{*}{$\begin{array}{c}\text { Transformador } \\
\text { de } \\
\text { Distribuição }\end{array}$} & \multicolumn{3}{|c|}{ Perdas de Energia (kWh) } & \multirow{3}{*}{$\begin{array}{c}\text { Valor } \\
\text { Correto de } \\
k\end{array}$} & \multirow{2}{*}{\multicolumn{2}{|c|}{$\begin{array}{c}\text { Erros } \\
(\%)\end{array}$}} \\
\hline & \multirow{2}{*}{$\begin{array}{l}\text { Cálculo } \\
\text { Direto }\end{array}$} & \multicolumn{2}{|c|}{ Cálculo Indireto } & & & \\
\hline & & $k=0,15$ & $k=\mathbf{0 , 3 0}$ & & $k=0,15$ & $k=\mathbf{0 , 3 0}$ \\
\hline 1 & 551,99 & 417,20 & 462,71 & 0,59 & $-24,42$ & $-16,17$ \\
\hline 2 & 97,02 & 98,33 & 108,99 & 0,13 & 1,35 & 12,34 \\
\hline 3 & 186,28 & 168,89 & 182,54 & 0,34 & $-9,33$ & $-2,01$ \\
\hline 4 & 14,66 & 12,42 & 13,61 & 0,43 & $-15,25$ & $-7,18$ \\
\hline 5 & 335,63 & 327,28 & 349,24 & 0,21 & $-2,49$ & 4,05 \\
\hline 6 & 193,94 & 161,18 & 176,90 & 0,46 & $-16,89$ & $-8,79$ \\
\hline 7 & 103,63 & 102,18 & 110,14 & 0,18 & $-1,40$ & 6,28 \\
\hline
\end{tabular}

As figuras a seguir ilustram melhor os resultados obtidos para os 21993 transformadores de distribuição considerados nesta análise. A figura 5.11 mostra um gráfico de dispersão onde estão os valores de $k$ para cada transformador e a figura 5.12 mostra como esses valores se distribuem ao longo de 20 faixas. 


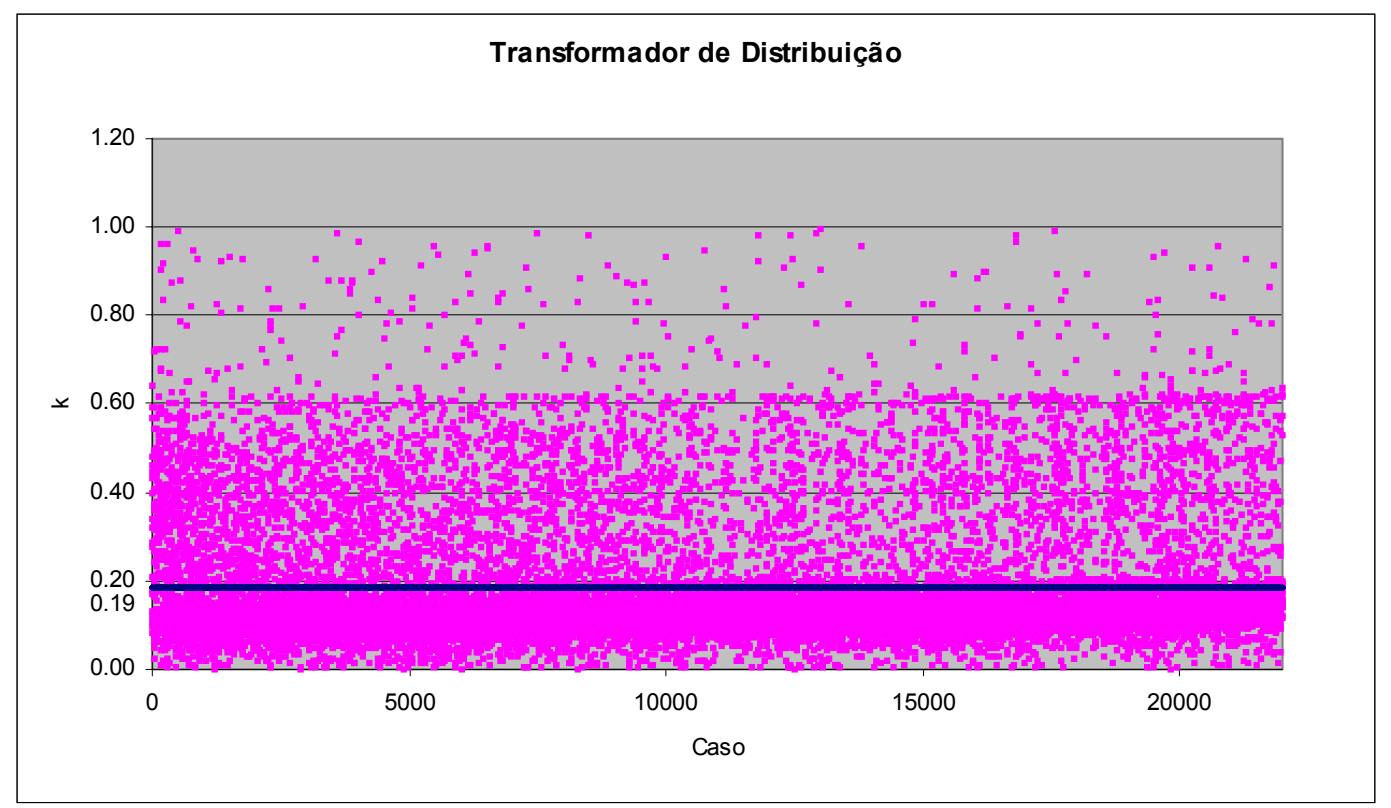

Figura 5.11 - Gráfico de dispersão (valores de $\mathrm{k}$ para cada transformador de distribuição)

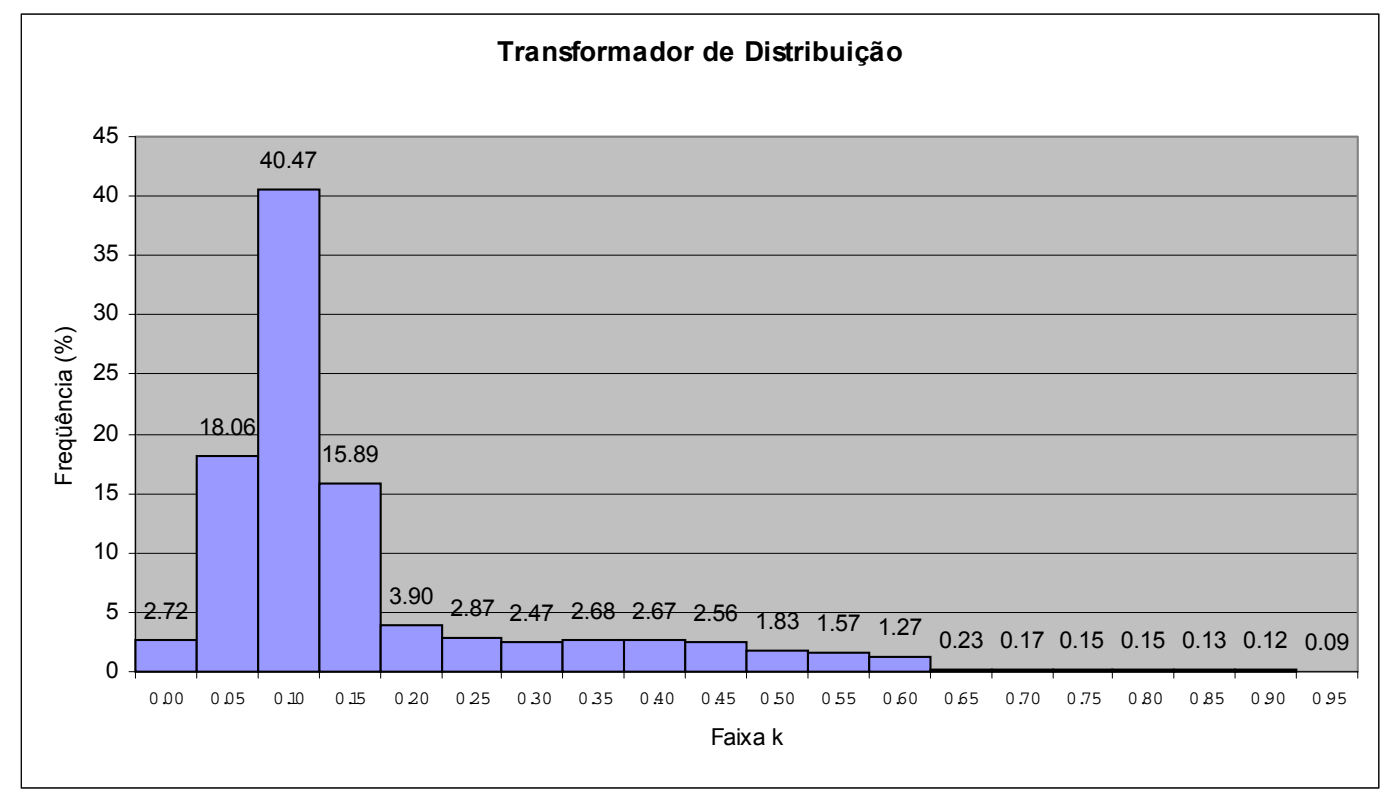

Figura 5.12 - Distribuição dos valores de $\mathrm{k}$ ao longo de 20 faixas

$\mathrm{Na}$ figura 5.11, a linha azul indica o valor médio de $k$ para o segmento transformador de distribuição. Considerando os transformadores analisados, o valor médio observado foi 0,19 com desvio padrão de 0,14 . A figura 5.12 mostra melhor a dispersão observada e nota-se que os valores mais freqüentes de $k$ encontram-se entre 0,10 e 0,15 , representando $40,47 \%$ dos transformadores analisados. 


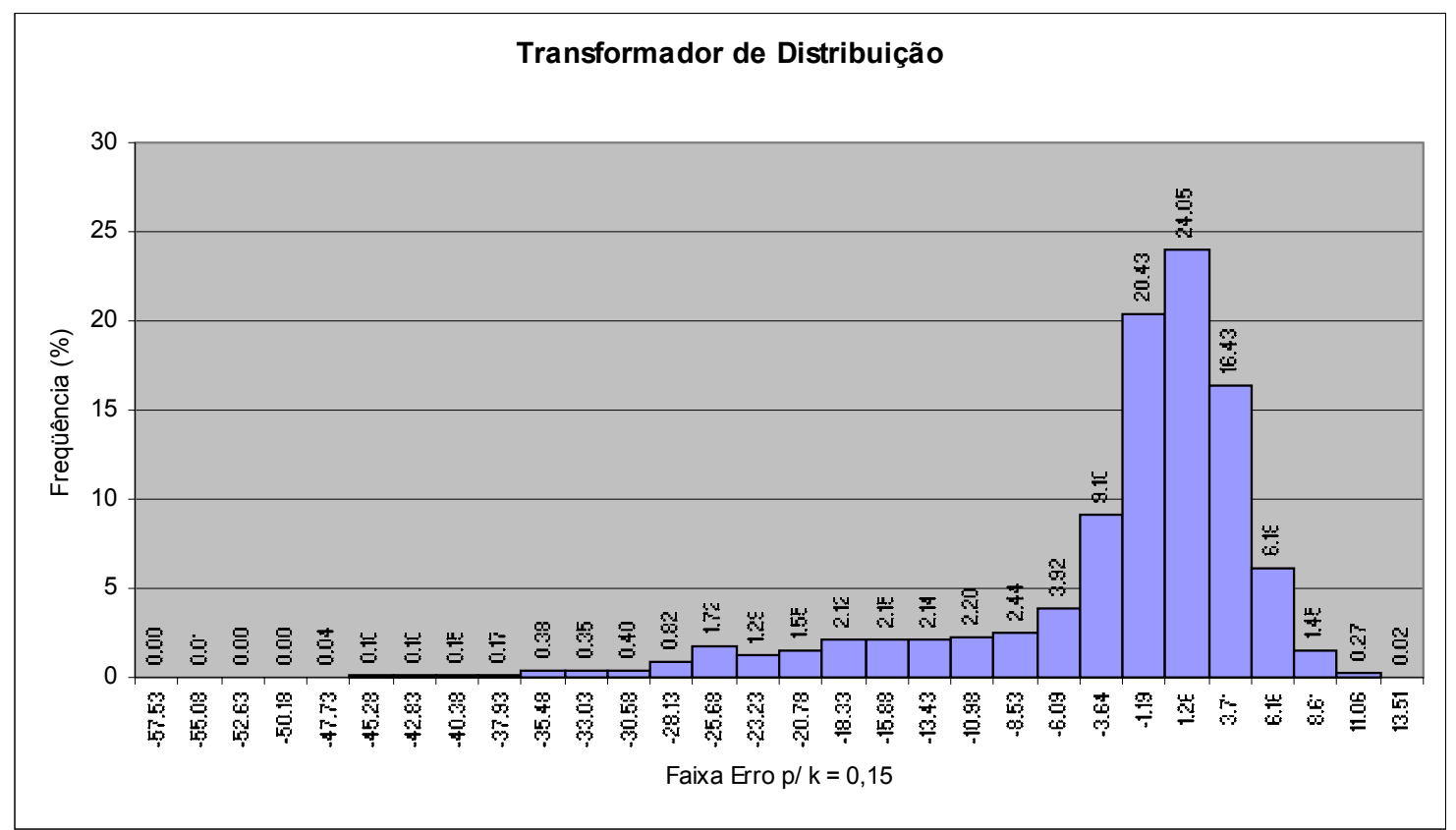

Figura 5.13 - Distribuição dos erros para $\mathrm{k}=0,15$ ao longo de 30 faixas

Também foi traçado o histograma dos erros percentuais do cálculo indireto em relação ao cálculo direto quando se utiliza $k$ igual a 0,15 e 0,30 . Esses histogramas são apresentados nas figuras 5.13 e 5.14 .

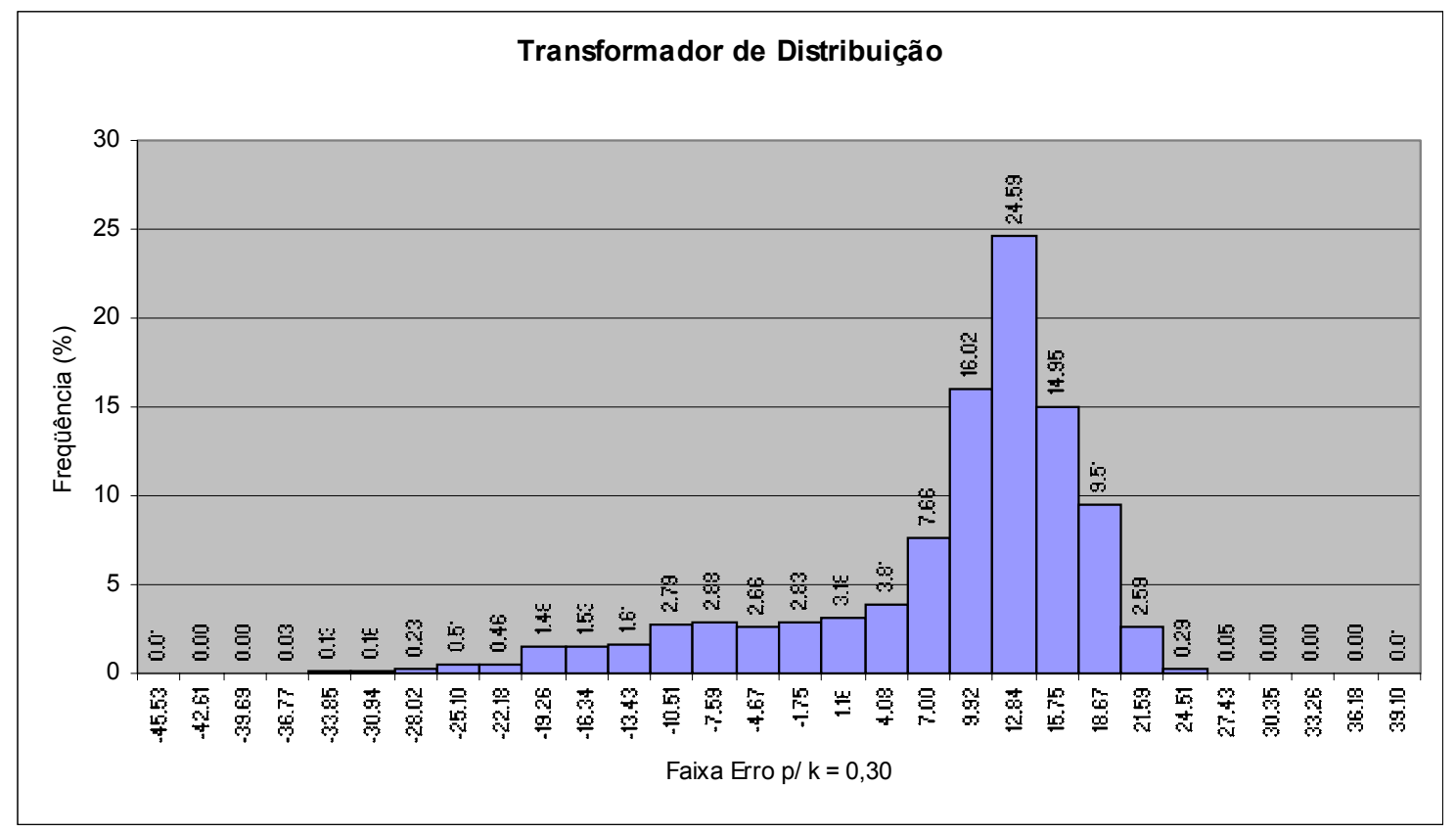

Figura 5.14 - Distribuição dos erros para $\mathrm{k}=0,30$ ao longo de 30 faixas

Pode-se observar pela figura 5.13 que grande quantidade dos transformadores $(82,55 \%)$ 
apresentam erros razoavelmente pequenos, entre $-8,53 \%$ e $8,61 \%$, quando se utiliza $k$ igual a 0,15 no cálculo indireto das perdas de energia. $\mathrm{O}$ restante dos transformadores $(17,45 \%)$ apresentam erros maiores, entre $-8,83 \%$ e $-57,53 \%$ ou entre $8,61 \%$ e $15,95 \%$.

De forma análoga, pode-se observar pela figura 5.14 que apenas 23,02\% dos transformadores apresentam erros entre $-7,59 \%$ e $9,92 \%$ quando se utiliza $k$ igual a 0,30 no cálculo indireto das perdas de energia. A maioria deles (76,98\%) apresentam erros elevados, entre $-7,59 \%$ e $-45,53 \%$ ou entre $9,92 \%$ e $42,02 \%$.

Para o valor médio de $k$ encontrado entre os casos analisados $(0,19)$, nota-se que, ao utilizar $k$ igual a 0,15 no cálculo indireto das perda de energia, comete-se erros menores.

\subsubsection{Rede Primária}

Neste segmento, foram consideradas 905 redes primárias na análise. A tabela 5.30 mostra os resultados obtidos para algumas dessas redes.

Tabela 5.30 - Perdas de Energia para Rede Primária

\begin{tabular}{|c|c|c|c|c|c|c|}
\hline \multirow{3}{*}{$\begin{array}{c}\text { Rede } \\
\text { Primária }\end{array}$} & \multicolumn{3}{|c|}{ Perdas de Energia (kWh) } & \multirow{3}{*}{$\begin{array}{c}\text { Valor } \\
\text { Correto de } \\
k\end{array}$} & \multirow{2}{*}{\multicolumn{2}{|c|}{$\begin{array}{c}\text { Erros } \\
(\%)\end{array}$}} \\
\hline & \multirow{2}{*}{$\begin{array}{l}\text { Cálculo } \\
\text { Direto }\end{array}$} & \multicolumn{2}{|c|}{ Cálculo Indireto } & & & \\
\hline & & $k=0,15$ & $k=\mathbf{0 , 3 0}$ & & $k=0,15$ & $k=\mathbf{0 , 3 0}$ \\
\hline 1 & 693,92 & 679,30 & 699,72 & 0,26 & $-2,11$ & 0,84 \\
\hline 2 & 494,66 & 470,89 & 499,68 & 0,27 & $-4,81$ & 1,02 \\
\hline 3 & 975,87 & 923,62 & 968,04 & 0,33 & $-5,35$ & $-0,80$ \\
\hline 4 & 210,46 & 255,24 & 270,82 & $-0,28$ & 21,28 & 28,68 \\
\hline 5 & 958,84 & 1132,62 & 1244,25 & $-0,08$ & 18,12 & 29,77 \\
\hline 6 & 2,75 & 2,13 & 2,40 & 0,48 & $-22,59$ & $-12,42$ \\
\hline 7 & 3322,88 & 2603,07 & 2718,57 & 1,08 & $-21,66$ & $-18,19$ \\
\hline
\end{tabular}

De forma análoga à rede secundária, é interessante notar como o valor de $k$ varia de componente para componente, aparecendo até valores menores que zero e maiores que 1,0 , o que indica que o fator de perdas $f_{p}$ não se encontra na faixa $f_{c}^{2} \leq f_{p} \leq f_{c}$, onde $f_{c}$ é o fator de carga.

As figuras a seguir ilustram melhor os resultados obtidos para as 905 redes primárias consideradas nesta análise. 


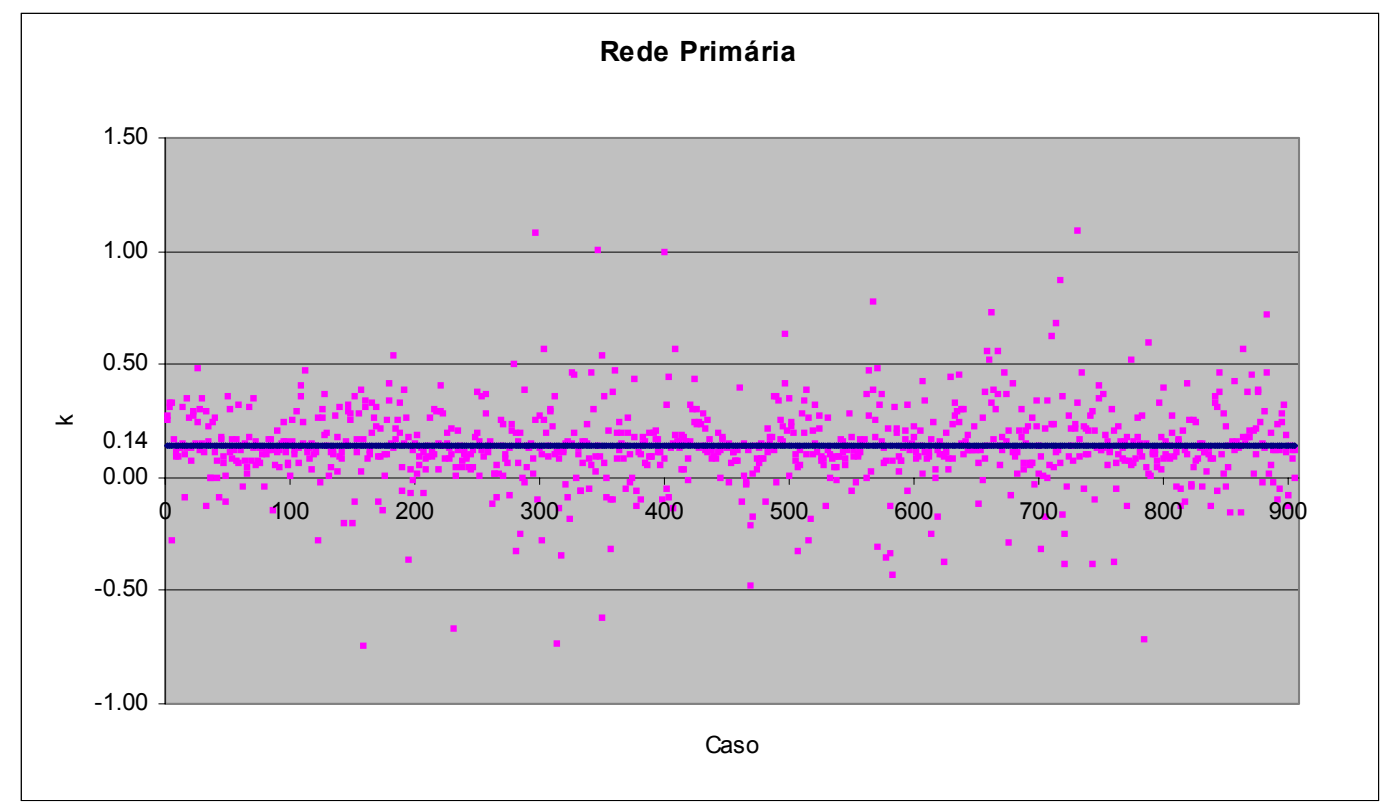

Figura 5.15 - Gráfico de dispersão (valores de k para cada rede primária)

A figura 5.15 mostra um gráfico de dispersão onde estão os valores de $k$ para cada rede primária e a figura 5.16 mostra como esses valores se distribuem ao longo de 20 faixas.

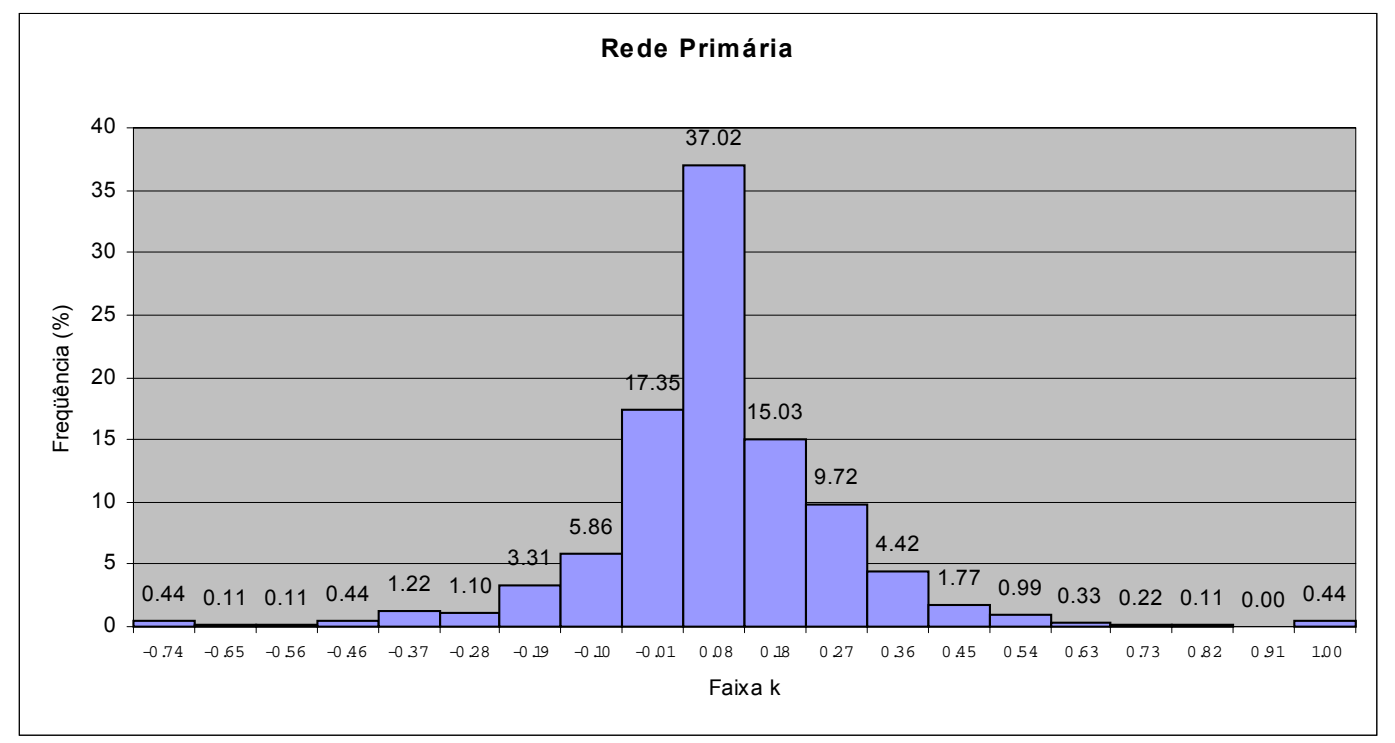

Figura 5.16-Distribuição dos valores de $\mathrm{k}$ ao longo de 20 faixas

$\mathrm{Na}$ figura 5.15, a linha azul indica o valor médio de $k$ para o segmento rede primária. Considerando as redes analisadas, o valor médio observado foi 0,14 com desvio padrão de 0,18 . A figura 5.16 mostra melhor a dispersão observada e nota-se que os valores 
mais freqüentes de $k$ encontram-se entre 0,08 e 0,18 , representando $37,02 \%$ das redes primárias analisadas.

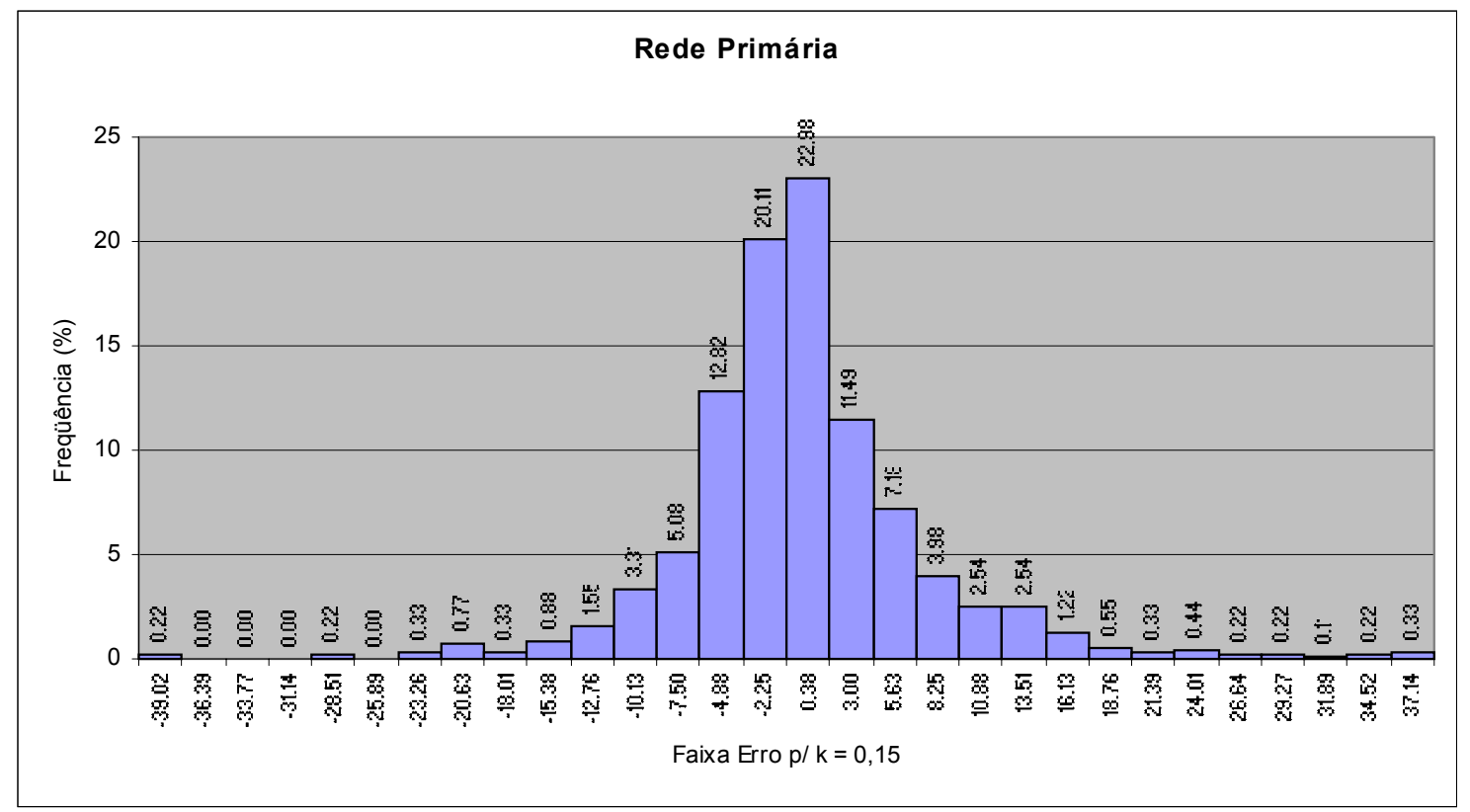

Figura 5.17 - Distribuição dos erros para $\mathrm{k}=0,15$ ao longo de 30 faixas

Também foi traçado o histograma dos erros percentuais do cálculo indireto em relação ao cálculo direto quando se utiliza $k$ igual a 0,15 e 0,30 . Esses histogramas são apresentados nas figuras 5.17 e 5.18 .

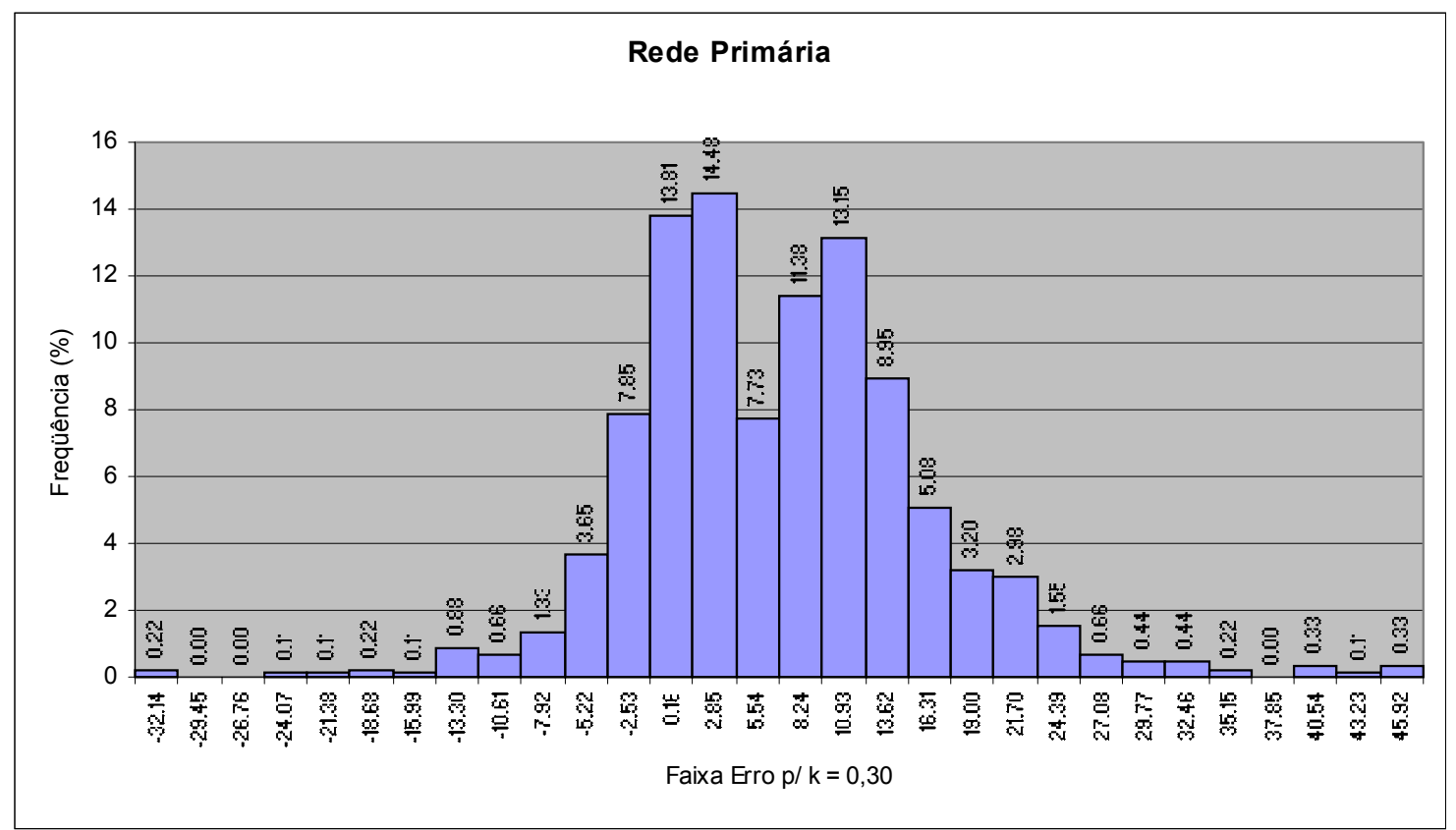

Figura 5.18 - Distribuição dos erros para $\mathrm{k}=0,30$ ao longo de 30 faixas 
Pode-se observar pela figura 5.17 que grande quantidade das redes primárias $(79,66 \%)$ apresentam erros razoavelmente pequenos, entre $-7,50 \%$ e $8,25 \%$, quando se utiliza $k$ igual a 0,15 no cálculo indireto das perdas de energia. $\mathrm{O}$ restante das redes primárias $(20,34 \%)$ apresentam erros mais elevados, entre $-7,50 \%$ e $-39,02 \%$ ou entre $8,25 \%$ e $39,77 \%$.

De forma análoga, pode-se observar pela figura 5.18 que 48,85\% das redes primárias apresentam erros entre $-7,92 \%$ e $8,24 \%$ quando se utiliza $k$ igual a 0,30 no cálculo indireto das perdas de energia. No entanto, grande parte delas $(51,15 \%)$ apresentam erros elevados, entre $-7,92 \%$ e $-32,14 \%$ ou entre $8,24 \%$ e $48,62 \%$.

Para o valor médio de $k$ encontrado entre os casos analisados $(0,14)$, nota-se que, ao utilizar $k$ igual a 0,15 no cálculo indireto das perda de energia, comete-se erros menores.

Pelo exposto acima, observa-se que ao realizar o cálculo indireto das perdas de energia pode-se estar incorrendo em erros consideráveis em muitos componentes de cada segmento.

Outro fato que merece atenção diz respeito ao valor de $k$, que pode apresentar valores diferentes para cada segmento. $\mathrm{Na}$ análise que foi realizada aqui, as diferenças observadas entre os 3 segmentos foram pequenas e os resultados obtidos podem variar um pouco dependendo do universo escolhido para análise.

Nota-se também que o valor de $k$ varia bastante de componente para componente dentro de um mesmo segmento, o que leva a grandes variações no fator de perdas e, consequentemente, nas perdas de energia.

Portanto, quando se deseja um cálculo de perdas de energia mais preciso, a melhor opção é utilizar o cálculo direto quando se dispõe das curvas de carga em cada componente do sistema de distribuição.

\subsection{Comparação com Outras Metodologias}

A seguir será realizada uma comparação dos resultados obtidos com a metodologia proposta neste trabalho com os resultados obtidos com outras metodologias apresentadas na revisão bibliográfica (capítulo 2). 
Nesta comparação, serão considerados apenas os segmentos rede secundária, transformador de distribuição e rede primária. Também foram consideradas apenas a metodologia proposta pelo CODI [3] e pelo CCON [12] e a metodologia proposta por Bacelar [1], pois a maior parte das metodologias apresentadas tratavam apenas de alguns procedimentos utilizados por algumas concessionárias, como recomendações ou sistemas informatizados para o cálculo das perdas.

Para realizar a comparação, uma boa parte dos dados necessários foram resultados de cálculo com o PERTEC. Em cada um dos itens a seguir serão apresentadas as comparações para cada segmento e também será explicado como foram obtidos os dados para a aplicação das metodologias.

\subsubsection{Rede Secundária}

Neste segmento, comparou-se os resultados obtidos com a metodologia proposta neste trabalho (Metodologia da Curva de Carga) com os resultados obtidos pelas expressões (2.13) a (2.15) do CODI / CCON. As expressões (2.10) e (2.11) não foram utilizadas por necessitarem da queda de tensão no circuito secundário, um dado que não foi possível obter dos resultados de cálculo com o PERTEC. Pelo mesmo motivo não foi possível aplicar as expressões (2.16) e (2.17) propostas por Bacelar [1].

As expressões (2.13) e (2.14) do CODI / CCON foram aplicadas a um universo de 328 transformadores SEC trifásicos, representando uma potência instalada total de 47985 kVA. Essas expressões destinam-se ao cálculo da perda de demanda. Em seguida, a perda de energia é calculada por (2.15).

Para os 328 transformadores selecionados, a tensão secundária utilizada foi $220 \mathrm{~V}$ e o fator de potência típico foi 0,95 (os mesmos valores utilizados no cálculo com o PERTEC). Foi adotado um fator de desequilíbrio igual a 1,1 e um fator de coincidência igual a 0,9 .

A partir da base de dados contendo todas as redes secundárias trecho a trecho, foi possível determinar o número médio de postes para as redes secundárias associadas aos transformadores SEC de potência $q$. Também foi possível determinar os tipos de cabos mais freqüentemente utilizados nos circuitos secundários.

A partir dos resultados obtidos com o PERTEC, foi possível calcular o fator de 
utilização médio quadrático dos transformadores SEC de potência $q$, uma vez que era conhecida a demanda máxima em cada transformador.

O fator de carga médio dos 328 transformadores foi calculado, resultando 0,569 e foi utilizado $k=0,15$ para calcular o fator de perdas pela expressão (3.1).

A tabela 5.31 apresenta os valores típicos das redes secundárias associadas aos transformadores SEC de potência $q$ que foram utilizados na aplicação da expressão (2.13).

Tabela 5.31 - Dados utilizados para a aplicação da expressão (2.13)

\begin{tabular}{cccccc}
\hline Potência (kVA) & $\begin{array}{c}\text { Quantidade de } \\
\text { Transfomadores } \\
\text { SEC }\end{array}$ & $\begin{array}{c}\text { Fator de } \\
\text { Utilização }\end{array}$ & $\begin{array}{c}\text { Número Médio } \\
\text { de Postes }\end{array}$ & Cabo 1 & Cabo 2 \\
\hline 30 & 9 & 0,443 & 11,7 & $1 / 0 \mathrm{~A}$ & $6 \mathrm{C}$ \\
\hline 45 & 17 & 0,389 & 10,7 & $1 / 0 \mathrm{~A}$ & $6 \mathrm{C}$ \\
\hline 75 & 79 & 0,412 & 11,3 & $1 / 0 \mathrm{~A}$ & $6 \mathrm{C}$ \\
\hline 112,5 & 28 & 0,459 & 8,8 & $336 \mathrm{~A}$ & $3 / 0 \mathrm{~A}$ \\
\hline 150 & 82 & 0,489 & 6,5 & $336 \mathrm{~A}$ & $3 / 0 \mathrm{~A}$ \\
\hline 225 & 111 & 0,508 & 9,2 & $336 \mathrm{~A}$ & $3 / 0 \mathrm{~A}$ \\
\hline 300 & 2 & 0,315 & 6,6 & $336 \mathrm{~A}$ & $3 / 0 \mathrm{~A}$ \\
\hline
\end{tabular}

O Cabo 1 e o Cabo 2 são, respectivamente, o cabo utilizado nos dois primeiros trechos de cada lado da rede a partir do transformador e o cabo utilizado nos demais trechos da rede.

Para a aplicação da expressão (2.14), foi utilizado um fator de utilização igual a 0,469, obtido a partir da média quadrática dos fatores de utilização de todos os transformadores SEC.

O número médio de postes obtido foi 9,2 , obtido a partir da média ponderada em relação à quantidade de transformadores SEC de potência $q$.

As resistências do Cabo 1 e do Cabo 2 foram obtidas a partir de uma média ponderada das resistências apresentadas na tabela 5.31 em relação à quantidade de transformadores SEC de potência $q$, ou seja, não foram utilizados cabos específicos na expressão (2.14). Foram utilizadas as resistências equivalentes, cujos valores calculados resultaram $0,32470 \Omega / \mathrm{km}$ para o Cabo 1 e $0,74069 \Omega / \mathrm{km}$ para o Cabo 2 .

Os resultados obtidos com a Metodologia da Curva de Carga e com a metodologia do CODI / CCON estão apresentados na tabela 5.32. Nessa tabela, o resultado da aplicação da expressão do CODI / CCON para concessionárias com banco de dados detalhado expressão (2.13) - está referenciada por CODI 1 e o resultado da aplicação da expressão 
para concessionárias com banco de dados simplificado - expressão (2.14) - está referenciado por CODI 2.

Tabela 5.32 - Comparação entre metodologias para o segmento Rede Secundária

\begin{tabular}{lccc}
\hline \multicolumn{1}{c}{ Perda de... } & $\begin{array}{c}\text { Metodologia } \\
\text { Curva de Carga }\end{array}$ & $\begin{array}{c}\text { Metodologia } \\
\text { CODI 1 }\end{array}$ & $\begin{array}{c}\text { Metodologia } \\
\text { CODI 2 }\end{array}$ \\
\hline Demanda $(\mathrm{kW})$ & 163,1 & $318.928,7$ & $3.824,5$ \\
\hline Energia $(\mathrm{kWh})$ & $42.288,8$ & $82.865 .938,5$ & $993.716,2$ \\
\hline
\end{tabular}

Para obter o total de perda de demanda com a Metodologia da Curva de Carga, também foi aplicado um fator de coincidência igual a 0,9 .

Como pode ser observado, as discrepâncias encontradas entre as metodologias foram muito grandes, de forma que foram calculadas as perdas de demanda para cada faixa de potência separadamente (apenas Metodologia CODI 1). Os resultados são mostrados na tabela 5.33 .

Tabela 5.33 - Perdas de demanda $(\mathrm{kW})$ para cada faixa de potência

\begin{tabular}{cccccc}
\hline \multirow{2}{*}{$\begin{array}{c}\text { Potência } \\
\text { (kVA) }\end{array}$} & Quantidade & $\begin{array}{c}\text { Perda Total (kW) } \\
\text { Metodologia } \\
\text { Curva de Carga }\end{array}$ & $\begin{array}{c}\text { Metodologia } \\
\text { CODI 1 }\end{array}$ & $\begin{array}{c}\text { Perda por Transformador (kW) } \\
\text { Curva de Carga }\end{array}$ & $\begin{array}{c}\text { Metodologia } \\
\text { CODI 1 }\end{array}$ \\
\hline 30 & 9 & 1,98 & 43,43 & 0,22 & 4,83 \\
\hline 45 & 17 & 3,46 & 255,50 & 0,20 & 15,03 \\
\hline 75 & 79 & 26,87 & $15.238,41$ & 0,34 & 192,89 \\
\hline 112,5 & 28 & 7,41 & $3.558,96$ & 0,26 & 127,11 \\
\hline 150 & 82 & 31,82 & $57.665,20$ & 0,39 & 703,23 \\
\hline 225 & 111 & 90,60 & $242.097,90$ & 0,82 & $2.181,06$ \\
\hline 300 & 2 & 0,93 & 69,32 & 0,47 & 34,66 \\
\hline
\end{tabular}

Nota-se que, em qualquer faixa de potência, a Metodologia CODI 1 fornece um resultado de perda de demanda bem acima do fornecido pela Metodologia da Curva de Carga. Além disso, quando se observa a perda por unidade transformadora, verifica-se que os valores obtidos pela Metodologia CODI 1 é incoerente na maioria dos casos. Para um transformador de $75 \mathrm{kVA}$, por exemplo, a perda é de 192,89 kW e para transformador de $225 \mathrm{kVA}$, a perda é de $2181,06 \mathrm{~kW}$. 


\subsubsection{Transformador de Distribuição}

Neste segmento, comparou-se os resultados obtidos com a Metodologia da Curva de Carga com os resultados obtidos pelas expressões (2.18) a (2.23) do CODI / CCON. Também foi aplicada a metodologia proposta por Bacelar [1] - expressões (2.24) a (2.28).

As metodologias foram aplicadas a um universo de 1334 transformadores trifásicos, representando uma potência instalada total de $882400 \mathrm{kVA}$.

No caso da metodologia do CODI / CCON, foi adotado um fator de coincidência igual a 0,9. No caso da metodologia de Bacelar, foi adotado um fator de contribuição na ponta igual a 0,9 .

A partir da base de dados contendo todos os transformadores de distribuição e seus dados de placa, foi possível determinar as perdas nominais no ferro e no cobre dos transformadores de uma mesma potência. Verificou-se que, para uma mesma potência, os dados de perdas nominais variavam muito de transformador para transformador. Por isso, utilizou-se como valores de perdas nominais para os transformadores de mesma potência a moda dos valores encontrados para aquela potência.

A partir dos resultados obtidos com o PERTEC, foi possível calcular o fator de utilização médio quadrático dos transformadores de mesma potência, uma vez que era conhecida a demanda máxima em cada transformador.

O fator de carga médio dos 1334 transformadores foi calculado, resultando 0,545 e foi utilizado $k=0,15$ para calcular o fator de perdas pela expressão (3.1).

As expressões (2.18) do CODI / CCON (Metodologia CODI 1) e as expressões (2.24) e (2.26) de Bacelar destinam-se ao cálculo da perda de demanda em concessionárias que possuem banco de dados detalhado. A tabela 5.34 apresenta os valores típicos dos transformadores de mesma potência que foram utilizados nessas duas metodologias, que são bem semelhantes. 
Tabela 5.34 - Dados utilizados para a aplicação das Metodologias CODI 1 e de Bacelar

\begin{tabular}{ccccc}
\hline Potência (kVA) & $\begin{array}{c}\text { Quantidade de } \\
\text { Transformadores }\end{array}$ & $\begin{array}{c}\text { Fator de } \\
\text { Utilização }\end{array}$ & $\begin{array}{c}\text { Perda no } \\
\text { Cobre (W) }\end{array}$ & $\begin{array}{c}\text { Perda no } \\
\text { Ferro (W) }\end{array}$ \\
\hline 30 & 19 & 0,758 & 570 & 200 \\
\hline 45 & 33 & 0,382 & 760 & 260 \\
\hline 75 & 238 & 0,410 & 1140 & 390 \\
\hline 112,5 & 149 & 0,401 & 1550 & 520 \\
\hline 150 & 450 & 0,436 & 1910 & 640 \\
\hline 225 & 394 & 0,422 & 2700 & 900 \\
\hline 300 & 51 & 0,293 & 3360 & 1120 \\
\hline
\end{tabular}

Para a aplicação da expressão (2.20) do CODI / CCON (Metodologia CODI 2), foi utilizado um fator de utilização igual a 0,424 , obtido a partir da média quadrática dos fatores de utilização de todos os transformadores.

As perdas nominais no transformador de potência média são calculadas pelas expressões (2.21).

Os resultados obtidos com a Metodologia da Curva de Carga, com as metodologias do CODI / CCON e com a metodologia de Bacelar estão apresentados na tabela 5.35.

Tabela 5.35 - Comparação entre metodologias para o segmento Transformador de Distribuição

\begin{tabular}{ccccc}
\hline Perda de... & $\begin{array}{c}\text { Metodologia } \\
\text { Curva de Carga }\end{array}$ & $\begin{array}{c}\text { Metodologia } \\
\text { CODI 1 }\end{array}$ & $\begin{array}{c}\text { Metodologia } \\
\text { CODI 2 }\end{array}$ & $\begin{array}{c}\text { Metodologia } \\
\text { Bacelar }\end{array}$ \\
\hline Demanda $(\mathrm{kW})$ & $1.402,6$ & $1.296,2$ & $1.305,4$ & $1.254,9$ \\
\hline Energia $(\mathrm{kWh})$ & $765.140,2$ & $734.872,9$ & $633.512,4$ & $756.892,7$ \\
\hline
\end{tabular}

Para obter o total de perda de demanda com a Metodologia da Curva de Carga, também foi aplicado um fator de coincidência igual a 0,9 .

Como pode ser observado, as discrepâncias encontradas entre as metodologias não foram muito grandes e são devidas, em parte, à qualidade dos dados utilizados no cálculo das perdas de demanda. A perda de energia obtida pela Metodologia CODI 2 apresentou o maior desvio $(17,20 \%)$ em relação ao resultado fornecido pela Metodologia da Curva de Carga.

É importante notar que a Metodologia da Curva de Carga realiza o cálculo de cada transformador, utilizando seus respectivos dados de placa. Como foi mencionado anteriormente, os valores de perdas nominais encontrados para transformadores de mesma potência variavam muito e, na aplicação da Metodologia CODI 1 e da Metodologia de Bacelar, foram utilizados apenas um valor para perda no cobre e outro para perda no ferro para todos os transformadores de uma mesma potência. 
Outro fator que deve ser considerado é que, apesar de utilizar fatores de utilização médios quadráticos para transformadores de mesma potência, na realidade os fatores de utilização individuais dos transformadores de uma mesma potência variam bastante. E isso pode introduzir erros nos resultados do cálculo quando se utiliza as metodologias CODI 1, CODI 2 ou a metodologia de Bacelar.

\subsubsection{Rede Primária}

Neste segmento, comparou-se os resultados obtidos com a Metodologia da Curva de Carga com os resultados obtidos pelas expressões (2.32) a (2.34) do CODI / CCON.

A expressão (2.32) do CODI / CCON foi aplicada a um universo de 241 circuitos primários. Essa expressão destina-se ao cálculo da perda de demanda em um único circuito. A perda total de demanda é calculada por (2.33) e, em seguida, a perda de energia é obtida por (2.34).

Para os 241 circuitos selecionados, o fator de potência típico utilizado foi 0,95 (o mesmo valor utilizado no cálculo com o PERTEC). Foi adotado um fator de coincidência igual a 0,9 .

A partir da base de dados contendo todas as redes primárias trecho a trecho, foi possível determinar, para cada circuito, o comprimento total, o número de pontos de carga, o número de circuitos da subestação a que pertence o circuito e a tensão utilizada. Também foi possível identificar o tipo de condutor predominante no tronco de cada circuito. Verificou-se que, na maior parte deles, o cabo mais freqüente era o 336A. Assim, foi utilizada a resistência do cabo 336A no cálculo das perdas de demanda em todos os circuitos primários.

A partir dos resultados obtidos com o PERTEC, foi possível obter a demanda máxima de cada circuito primário.

O fator de carga médio dos 241 circuitos foi calculado, resultando 0,657 e foi utilizado $k$ $=0,15$ para calcular o fator de perdas pela expressão (3.1).

Os resultados obtidos com a Metodologia da Curva de Carga e com a metodologia do CODI / CCON estão apresentados na tabela 5.36. 
Tabela 5.36 - Comparação entre metodologias para o segmento Rede Primária

\begin{tabular}{ccc}
\hline Perda de... & $\begin{array}{c}\text { Metodologia } \\
\text { Curva de Carga }\end{array}$ & $\begin{array}{c}\text { Metodologia } \\
\text { CODI }\end{array}$ \\
\hline Demanda $(\mathrm{kW})$ & $10.677,9$ & $14.164,5$ \\
\hline Energia $(\mathrm{kWh})$ & $3.576 .017,3$ & $4.741 .808,0$ \\
\hline
\end{tabular}

Para obter o total de perda de demanda com a Metodologia da Curva de Carga, também foi aplicado um fator de coincidência igual a 0,9 .

Nota-se que a Metodologia CODI obteve uma boa estimativa da perda de demanda, apresentando um erro de 32,65\% em relação à Metodologia da Curva de Carga. Um erro de mesma ordem de grandeza $(32,60 \%)$ foi encontrado no que diz respeito à perda de energia.

No entanto, ao verificar o erro que foi cometido no cálculo de cada circuito, observou-se que a Metodologia CODI pode apresentar erros bem maiores. No caso estudado, o módulo do erro mínimo encontrado foi $0,009 \%$, enquanto o módulo do erro máximo encontrado foi $414,28 \%$. Nota-se que a metodologia fornece uma boa estimativa quando se analisa um conjunto de circuitos e é inadequada para o cálculo das perdas de um único circuito.

\subsection{Análise da Influência da Temperatura dos Condutores no Cálculo das Perdas}

Todas as metodologias analisadas, inclusive a proposta neste trabalho, consideram que a resistência dos condutores não sofre variação ao longo do dia.

No entanto, sabe-se que a resistência de um condutor depende de sua temperatura e da temperatura ambiente. A temperatura do condutor, por sua vez, depende da corrente que por ele flui. Assim, para determinar a resistência do condutor em cada instante do dia, seria necessário conhecer a temperatura ambiente e a temperatura do condutor em cada instante do dia.

Em uma análise mais simples, foi verificado qual seria a influência da temperatura do condutor no valor da resistência e, consequentemente, no cálculo das perdas. Esta análise foi realizada para um condutor de alumínio, cujo coeficiente $\alpha$ de variação da resistividade com a temperatura é de $0,00403{ }^{\circ} \mathrm{C}^{-1}$. Também foi considerada uma temperatura de referência de $20^{\circ} \mathrm{C}$.

Sabe-se que a resistência $R_{T}[\Omega]$ de um condutor a uma temperatura $T$ é obtida por 


$$
R_{T}=R_{0} \cdot\left[1+\alpha \cdot\left(T-T_{0}\right)\right][\Omega]
$$

onde:

- $R_{0}$ - é a resistência do condutor na temperatura de referência [ $\left.\Omega\right]$;

- $\alpha$ - é o coeficiente de variação da resistividade do material com a temperatura $\left[{ }^{\circ} \mathrm{C}^{-1}\right]$;

- $T$ - é a temperatura do condutor $\left[{ }^{\circ} \mathrm{C}\right]$;

- $T_{0}$ - é a temperatura de referência $\left[{ }^{\circ} \mathrm{C}\right]$.

A perda $p_{T}[\mathrm{~W}]$ no condutor para uma determinada temperatura é obtida por

$$
p_{T}=R_{T} \cdot I^{2}[\mathrm{~W}]
$$

onde:

- $R_{T}$ - é a resistência do condutor a uma temperatura $T[\Omega]$;

- I - é a corrente que flui através do condutor [A].

Combinando-se as expressões (5.1) e (5.2), obtém-se

$$
p_{T}=R_{0} \cdot\left[1+\alpha \cdot\left(T-T_{0}\right)\right] \cdot I^{2}[\mathrm{~W}] .
$$

Para obter a variação de perdas dada uma variação de temperatura $T_{2}-T_{1}$, basta aplicar a expressão (5.3) às duas temperaturas e dividir uma expressão pela outra, como a seguir:

$$
\frac{p_{T_{2}}}{p_{T_{1}}}=\frac{R_{0} \cdot\left[1+\alpha \cdot\left(T_{2}-T_{0}\right)\right] \cdot I^{2}}{R_{0} \cdot\left[1+\alpha \cdot\left(T_{1}-T_{0}\right)\right] \cdot I^{2}}=\frac{\left[1+\alpha \cdot\left(T_{2}-T_{0}\right)\right]}{\left[1+\alpha \cdot\left(T_{1}-T_{0}\right)\right]} .
$$

Com a expressão (5.4), foi determinada a variação percentual das perdas dada uma variação na temperatura. Foram consideradas as temperaturas: 50, 60, 70, 80 e $90^{\circ} \mathrm{C}$. Os resultados estão na tabela 5.37 . 
Tabela 5.37 - Variação das perdas X Variação da temperatura

\begin{tabular}{cc}
\hline Temperatura $\left({ }^{\circ} \mathbf{C}\right)$ & Perdas $(\%)$ \\
\hline 50 & 100 \\
\hline 60 & 103,6 \\
\hline 70 & 107,2 \\
\hline 80 & 110,8 \\
\hline 90 & 114,4 \\
\hline
\end{tabular}

Analisando a tabela 5.37, conclui-se que, dado um acréscimo de $20 \%$ na temperatura do condutor, as perdas sofrem um acréscimo de 3,6\%.

Desta forma, conclui-se que um possível refinamento adicional no modelo proposto seria o de se efetuar estudo específico de transferência de calor para o cálculo da temperatura do condutor e, consequentemente, da sua resistência em função da corrente passante em cada um dos intervalos do dia. 


\subsection{Conclusões}

Pelo exemplo de aplicação que foi visto neste capítulo, fica fácil notar que o sistema computacional desenvolvido permite a avaliação das perdas técnicas não só em nível agregado como também em certas regiões ou componentes dos sistema de distribuição.

Também pode ser verificado que a metodologia adotada permite a obtenção de curvas de carga de perfil semelhante às curvas de carga reais, apresentando desvios aceitáveis. Dessa forma, os resultados obtidos são mais precisos, pois muitas aproximações são eliminadas, como já foi explicado no capítulo 3.

$\mathrm{Na}$ análise de influência do fator de perdas, foi mostrado que o cálculo indireto das perdas de energia pode apresentar erros consideráveis. Também foi mostrado que o valor de $k$ para estimar o fator de perdas a partir do fator de carga pode variar bastante $\mathrm{e}$ que, no caso das redes primárias e secundárias, ele pode assumir valores menores que zero e maiores que 1,0 , pois seu cálculo é realizado a partir dos dados de energia, demanda máxima, perda de energia e perda de demanda no início do circuito. $\mathrm{Na}$ realidade, como cada trecho de rede está submetido a uma curva de carga diferente, cada trecho de rede possui um valor diferente para o fator de perdas e, consequentemente, um valor diferente para $k$.

Também neste capítulo foi realizada uma comparação entre algumas metodologias apresentadas no capítulo 2 e a metodologia proposta neste trabalho. De uma forma geral, pode-se concluir que os resultados podem variar muito de acordo com a qualidade das informações que são utilizadas nas metodologias que visam calcular a perda global no segmento. Como conseqüência, a Metodologia da Curva de Carga, que realiza cálculo detalhado em cada componente, pode fornecer resultados bem diferentes daqueles fornecidos por outras metodologias.

Finalmente, foi apresentada uma análise simples do impacto da influência da temperatura na resistência dos condutores e seu conseqüente impacto no cálculo das perdas. 


\section{CAPÍTULO 6}

\section{CONCLUSÕES E TÓPICOS PARA FUTURO DESENVOLVIMENTO}

Este trabalho procurou estabelecer uma nova metodologia para o cálculo das perdas técnicas por segmento num sistema de distribuição. No total, foram considerados 8 segmentos: medidor de energia, ramal de ligação, rede secundária, transformador de distribuição, rede primária, subestação de distribuição, sistema de alta tensão e outros. A metodologia proposta mostrou ser uma ferramenta poderosa. Uma de suas grandes vantagens é que ela realiza o cálculo detalhado das perdas técnicas de energia utilizando diretamente a curva de carga, não havendo a necessidade do cálculo indireto a partir da perda máxima de demanda e do fator de perdas que, por sua vez, é estimado a partir do fator de carga. Outra grande vantagem da metodologia reside no fato do cálculo das perdas serem realizados por fase, o que considera os desequilíbrios de correntes na rede e nos equipamentos sem a necessidade de estimar um fator de desequilíbrio. Dessa forma, os resultados obtidos são mais precisos.

Para a aplicação dessa metodologia, é necessário que a concessionária possua uma base de dados onde estão cadastrados os dados de todas as suas redes secundárias, redes primárias, transformadores de distribuição, subestações de distribuição e também os dados de todos os seus consumidores.

Como o cálculo é realizado de forma detalhada, são calculadas as perdas em cada componente de cada segmento do sistema. Assim, pode-se determinar não só as perdas agregadas e os segmentos que mais contribuem para as perdas como também quais os componentes de um determinado segmento que apresentam perdas elevadas.

A metodologia foi implementada por meio do desenvolvimento de um sistema computacional composto por 2 módulos.

O Módulo PERTEC é destinado ao cálculo detalhado das perdas técnicas por segmento.

O Módulo de Balanço de Energia é destinado a fazer o balanço de energia no sistema de distribuição e determinar as perdas não técnicas. Como ele utiliza os valores de perdas 
percentuais por segmento calculadas pelo Módulo PERTEC, o Módulo de Balanço de Energia também pode determinar as perdas de energia por segmento para o sistema de distribuição como um todo a partir de uma parcela representativa do sistema.

Os resultados obtidos ajudam a tomar decisões no sentido de priorizar ações para reduzir as perdas no sistema.

Pelo exemplo de aplicação que foi visto (comparando-se os resultados com medições em campo), fica claro que a metodologia utilizada proporciona uma estimativa muito boa da curva de carga real e, consequentemente, um cálculo de perdas mais preciso.

Os esforços de pesquisa deste trabalho mostram que alguns tópicos relevantes no que diz respeito à metodologia utilizada ainda necessitam de mais investigações, destacando-se:

- Atualização da base de dados que contém as curvas típicas de carga para os consumidores secundários e primários. As curvas de carga dependem diretamente dos hábitos de consumo e estes, por sua vez, podem apresentar variações a longo prazo devido a diversos fatores. Ao atualizar as curvas típicas de carga, também seria de grande interesse obter curvas típicas para o fator de potência ou para a demanda reativa, além da demanda ativa. Finalmente, como os hábitos de consumo apresentam variações sazonais, seria interessante que as curvas típicas carga fossem obtidas para cada época do ano.

- Inclusão, no modelo de cálculo de perdas, da estimativa das perdas técnicas devido a consumidores clandestinos. Sabe-se que a energia consumida por um consumidor clandestino constitui uma perda não técnica. Porém, ela implica numa perda técnica na rede que atende esse consumidor.

- Inclusão, no modelo de cálculo de perdas, da influência da temperatura na resistência dos condutores. Sabe-se que a passagem de corrente num condutor provoca o seu aquecimento e, consequentemente, alteração no valor de sua resistência, o que pode influir no cálculo das perdas.

- Desenvolvimento de um estimador de estado para determinar as perdas no sistema de alta tensão quando essa determinação for feita a partir de medições. As medições apresentam imprecisões e combiná-las com o uso de um estimador de estado seria 
uma boa alternativa para obter um resultado mais preciso das perdas neste segmento.

- Desenvolvimento de uma ferramenta que permita realizar análises de viabilidade técnico-econômica de ações que tenham por objetivo a redução das perdas. Essa ferramenta utilizaria os resultados obtidos com o sistema computacional desenvolvido neste trabalho. 


\section{REFERÊNCIAS BIBLIOGRÁFICAS}

[1] BACELAR, J. Perdas no Sistema de Distribuição da COELBA, Relatório 214R COELBA, Salvador, Setembro de 1994.

[2] CIPOLI, J A; BORGES, J A M. Avaliação das Perdas de Energia no Sistema Elétrico, I-SIDEE, Belo Horizonte, Novembro de 1990.

[3] CODI - Comitê de Distribuição. Método para Determinação, Análise e Otimização das Perdas Técnicas em Sistemas de Distribuição, Doc. Técnico CODI-3.2.19.34.0, Agosto de 1996.

[4] POVEDA, M. A New Method to Calculate Power Distribution Losses in an Environment of High Unregistered Loads, IEEE Transmission and Distribution Conference, 1999.

[5] CELPE - Companhia Energética de Pernambuco. Determinação das Perdas do Sistema de Distribuição, ASEP / DEME - CELPE, Agosto de 1993.

[6] GRAINGER, J J; KENDREW, T J. Evaluation of Technical Losses on Electric Distribution Systems, CIRED, 1989.

[7] LEITE, G F; ARAÚJO, R J P; MARTINS, V L. Determinação das Perdas Elétricas em Circuitos Secundários de Distribuição, CIER, São Paulo, Outubro de 1985.

[8] AMENDOLA, A G; ROCHA, M C. Determinação do Algoritmo Árvore Cronológica de Comprimento Mínimo para Aplicação em Estudos de Planejamento de Redes de Média Tensão, XI SENDI, Blumenau, Setembro de 1992. 
[9] BACELAR, J. Equações de Fatores de Perdas, CONLADIS, Chile, 1996.

[10] JARDINI, J A; TAHAN, C M V; CASOLARI, R P; AHN, S U; FIGUEIREDO, F M. Curvas Diárias de Carga - Base de Dados Estabelecida com Medições em Campo, CIRED, Argentina, 1996.

[11] JARDINI, J A; CASOLARI, R P; FERRARI, E L e outros. Curvas Diárias de Carga de Consumidores Comerciais e Industriais, XIII SENDI, São Paulo, Maio de 1997.

[12] CCON - Comitê Coordenador de Operações Norte / Nordeste. Determinação de Perdas em Sistemas de Distribuição, XI SENDI, Blumenau, Setembro de 1992.

[13] SILVA, R M; NETO, C O. Estimativa das Perdas Técnicas no Sistema Distribuidor da Light em 1984, CIER, 1984.

[14] SUN, D I H; EICHENBERGER, P e outros. Calculation of Energy Losses in a Distribution System, IEEE Transactions on Power Apparatus and Systems, Vol. PAS-99, No 4, July/August 1980.

[15] FLATEN, D L. Distribution System Losses Calculated by Percent Loading, IEEE Transactions on Power Systems, Vol. 3, No 3, August 1988.

[16] BOICE, D G; GURSKY, R J. Cost of Electrical Power System Losses for Use in Economic Evaluations, IEEE Transactions on Power Systems, Vol. 4, No 2, May 1989.

[17] VEMPATI, N; SHOULTS, R R; CHEN, M S; SCHWOBEL, L. Simplified Feeder Modeling for Load Flow Calculations, IEEE Transactions on Power Systems, Vol. PWRS-2, No 1, February 1987. 
[18] WILliamS, J A; BUCKWEITZ, M D; BURGHART, R R e outros. Loss Evaluation for Underground Transmission and Distribution Cable Systems, IEEE Transactions on Power Delivery, Vol. 5, Nº 4, November 1990.

[19] ELETROBRÁS / MME / DNAEE. Nova Tarifa de Energia - Metodologia e Aplicação, Capítulo II - Análise da Carga, Brasília, 1985.

[20] JARDINI, J A; CASOLARI, R P; FERRARI, E L e outros. Curva de Carga de Consumidores Industriais de Média Tensão da Eletropaulo, CED 202 / PLAN 006 / NT 004 / OR, São Paulo, Setembro de 1995.

[21] CORDEIRO, A A e outros. Sistemática para Determinação e Acompanhamento das Perdas nas Empresas do CCON - Aplicação na SAELPA, XIII SENDI, São Paulo, Maio de 1997.

[22] WOOD, A J; WOLlENBERG, B F. Power Generation, Operation and Control, Chapter 12 - An Introduction to State Estimation in Power Systems, John Wiley \& Suns, New York, 1984. 